\title{
Characterizing Vegetation Metrics Across Multiple Habitats and Spatial Scales at Daring Lake, NT.
}

by

Claire Elliott

A thesis submitted to the Faculty of Graduate and Postdoctoral Affairs in partial fulfillment of the requirements for the degree of

Master of Science

in

Geography

Carleton University

Ottawa, Ontario

(C) 2016

Claire Elliott 


\begin{abstract}
Normalized difference vegetation index (NDVI) is used to monitor vegetation dynamics and infer changes in productivity and carbon fluxes globally and in particular, in the Arctic, where remote sensing helps overcome lack of access in remote regions. This study examined how ground-based NDVI related to vegetation metrics, notably leaf area index (LAI) and percent vascular vegetation cover, across three tundra vegetation communities and across multiple measurement resolutions at Daring Lake, NT, in Canada's Southern Arctic.

Results demonstrated that LAI and percent vascular vegetation cover strongly correlated with NDVI, with NDVI showing the greatest responses to LAI at the $5 \mathrm{~m}$ resolution. However, NDVI did tend to saturate at LAI greater than 1.5. Stepwise linear regression produced some differences in the NDVI-LAI relationship between the three sites but when analyzed with an adapted version of the Shaver et al. (2007) model, the relationship did not appear to differ greatly between sites.
\end{abstract}




\section{Acknowledgements}

The completion of this thesis would not have been possible without the continued support of my family, friends, and colleagues. This has been a challenging project from start to end and I will always be grateful for the people who've helped me to succeed. I would like to thank my supervisor, Dr. Elyn Humphreys. I am very grateful for her guidance, encouragement, and enduring support. Thanks to Mom, Dad, Megan, and Mike for the visits, care packages, support, and love.

The field work components of this thesis were quite demanding, and I would not have a finished thesis without my amazing field team. Alice and Sean: you both are amazingly hard workers and fantastic friends to have during long field days. Thanks also goes out to Kristyn Foster, Le Ge, Mary-Claire Buell, Susan Machan, Paden Lennie for their help in the field and fun at camp, and Joachim Obst for sharing with me his love of the tundra.

I would like to thank Karin Clark of the Government of the Northwest Territories, Mike Treberg for his technical support, Wenjun Chen and Sylvain Leblanc of Natural Resources Canada, and to my committee of Dr. Andrew Davidson and Dr. Scott Mitchell.

This research would not have been completed without the generous funding from Natural Resources Canada - Canadian Centre for Remote Sensing, the Northern Scientific Training Program (NSTP) of the Canadian Polar Commission, the Cumulative Impact Monitoring Program of the Government of the Northwest Territories (NWT CIMP), and Carleton University. 


\section{Table of Contents}

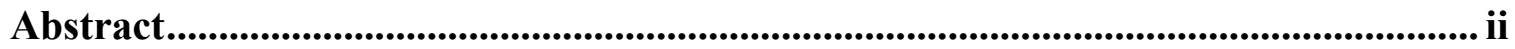

Acknowledgements ......................................................................................................ii

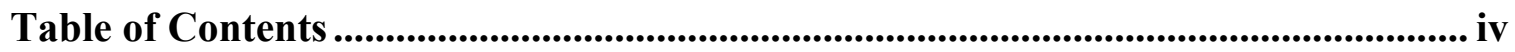

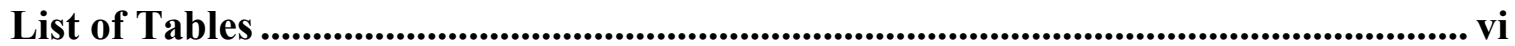

List of Figures....................................................................................................................... vii

List of Appendices......................................................................................................... ix

List of Abbreviations and Symbols ......................................................................................... $\mathrm{x}$

1: Introduction ............................................................................................................................. 12

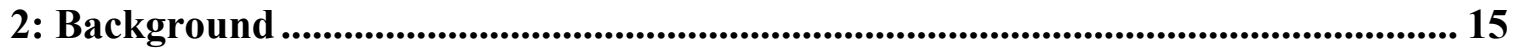

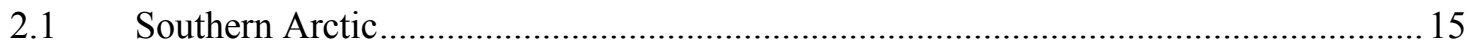

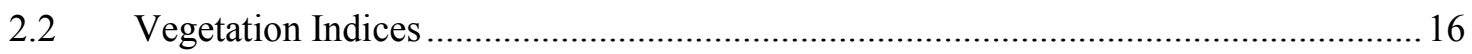

2.2.1 The Normalized Difference Vegetation Index ………………………………...... 18

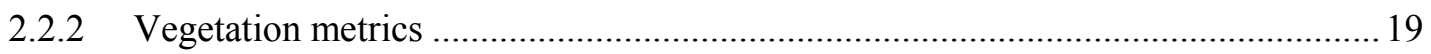

$2.3 \quad$ Issues with Scale

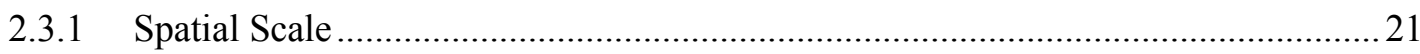

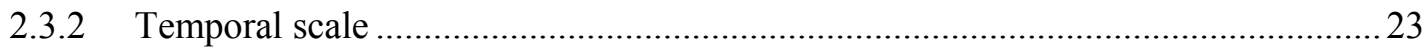

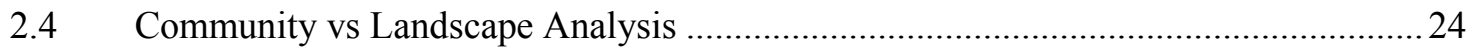

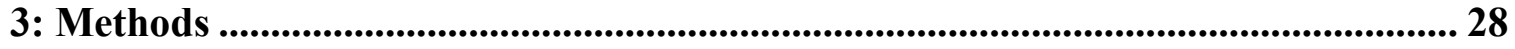

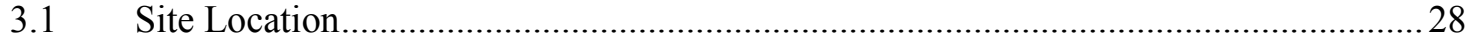

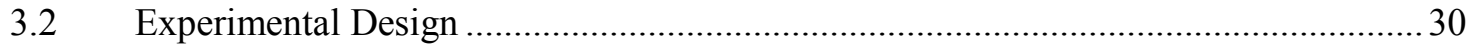

3.3 NDVI Measurements .......................................................................................

3.4 Leaf Area Index and Percent Vegetation Cover ………………………………….....38

3.5 Soil Volumetric Water Content ............................................................................

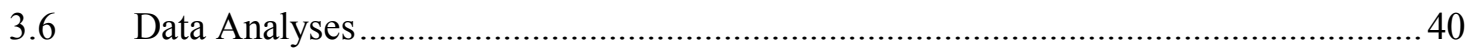




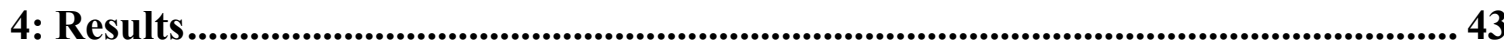

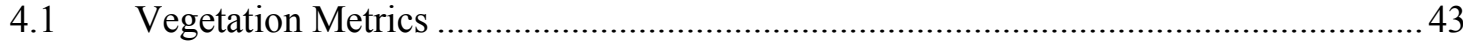

4.2 Temporal Variations in Vegetation Metrics ………………………………………....4 46

4.3 Relationships Among Vegetation Metrics \& Other Variables ......................................51

4.4 Effects of Measurement Scale ..........................................................................56

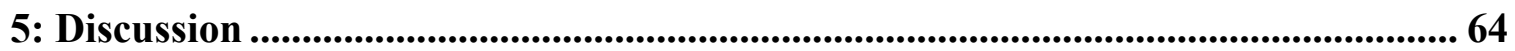

5.1 The Relations between Vegetation Metrics and NDVI ……………………………....... 64

5.2 The Relations between Vegetation and Soil Moisture ..................................................68

5.3 The Differences between the Tetracam and Canon NDVI..............................................69

5.4 The Effects of Non-vascular Vegetation on NDVI ……………………………...... 70

5.5 The Effects of View Angle and Atmospheric Conditions ………………………...... 72

6: Conclusion .......................................................................................................................... 74

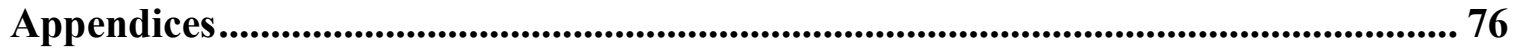

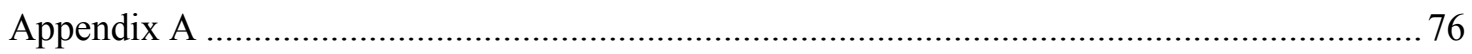

A.1 Orthogonal Regressions, Combined Sites, Peak Greenness........................................76

A.2 Orthogonal Regressions, Individual Sites, Peak Greenness....................................... 81

A.3 Analysis of NDVI residuals from above orthogonal regression against LAI ..........95

A.4 Plant community analysis ....................................................................................96

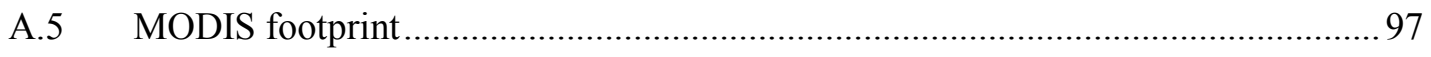

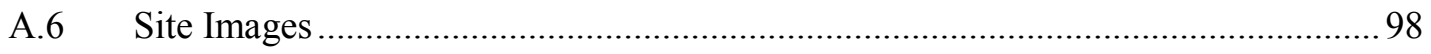

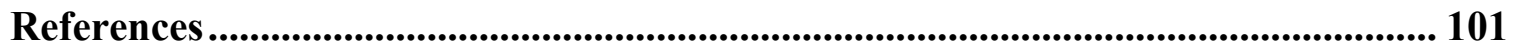




\section{List of Tables}

Table 1. Mean plot value (Avg) and standard deviation (SD) for vegetation metrics and soil volumetric water content at DL, LK and FN sites at the end of July 2014 for the three measurement scales; $0.5 \mathrm{~m}, 5 \mathrm{~m}, 30 \mathrm{~m}(\mathrm{n}=63,18,9$, respectively). 44

Table 2. Selected vegetation metrics for the three communities determined using k-means cluster analysis. Plant values indicate number of pin contacts (out of a total of 25 pin drops) during point frame measurements at peak greenness. Values with subscripts i indicate significant differences among groups $(\mathrm{p}<0.05)$ using the Student's $t$ test. ....... 45 Table 3. Pearson correlations (r) and probabilities ( $\mathrm{p}$ ) for the relationships between variables at peak greenness for all sites combined, $\mathrm{n}=147$. Significant correlations are shaded (when $\mathrm{p}<0.05$ ). 52

Table 4. F-statistics (F) and probabilities (p) for all measurement variables analysed with nested ANOVA for the three measurement resolutions $(200 \mathrm{~m}, 30 \mathrm{~m}$, and $5 \mathrm{~m})$ at DL and LK sites (FN site was not included due to a lack of replication at the $30 \mathrm{~m}$ resolution). . 56 Table 5. Pearson correlations ( $\mathrm{r}$ ) and calculated probabilities (p) for relationships between variables at DL site. A p-value $<0.05$ determines significance.

Table 6. Pearson correlations (r) and probabilities (p) for relationships between variables at LK site. A p-value $<0.05$ determines significance.

Table 7. Pearson correlations (r) and probabilities (p) for the relationships between variables at $\mathrm{FN}$ site. A p-value $<0.05$ determines significance. 


\section{List of Figures}

Figure 1. The location of the Daring Lake Tundra Ecosystem Research Station and the

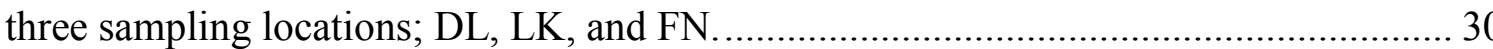

Figure 2. The DL and LK sampling regime showing the unbalanced nested design of 63 $0.5 \mathrm{~m}$ plots within a $200 \mathrm{~m}$ eddy covariance flux tower footprint. Groupings of 3 plots are spatially averaged to create a $5 \mathrm{~m}$ resolution and two groupings of three plots along with a lone single plot form a $30 \mathrm{~m}$ resolution. The FN site was made up of a modified version of this design due to the constraints of a boardwalk.

Figure 3. The Tetracam calibration image of the white Teflon calibration plate (top), and an image captured with the Tetracam multispectral camera, with the plot vegetation used to calculate NDVI highlighted in white (bottom). In these images, green vegetation appears red. Soil and non-green vegetation presents in dark tones. ................................ 35

Figure 4. An image captured with the modified Canon digital camera, including the metal frame used to denote the plot and the three calibration disks used to adjust the pixel DN for the current light conditions.

Figure 5. An image captured with the modified Canon digital camera after being run through the NRCan software that semi-automatically detects the calibration disks and frame. The highlighted area within the frame is the area of the image for which NDVI is calculated. 37

Figure 6. The point-frame method being carried out in the field 39

Figure 7. Percent vascular vegetation cover (left panels) and leaf area index as measured using point intercept method (right panels) at the $0.5 \mathrm{~m}$ plot scale over the course of the growing season for the DL, LK and FN sites. 
Figure 8. Tetracam NDVI (left panel) and Canon NDVI (right panel) at the $0.5 \mathrm{~m}$ plot scale over the course of the growing season for a) DL site, b) LK site, and c) FN site. Note that Canon NDVI was not measured at the FN. MODIS-based NDVI is also shown on each figure (black + symbols are the $500 \mathrm{~m}$ 16-day values and black circles are the 250 m 3-day values)

Figure 9. NDVI measured using the Tetracam vs. LAI (left) and vs. percent vascular vegetation cover (right) for the three research sites at Daring Lake at the $0.5 \mathrm{~m}$ resolution for all measurement dates (top) and peak greenness (below). The relationship between NDVI and LAI is modified from Shaver et al. (2007) where estimated NDVI is reduced by 0.4 . The relationship between NDVI and \% cover is the orthogonal regression with slope $=0.002$ and offset of 0.2032 (for all measurement dates) 53 Figure 10. The slopes of the orthogonal regressions for percent vascular vegetation cover and Tetracam NDVI (a) and Canon NDVI (b) (top panels) and LAI vs. Tetracam NDVI (a) and Canon NDVI (b) (bottom panels). 58

Figure 11. The slopes of the orthogonal regressions for soil volumetric water content and (a) Tetracam NDVI and (b) Canon NDVI at DL 59 


\section{List of Appendices}

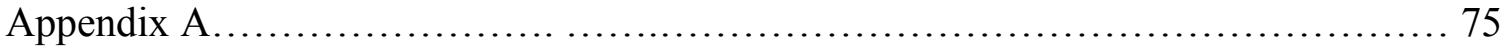

A.1 Orthogonal Regression, Combined Sites, Peak Greenness......................75

A.2 Orthogonal Regression, Individual Sites, Peak Greenness......................80

A.3 Analysis of NDVI residuals from above orthogonal regression against LAI......94

A.4 Plant community analysis.......................................... 95

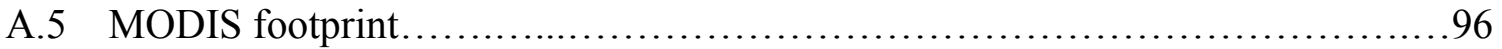

A.6 Site Images......................................................... 98 


\section{List of Abbreviations and Symbols}

\begin{tabular}{ll}
\hline Symbol & Definition \\
\hline aPAR & Absorbed Photosynthetically Active Radiation \\
\hline Blue & Blue Reflectance \\
\hline DL & Daring Lake Site \\
\hline ER & Ecosystem Respiration \\
\hline EVI & Enhanced Vegetation Index \\
\hline EVI2 & Two-band Enhanced Vegetation Index \\
\hline FN & Fen Tower Site \\
\hline fPAR & Fraction of Absorbed Photosynthetically Active Radiation \\
\hline GEP & Gross Ecosystem Productivity \\
\hline GPP & Gross Primary Productivity \\
\hline Green & Green Reflectance \\
\hline LAI & Leaf Area Index \\
\hline LK & Lake Tower Site \\
\hline MSAVI & Modified Soil Adjusted Vegetation Index \\
\hline NDVI & Normalized Difference Vegetation Index \\
\hline NEP & Net Ecosystem Productivity \\
\hline NIR & Near Infrared Reflectance \\
\hline NPP & Net Primary Productivity \\
\hline PAR & Photosynthetically Active Radiation \\
\hline RED & Red Reflectance \\
\hline
\end{tabular}




SAVI Soil Adjusted Vegetation Index

SVI Spectral Vegetation Index

SWIR Short-wave Infrared Reflectance 


\section{1: Introduction}

Climate change in Arctic regions has the potential to greatly impact many ecosystem processes. Temperatures in the Arctic are increasing at a rate almost double the global average and by the end of the $21^{\text {st }}$ century are expected to have risen by as much as $8^{\circ} \mathrm{C}$ (Soloman et al., 2007). The Arctic has begun to experience a number of changes including reduced extent and thinning sea ice (Rothrock et al., 1999; Serreze et al., 2007), loss of permafrost starting at the southern margins of the distribution (Lawrence \& Slater, 2005; Burn \& Kokelj, 2009), increasing active layer temperature and changes in active layer depths (Osterkamp \& Romanovsky, 1999; Sturm et al., 2005; Burn \& Kokelj, 2009), and an increase in vegetation abundance observed as a 'greening' of the Arctic (Tape et al., 2006; Fraser et al., 2014). Continued increases in temperature could bring on further changes to plant phenology, species composition, soil microbial activity, and many more ecosystem process that drive ecosystem carbon exchange between the ground surface and the atmosphere (La Puma et al., 2007). Recent research shows that some tundra sites may act as a net sink for carbon dioxide $\left(\mathrm{CO}_{2}\right)$ (Humphreys and Lafleur, 2011; Maguire et al., 2012) while others may be a net source (Oechel et al., 1993). As a result, there is the potential for both positive and negative feedbacks to climate change. The structure of plant communities and the functions of these communities are fundamental drivers of carbon exchange dynamics, thus it is imperative to understand how best to measure change in various vegetation properties in order to characterize carbon exchange and climate change impacts on northern landscapes in the future.

The Normalized Difference Vegetation Index (NDVI) is used in many studies in biomes around the world to estimate vegetation productivity. In the Arctic, satellite- 
based NDVI has been used to produce evidence of a 'greening' trend in tundra vegetation communities in association with a warming climate (Stow et al. 2004; Goetz et al., 2005; Tape et al., 2006; Fraser et al., 2014) and to evaluate potential changes in productivity and carbon exchange with the atmosphere (Boelman et al., 2003; La Puma et al., 2007; Street et al., 2007; Dagg \& Lafleur, 2010; Gamon et al. 2013). There are a number of studies that examine the relationship between NDVI and Arctic vegetation communities (Laidler et al., 2008; Williams et al., 2008; Dagg \& Lafleur, 2010; Dorion et al., 2013) but there is further need for studies that look at a wide variety of habitats and spatial scales across the Canadian and circumpolar regions.

Spatial and temporal trends of vegetation reflectance and vegetation indices can be used to infer current and future $\mathrm{CO}_{2}$ exchange. For example, Eklundh et al. (2011) used NDVI sensors to characterize vegetation phenology within the footprint of eddy covariance-based measurements of $\mathrm{CO}_{2}$ flux. Others have used simple light-useefficiency models to estimate gross primary productivity (Turner et al., 2003; Kross et al., 2013). However, spatial and/or temporal increases in NDVI may (Boelman et al., 2003; La Puma et al., 2007; Street et al., 2007; Dagg \& Lafleur, 2010) or may not (Boelman et al., 2003; Dagg \& Lafleur, 2010) be linearly related to increases in gross or net productivity. To better understand the relationships between NDVI and carbon exchange, or any other environmental variable, there is a need to examine further the factors influencing NDVI in tundra landscapes. This study aims to characterize the relationships among ground-and-satellite-based NDVI measurements and key vegetation metrics, primarily LAI and percent vascular vegetation cover, across three distinct tundra vegetation communities and across multiple measurement resolutions. By understanding 
the controls on NDVI measurements, future studies that relate NDVI to carbon exchange will be better able to discern what vegetation properties NDVI actually represents in tundra environments.

Based on this research objective there are three central hypotheses:

1. The leaf area index (LAI) will be the dominant control on NDVI measurements, where higher LAI will correlate with greater NDVI. This hypothesis was built upon findings by Gamon et al. (1995) where NDVI was shown to be most sensitive to LAI of green vegetation and chlorophyll content for a variety of vegetation communities in temperate regions. Percent cover of vegetation is also expected to relate to NDVI (Laidler et al., 2008), while lichen and moss cover, and soil moisture are not expected to impact NDVI to any great extent. This is based on research by Bubier et al. (1997) showing that the different internal structures of non-vascular vegetation as compared to vascular vegetation create different spectral reflectance responses that do not strongly influence NDVI.

2. The relationship between LAI and NDVI will be community specific. This hypothesis was developed based on earlier findings by Dagg and Lafleur (2010) that showed LAI only correlated with NDVI for some low Arctic vegetation communities.

3. The relationship between LAI and NDVI will be significant across $0.5,5$ and 30 $\mathrm{m}$ measurement resolutions. This follows the results obtained by Laidler et al. (2008) who showed percent vegetation cover correlated significantly with NDVI at various measurement resolutions for high Arctic tundra vegetation. 


\section{2: Background}

\subsection{Southern Arctic}

The Southern Arctic represents a massive ecosystem spanning the circumpolar north, with $38 \%$ of its land base located in the Canadian Arctic, for a Canadian total of $1.3 \times 10^{6} \mathrm{~km}^{2}$ (Walker et al., 2005). Although the tundra is typically described as a heterogeneous landscape, the interactions of many landscape variables such as vegetation, microtopography, soil, permafrost, and seasonal snow cover create a mosaic of relatively homogenous communities that can be studied as single units (Fox et al., 2008). The Arctic tundra is host to approximately 1800 vascular plant species, and a wide variety of non-vascular plants, all of which are important to the function and structure of the entire global ecosystem (Maguire et al., 2012). A recent attempt to classify the geography of pan Arctic vegetation resulted in the Circumpolar Arctic Vegetation Map (Walker et al., 2005). This culminated in the global Arctic being split into five separate zones, from zone $\mathrm{A}$ in the far north to zone $\mathrm{E}$ covering the south all the way to the northern edge of the tree line, with 15 vegetation community map units nested within the zones (Walker et al., 2005). Subzones D and E cover what has previously been classified as the Low Arctic (Bliss, 1997), the Low Erect Shrub zone (Edlund et al., 1989), the Erect Dwarf Shrub zone (Walker et al., 2002), and the Southern Arctic (Ecosystem Classification Group, 2012) amongst other classifications (Walker et al., 2005). Of all the vegetation zones, subzone $\mathrm{E}$ is the most densely vegetated and is mainly comprised of erect shrub vegetation, dwarf shrub, tussock-sedge, and moss tundra communities, as well as a plethora of wetland and riparian vegetation communities (Walker et al., 2005). Across the global subzone $\mathrm{E}$, there is a distinct east to west variation in floral regimes 
(Walker et al., 2005), which could lead to a regionalization of the methods and results of studies that focus on vegetation and vegetation community dynamics.

A major research question for northern scientists is how climate change might alter carbon cycling processes in these tundra ecosystems resulting in feedbacks that could have global impacts to the climate system through the exchange of greenhouse gases such as carbon dioxide and methane (Maguire et al., 2010). The world's permafrost soils are an important store for carbon, equaling twice the carbon stored in the atmosphere (Tarnocai et al., 2009; Hugelius et al., 2014). Early estimates of organic carbon storage had permafrost soils holding as much as $192 \mathrm{Pg}$ or $13 \%$ of global carbon stores (Post et al., 1982). New estimates have permafrost soils holding up to $1307 \mathrm{Pg}$ of carbon (Hugelius et al., 2014). Tundra soils become an even more important carbon store when one takes into account that the Arctic tundra ecosystem represents only $8 \%$ of the planet's land mass (Maguire et al., 2012). Carbon enters the soil system through above and below-ground plant litter inputs and if inputs exceed decomposition losses, accumulation of carbon occurs. Consequently, tundra vegetation dynamics and the productivity of vegetation are important to consider when evaluating the future fate of circumpolar carbon stocks.

\subsection{Vegetation Indices}

Plants are well suited for remote sensing studies due to their unique internal leaf structures and related spectral characteristics. Chlorophyll, the chemical compound found in most vegetation that is responsible for the absorption of light energy, is crucial to photosynthesis and gives plants their characteristic green colouring. The reflectance spectra of plants are quite different from other surface features, both natural and man- 
made, across the visible and near infrared (NIR) radiation spectrum due to the presence of chlorophyll (Knipling, 1970; Simms \& Gamon, 2002). Green vegetation has strong absorption of visible spectrum radiation in blue $(\sim 400-480 \mathrm{~nm})$ and red $(\sim 600-700$ $\mathrm{nm}$ ) wavebands with slightly less absorption in the green (around $500 \mathrm{~nm}$ ) and strong reflectance of NIR radiation (700 to $1300 \mathrm{~nm}$ ) (Knipling, 1970). In contrast, water has only minimal reflectance between 400 and $\sim 800 \mathrm{~nm}$ and near total absorption of NIR radiation, while soils have a profile of steeply increasing reflectance from $400 \mathrm{~nm}$ to $1300 \mathrm{~nm}$, with less contrast in reflectance between red radiation and NIR than vegetation (Peltoniemi et al., 2008; Goswami et al., 2010). NIR reflectance increases with increasing water turbidity (Goswami et al., 2010) while soils' reflectance decreases in the NIR regions with increasing soil water content (Peltoniemi et al., 2008). The unique spectral reflectance pattern of vegetation allows researchers to distinguish plants from other surface features and has led to the development of many different spectral vegetation indices (SVI).

In remote sensing, spectral indices are the mathematical combination of two or more spectral bands (Jones \& Vaughan, 2010). SVIs are most often derived from red and infrared (NIR or shortwave infrared (SWIR)) measurements) and are used to express the amount of green vegetation in a pixel (Jones \& Vaughan, 2010). An attempt to extract information on vegetation from a single waveband of radiation will often be confounded by factors such as the solar zenith angle (Rouse et al., 1974). Spectral indices of two or more wavebands offer a normalizing effect for solar zenith angle (Rouse et al., 1974). Multiple types of SVI have been developed to express information on some chosen quality of vegetation in a pixel (Jones \& Vaughan, 2010). 


\subsubsection{The Normalized Difference Vegetation Index}

NDVI is the fraction of the difference between NIR reflectance and red reflectance and the sum of NIR reflectance and red reflectance (Rouse et al., 1974). NDVI is widely available from most multispectral platforms at many spatial and temporal scales and is a common tool applied in ecological studies (Laidler et al., 2008; Doiron et al., 2013). NDVI, which has no intrinsic physical quality, is often used to estimate physical properties of vegetation, including LAI, fractional vegetation cover, and biomass (Carlson \& Ripley, 1997). In previous studies, NDVI has been found comparable to soiladjusted indices, the soil adjusted vegetation index (SAVI) and modified soil adjusted vegetation index (MSAVI), in its ability to explain variation in above-ground biomass for temperate grasslands (Davidson \& Csillag, 2001). NDVI, being less computationally complex that SAVI or MSAVI, may be seen as preferable for use in large scale studies (Davidson \& Csillag, 2001). NDVI has also been compared with the enhanced vegetation index (EVI) and the two-band enhanced vegetation index (EVI2) for predicting variation in leaf area harvests in Alaskan tussock tundra (Rocha \& Shaver 2009). EVI and EVI2 excelled in minimizing background reflectance and performed better than NDVI at high leaf area (Rocha \& Shaver 2009). However unlike EVI, NDVI does not require blue reflectance inputs, which are not readily available from some satellite platforms (Rocha \& Shaver, 2009). EVI2 has been developed to have the advantages of EVI without the requirement of blue reflectance inputs, but it has not been widely validated in the field like NDVI (Rocha \& Shaver, 2009). Monteith $(1972,1977)$ originally related biological productivity, measured as gross primary productivity (GPP), to the fraction of absorbed photosynthetically active radiation (fPAR) and a adiation-use efficiency term. This 
relationship can be extended to net primary productivity (NPP), as GPP minus autotrophic respiration. The fPAR of a canopy is measured as the quotient of absorbed photosynthetically active radiation (aPAR) and total incoming photosynthetically active radiation (PAR) (Running et al., 2004). Based on Beer's law, fPAR will increase roughly exponentially with increasing canopy interception area (Atwell et al., 1999). NDVI can also be described as evaluating fPAR as a measure of greenness (Running et al., 2004).

The satellite-based fPAR product from the moderate resolution imaging spectroradiometer (MODIS) MOD15a2 gives values at 8-day intervals at a resolution of $500 \mathrm{~m}$, but some studies have found it limiting due to its coarse spatial resolution and a lack of good quality measurements values over large spatial extents (Steinberg \& Goetz, 2009). Satellite-based NDVI from both MODIS and Advanced Very High Resolution Radiometer (AVHRR), has since been used as a proxy for fPAR (Steinberg \& Goetz, 2009; Peng et al., 2012) with the advantage of equal or higher spatial resolution ranging from $250 \mathrm{~m}$ to $1000 \mathrm{~m}$. IKONOS, with $4 \mathrm{~m}$ resolution, and Landsat, with $30 \mathrm{~m}$ resolution, data also can be used to measure NDVI and other SVI with complimentary results to one another (Laidler et al., 2008) and can be used to validate coarser resolution MODIS-based studies (Asner \& Warner, 2003).

\subsubsection{Vegetation metrics}

Vegetation may be characterized using ecological descriptors of abundance and diversity, in terms of mass such as dry aboveground biomass, and in terms of distribution and density such as percent cover, stem density, and LAI. LAI represents the surface area of green vegetation per unit of ground surface (Watson, 1947). It may be expressed either as projected (one-sided), used in this study, or total leaf area per unit ground area. 
LAI may be measured directly by scanning leaves or by allometric relationships between biomass and leaf area, and indirectly by optical methods, to name a few (Breda, 2003). Optical methods derive LAI from the probability of a beam of light passing through a canopy without meeting any obstruction (Gower et al., 1995). To measure transmittance they require a model of leaf orientation, randomness, and transmissivity with which to apply the Lambert-Beer Law for the attenuation of radiation (Gower et al., 1995; Breda, 2003). Modern sensors measure LAI as the inversion of the exponential equation of gap fraction, where gap fraction is the percentage of background area viewed by the sensor, and is equal to transmittance where leaf size is small compared to canopy size and leaves are randomly placed within the canopy (Gower et al., 1995; Breda, 2003). However, despite their name, optical methods of LAI are actually a plant-area-index, because all parts of the plant, leave, stems, flowers, etc, intercept incoming light before it reaches the sensor (Gower et al., 1995) which is a key difference from direct methods where only leaves are measured.

Similarly, by interpreting reflected radiation, NDVI or other SVIs can also be used to estimate LAI. Shaver et al. (2007) developed the following relationship, LAI = $0.0026 \mathrm{e}(8.0783 \mathrm{NDVI})$ reflecting the exponential relationship between the two variables where NDVI tends to saturate at increasing LAI (Carlson \& Ripley, 1997; Tittebrand et al., 2009). LAI is not a one dimensional measure, like fractional vegetation cover. Instead LAI is made up of multiple canopy layers acting together. However, NDVI sensors are only able to view the surface of a canopy, and lower canopy vegetation does not linearly contribute to the overall greenness of a NDVI measurement. There is some argument within the literature whether the NDVI-LAI relation is scale invariant (Shaver 
et al., 2007; Williams et al., 2008) or whether the NDVI-LAI relation is community specific (Chen et al., 2002; Breda, 2003; Street et al., 2007; Dagg \& Lafleur, 2010). At ground level, NDVI has been found to correlate strongly with LAI (Street et al., 2007; Dagg \& Lafleur, 2010). However for satellite level NDVI, site specific calibrations have been needed in order to estimate LAI, especially in dense vegetation (Chen et al., 2002; Breda, 2003).

Both sunlit and shaded leaf area of vegetation determine in part rates of photosynthesis and plant-atmosphere $\mathrm{CO}_{2}$ exchange (Williams et al., 2008). A relationship between LAI and ecosystem photosynthesis has been found by some to hold static regardless of vegetation type, allowing for simplified measurement of GPP and other carbon flux variables (Street et al., 2007; Loranty et al. 2010). In other cases relationships between NDVI and gross ecosystem productivity were only found to be significant for shrub and sedge tundra vegetation communities, and not for tussock and heath communities (Dagg \& Lafleur, 2010). The lack of relationship in heath communities may be due in part to the greater contributions of non-vascular plant matter to the NDVI measurements (Dagg \& Lafleur, 2010; Boelman et al, 2005). In tussock communities it was hypothesized that the shape of the tussocks could be changing the orientation of the leaves, reducing canopy closure, and increasing the influence of nongreen plant material on NDVI measurements (Boelman et al., 2005).

\subsection{Issues with Scale}

\subsubsection{Spatial Scale}

Central to studies using remote sensing tools is the issue of identifying the optimal spatial scale of measurement for the phenomena under evaluation. In the case of 
many satellite-based remote sensing studies, the size of a pixel is much larger than the spatial variability of the studied phenomenon (Jones \& Vaughan, 2010). Mixed pixel signals, where factors other than the object/phenomena of study contribute to the overall spectral signal, may become a problem in this case (Davidson \& Csillag, 2001). This results in the loss of any detail and variation smaller than the pixel size (Davidson \& Csillag, 2001; Jones \& Vaughan, 2010). Conversely, it may then seem desirable to obtain the smallest pixel size possible for any study, but this leads to the opposite issue where irrelevant variation is captured and this may obscure the larger scale patterns that are important to the study (Jones \& Vaughan, 2010). One study found NDVI had to be combined with an optical measurement of LAI in order to predict destructive harvest LAI using a maximum likelihood approach at the $0.2 \mathrm{~m}$ resolution, due in part to LAI expressing the greatest amount of variability at very small sampling scales (Van Wijk \& Williams, 2005; Williams et al., 2008). When Williams et al. (2008) investigated the same relationship in similar vegetation communities for a range of larger sampling resolutions, $1.5-9 \mathrm{~m}$, the NDVI alone was able to predict LAI using maximum likelihoods. This demonstrates that the choice of data collection unit can play a role in dictating the results of the analysis (Marceau \& Hay, 1999). When two or more variables are combined in a model, each with different variations in space, it becomes more difficult to find an optimal measurement resolution (Marceau \& Hay, 1999). This has led some researchers to investigate variable relationships in scaling studies.

There are multiple spatial scales of homogeneity within a tundra ecosystem ranging from centimeters, from hummock to hummock, to hundreds of meters encompassing an entire community (McFadden et al., 1998). The spatial variability of 
LAI and NDVI was found to increase when evaluated with decreasing plot size (Williams et al., 2008). Williams et al. (2008) used semi-variogram analysis to determine that LAI measurements were spatially autocorrelated with less than $1 \mathrm{~m}$ separation and concluded that the vegetation patch size was roughly $0.5 \mathrm{~m}$ in a tundra-taiga research site in subArctic Sweden. High variability at the sub $0.5 \mathrm{~m}$ scale is most likely the result of small differences in plant species composition, microtopography, moisture regimes, and type and presence of exposed soils in each plot rather than a reflection of the variability in the vegetation community (Gamon et al., 2013).

In order to study carbon exchange or vegetation metrics over large areas, satellite-based SVIs are useful (Chen et al., 2002; Shaver et. al., 2007; Street et al., 2007; Boelman et al., 2003; Laidler et al., 2008; Williams et al., 2008). The relationship between NDVI and vegetation metrics, such as LAI and fractional cover, were found to hold for various measurement scales and sensor platforms (Laidler et al., 2008; Williams et al., 2008). These are important findings for regional or global change studies plant dynamics that require inputs of LAI (Jia et al., 2006) or for the large scale monitoring (Stow et al., 2004; Goetz et al., 2005) and mapping (Chen et al., 2002; Williams et al., 2008) of land cover change.

\subsubsection{Temporal scale}

The timing of NDVI measurements is the second scale consideration present within the literature. The temporal scale of all remote sensing measurements is the result of the programmed measurement interval for automated ground-based instruments, the ability to revisit the research site by foot for manual measurements, or by the return interval due to particular satellite orbits. There is a wide variety of revisit intervals from 
approximately two weeks (La Puma et al., 2007) to minutes (Gamon, 2015) for various percentages of a complete growing season to multi-year records. All measurements are limited by sky conditions where measurements made in the dark, during low sun angles, or inclement weather are not typically of sufficient quality. In most studies with manual measurements, readings are taken at a consistent time of day, many at high noon, to control for sun zenith angle which could cause shadowing errors in the reflectance data (Davidson \& Csillag, 2001; Dagg \& Lafleur, 2010; Jiang et al., 2006).

With respect to the evaluation of tundra vegetation phenology and carbon exchange, the timeframe will determine the nature of the responses to the environment that can be observed. For example, 16 day returns may completely miss the stages of green up after snowmelt. Instead, one might observe snow on one pass followed by green leaves on the next. Another issue relates to the response of NDVI to phenology and carbon exchange. The remotely sensed index could be sensitive to the full range in leaf reflectance changes through the growing season. However, there may be less response in reflectance for some changes in plant function. For instance, short term weather events may not have an immediate effect on the greenness of vegetation, but could cause an immediate depression in GPP (La Puma et al., 2007).

\subsection{Community vs Landscape Analysis}

As a consequence of the issues with spatial and temporal scale, there arises in the literature the theme of community-specific analysis versus generalized landscape analysis. Community-specific analysis involves the development of relationships between SVIs and vegetation metrics or carbon flux that can only be generalized for relatively homogeneous vegetation communities which typically only cover small areas 
of the tundra (Dagg \& Lafleur, 2010; La Puma et al., 2007). A larger scale approach involves relating vegetation indices with vegetation metrics or carbon flux by averaging many distinct tundra vegetation communities together, reasoning that commonalities between these communities allow for the large scale measurement (Laidler et al., 2008; Williams et al., 2008; Shaver et al., 2007; Street et al., 2007). This is a disagreement on the necessary scale of vegetation indices for the optimization of vegetation metrics or carbon flux estimation and on the use of site-specific, or even patch-specific, calibration coefficients (Chen et al., 2002; Breda, 2003).

At the community level there is still a great amount of variability in species composition leading researchers to believe that small patch-scale studies capture the most variability in LAI (Van Wijk et al., 2005; Williams et al., 2008; Dagg \& Lafleur, 2010). If the vegetation differs spectrally among various regions of the Arctic tundra or even within relatively homogenous communities, careful region-specific calibrations may be necessary if a goal exists to scale up a particular vegetation metric or ecosystem carbon flux (La Puma et al., 2007).

In two different studies, NDVI was able to explain less than half the variation in net carbon flux exchange at the $0.4 \mathrm{~m}$ resolution (Dagg et al., 2010; La Puma et al., 2007). NEE is the difference of GEP and ER and variables that might more directly impact ER such as soil type, soil moisture, and snow cover may help explain more of the variation in NEE (Loranty et al. 2010; Gamon et al., 2013). In one study, there was significant relation between NDVI and ER for the various vegetation communities, excluding wet sedge (Dagg et al., 2010) while in another study, there was a small but 
significant relation between NDVI and ER $\left(\mathrm{R}^{2}=0.36\right)$ for moist tussock tundra (La Puma et al., 2007).

The argument to the move away from the direct use of NDVI to estimate GPP or NPP arises from the conclusion that there is a tightly constrained relationship between LAI and GPP that will hold for all canopies (Street et al., 2007). Shaver et al. (2007) discuss the idea of functional convergence where Arctic plant functional groups, despite their differences in composition, are subject to similar limitations. There may be similar relationships between LAI and GPP because the ratio of nitrogen per unit leaf area was found to be relatively constant for a large number of tundra vegetation types and both leaf nitrogen and LAI are key controls on the rate of photosynthesis (Van Wijk et al., 2005). Street et al. (2007) were able to produce a model in which LAI, derived from NDVI measurements calibrated from destructively harvested leaf area, explained $90 \%$ of the variation in photosynthesis chamber-based measurements of GPP at a $1 \mathrm{~m}$ resolution. Shaver et al. (2007) was able to explain $80 \%$ of the variation in the observed NEE (from chamber measurements of $\mathrm{CO}_{2}$ flux) using NDVI estimates of LAI (based on regression between NDVI and harvested leaf area) at $1 \mathrm{~m}$ resolution. These coefficients of determination are considerably larger than those found in studies that separated sampling by vegetation community at similar plot scales (La Puma et al., 2007; Dagg \& Lafleur, 2010).

In order to use NDVI to estimate carbon exchange at a given tundra site, a careful evaluation of how ground-based remotely sensed NDVI relates to vegetation metrics is helpful. This thesis project will help evaluate the usefulness of NDVI as a tool and 
address issues of spatial and temporal scale at a long-term Southern Arctic carbon study site in Canada's Northwest Territories. 


\section{3: Methods}

\subsection{Site Location}

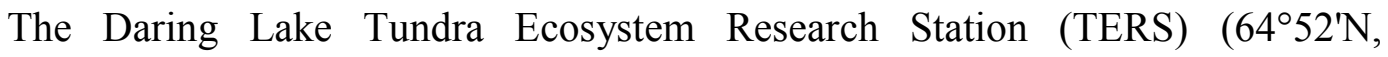
$\left.111^{\circ} 35^{\prime} \mathrm{W}\right)$ is located on the northern shore of Daring Lake, Northwest Territories. Daring Lake is located south of the much larger Yamba Lake, near the border of Nunavut, approximately $300 \mathrm{~km}$ northeast of Yellowknife, NT and $70 \mathrm{~km}$ north of the tree line (Lafleur \& Humphreys, 2007). The tundra plain in this region is broken up by many small to large water bodies, exposed bedrock outcrops and eskers, and is in a zone of continuous permafrost. Mean annual temperature for the research site is $-8.9^{\circ} \mathrm{C}$ (on-site weather station data for the period 1996 - 2009, Lafleur et al., 2012) and the mid-range estimate of mean annual precipitation in the area is $250 \mathrm{~mm}$ (Climatological Atlas of Canada, 1984). The average summer temperature during 1996 through 2009 was $10.4^{\circ} \mathrm{C}$ and average summer precipitation was $59.4 \mathrm{~mm}$, where summer is referring to the months of June through August (Lafleur et al., 2012).

This region is referred to as the low Arctic in subzone E (Walker et al., 2005) or the Southern Arctic (Ecosystem Classification Group, 2012) and is located in the central part of the Slave geological province (Dredge et al., 1999). Local bedrock types include the Archean metasediments (Yellowknife subgroup) and Archean granite and gneiss (Dredge et al., 1999). The surface features of this geologic province are a result of the last glaciation, with glaciers retreating from the southern part of the province and vegetation dominating the landscape by $8530 \pm 130$ BP (Dredge et al., 1999). The most common surface materials are glacial till deposits, and surface relief in the Daring Lake region 
predominantly takes the form of glacially formed eskers and hydrologic features, such as ponds and lakes (Dredge et al., 1999).

Sampling at Daring Lake was carried out at three sites representative of different tundra types in the region; the Daring Lake main site, DL, the Lake Site, LK, and the Fen Site, FN (Figure 1 and Appendix 6). The DL site primarily consists of erect dwarf-shrub tundra (Unit S1) and tussock-sedge, dwarf-shrub, moss tundra habitats (Unit G4) (as defined by Walker et al., 2005). Deciduous shrubs [Betula glandulosa (Michx.), Rubus chamaemorus (L.), Vaccinium uliginosum (L.)], evergreen and mat-forming shrubs [Rhododendron tomentosum subsp. subamrcticum (Harmaja) G.D. Wallace, Vaccinium vitis-idaea (L.), Empetrum nigrum (L.), Kalmia procumbens (L.) Gift \& Kron] dominated at this site, with scattered tussock forming graminoid cover (Eriophorum and Carex spp.) in wet areas, and a variable ground cover principally made up of lichen or moss or none depending on moisture. The deciduous shrubs cover $17 \%$ of the surface in the area with an average height ( \pm 1 standard error (SE)) of $18.2 \pm 1.3 \mathrm{~cm}$. The LK site is mainly made up of erect dwarf-shrub tundra (S1, as defined by Walker et al., 2005). This site has a similar vegetation structure to the DL site, but ground cover is dominated by moss species, with a lesser percentage of lichen cover. The deciduous shrub cover is $45 \%$ with a height of $21.6 \pm 0.8 \mathrm{~cm}$. At the DL and LK sites, sand to loamy sand mineral soils are covered by an organic layer of up to $\sim 22 \mathrm{~cm}$ in depth (Humphreys and Lafleur, 2011). The FN site is representative of sedge, moss, low-shrub wetland (W3, as defined by Walker et al., 2005). The dominant plant types at FN include Carex sp, and other graminoids, with sparsely scattered and low-growing Salix sp., and Andromeda polifolia (L.), and an almost complete ground cover of Sphagnum sp. Patches of B. glandulosa 
occur in raised formations in some areas of the wetland. Soils at the FN site consist of silt loam mineral soil covered by a layer of peat ranging from $40 \mathrm{~cm}$ to $70 \mathrm{~cm}$ in depth (Humphreys \& Lafleur 2011). During the 2014 measurements season, the water table was $13 \mathrm{~cm}$ below the lawn surface.

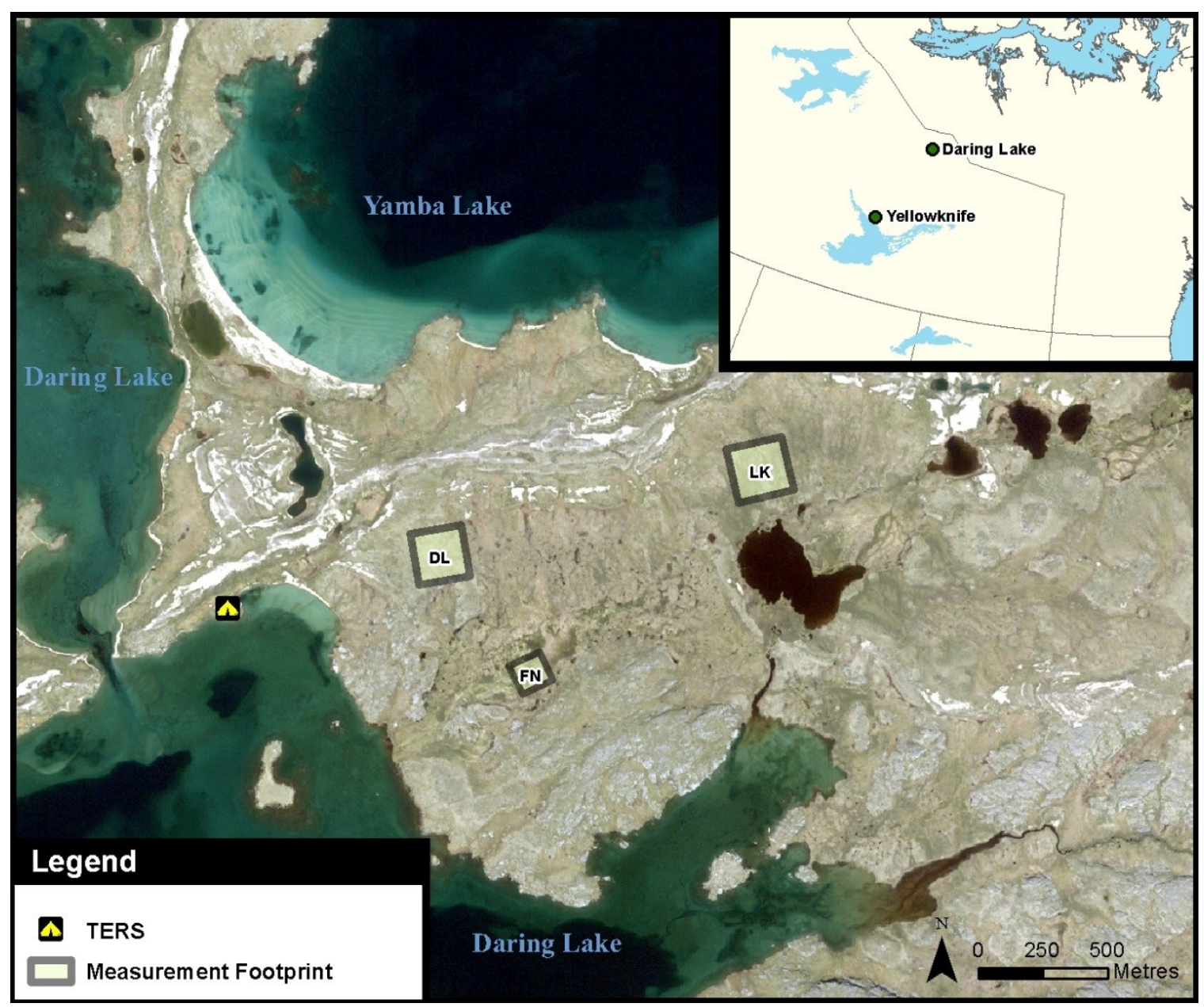

Figure 1. The location of the Daring Lake Tundra Ecosystem Research Station (TERS) and the three sampling locations; DL, LK, and FN.

\subsection{Experimental Design}

An unbalanced nested sampling design was used for field data sampling similar to the one used by Davidson and Csillag (2001). A nested design was used in order to 
investigate the scaling relationships between measurement variables. Plot level measurements of $0.5 \mathrm{~m}$ were nested to provide measurements at coarser resolutions of 5 $\mathrm{m}, 30 \mathrm{~m}$, and $200 \mathrm{~m}$. These scales approximately represent the measurement resolutions of IKONOS (4 m), Landsat Thematic Mapper (30 m), and MODIS (200-1000 m). The $200 \mathrm{~m}$ scale also approximates the typical footprint of the eddy covariance flux tower deployed at Daring Lake, in which the nested design was centered (Figure 2). For data collection at the coarser resolutions, measurements at the $0.5 \mathrm{~m}$ plot level were spatially averaged (Figure 2). Data collection took place during the 2014 growing season from May 1, 2014 - August 28, 2014, with roughly one site visit per week. At each visit all 63 $0.5 \mathrm{~m}$ plots at DL and LK and $210.5 \mathrm{~m}$ plots at $\mathrm{FN}$ were sampled for reflectance to calculate NDVI, and for soil volumetric water content. Due to time constraints, a subset of the plots at DL and LK (plot numbers 1-7, 29-35, and 58-63) were sampled for LAI, percent vascular vegetation cover, lichen cover, and moss cover. A total of 13 measurement sets were collected over the 2014 season approximately 1 week apart. Near the time of peak greenness (the last week of July), all $630.5 \mathrm{~m}$ plots at DL and LK and 21 plots at FN were sampled for all variables. 


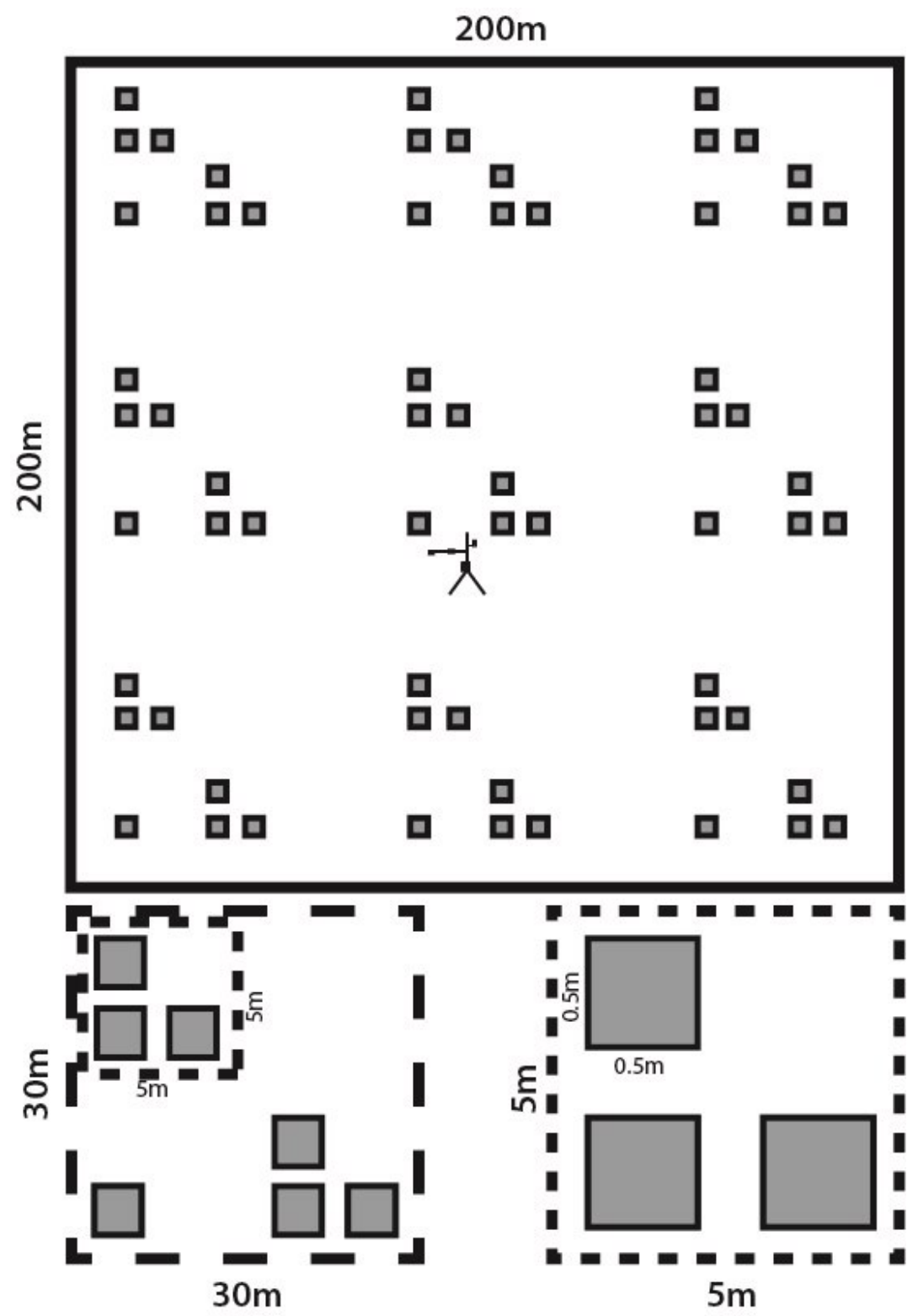

Figure 2. The DL and LK sampling regime showing the unbalanced nested design of 63 $0.5 \mathrm{~m}$ plots within a $200 \mathrm{~m}$ eddy covariance flux tower footprint. Groupings of 3 plots are spatially averaged to create a $5 \mathrm{~m}$ resolution $(\mathrm{n}=18)$ and two groupings of three plots along with a lone single plot form a $30 \mathrm{~m}$ resolution $(\mathrm{n}=9)$. The FN site was made up of a modified version of this design due to the constraints of a boardwalk. 


\subsection{NDVI Measurements}

During the field season, solar zenith angles ranged from $48.3^{\circ}$ on June $5^{\text {th }}, 2014$ to $60.5^{\circ}$ on August $27^{\text {th }}, 2014$. Reflectance measurements were taken with two cameras levelled at breast-height within $\sim 2$ hours of solar-noon and in a south-facing direction. Images were generally captured on clear sky days, though this was not always possible due to long periods of inclement weather or forest fire smoke in the region.

NDVI was calculated using:

$$
(\mathrm{NIR}-\mathrm{VIS}) /(\mathrm{NIR}+\mathrm{VIS})
$$

where NIR is the spectral reflectance measurement gathered for the NIR region of the electromagnetic spectrum and VIS is the measurement acquired in the visible region (red, green, or blue) of the spectrum.

NDVI measurements were captured via two cameras: a multispectral camera (model ADC, Tetracam Inc., Chatsworth, CA) (hereby referred to as the Tetracam) and a modified EOS Rebel T2i (Canon Inc., Tokyo, Japan) (hereby referred to as the Canon camera). The Tetracam produces multispectral images with sensitivities to the following spectral bands: green at 520-620 nm, red at 620-750 nm, and NIR at 750-950 nm. Landsat Thematic Mapper bands 2, 3, and 4 roughly correlate with the above Tetracam wavelengths. The raw images from the Tetrcam were processed using the Pixelwrench II software (Tetracam Inc). All images from a single sampling day were calibrated using a calibration plate made of white Teflon. An image of the calibration plate, consisting of the photographer holding the calibration plate in their palm about a foot away from the camera lens, was taken at the start of sampling. The Pixelwrench II software uses the image of the calibration plate to teach the software of the spectral balance of the sunlight 
at the time of measurement (Tetracam Inc., 2011). For the VIS part of equation (1), the Tetracam uses red reflectance.

Throughout the season, some plots had NDVI values of less than 0.09 . Other authors have defined an NDVI value of 0.09 as the minimum threshold value for growing season measurements (Goward et al., 1991; Jia et al. 2002). Previous studies chose to exclude Tetracam values under 0.09 (Dagg \& Lafleur, 2010), however for this study, low values were retained in the dataset because the Tetracam NDVI measurements tend to be low relative to other sensors (see Figure 8 for example) and because the low value could represent cases where plots contained expanses of bare soils, puddled water, non-leafy biomass, or non-vascular vegetation cover. 


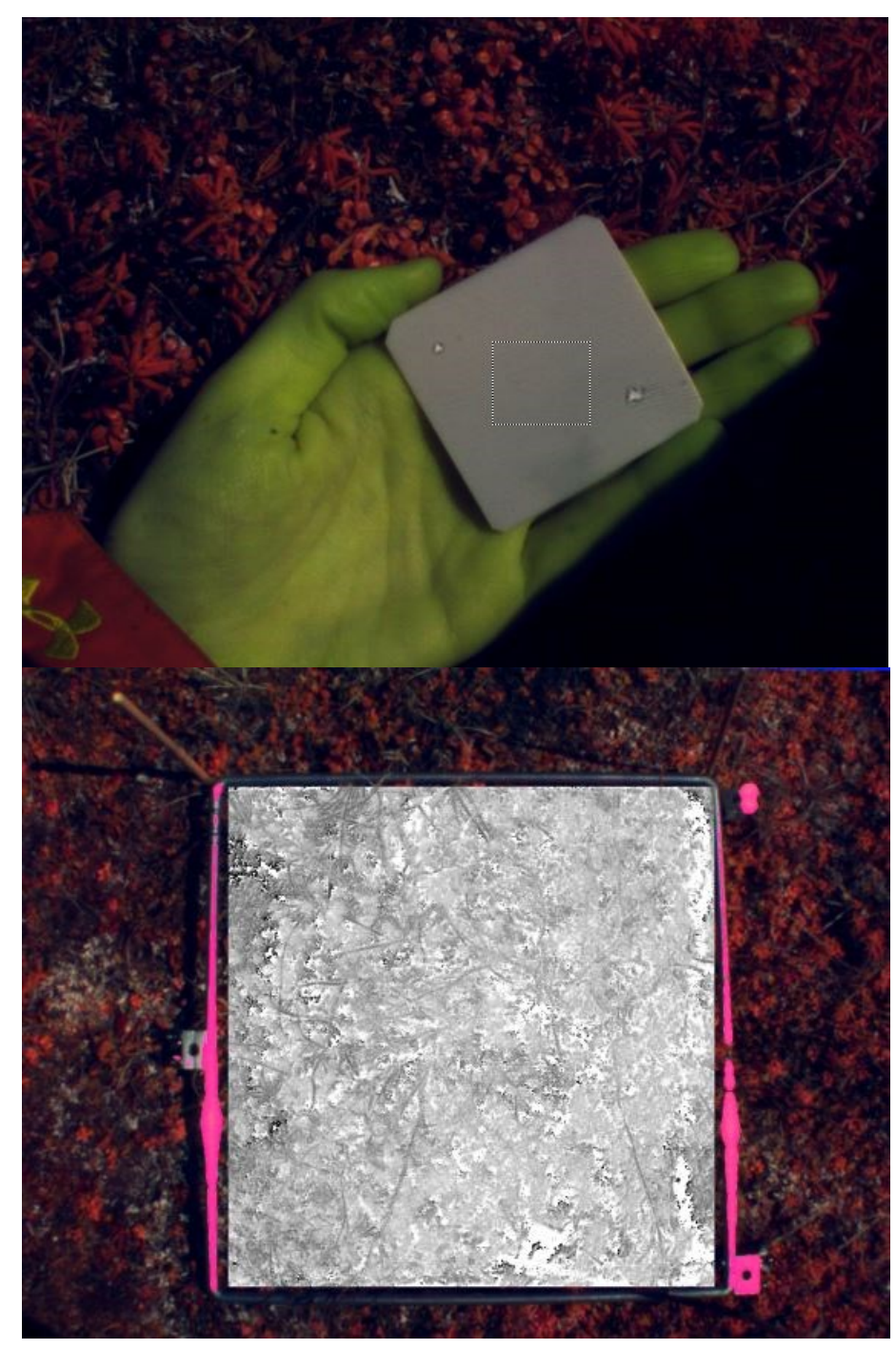

Figure 3. The Tetracam calibration image of the white Teflon calibration plate (top), and an image captured with the Tetracam multispectral camera, with the plot vegetation used to calculate NDVI highlighted in white (bottom). In these images, green vegetation appears red. Soil and non-green vegetation presents in dark tones.

The second NDVI camera is a modified Canon digital camera with increased sensitivities to infrared light. Typically in digital photography, an internal filter blocks infrared light from reaching the camera sensors. The filter in the Canon was changed to allow NIR light to reach the sensor (Leblanc et al., 2014). The camera is sensitive to the following wavebands; 470-670 $\mathrm{nm}$ in the green channel and $380-520 \mathrm{~nm}$ in the blue 
channel. The red channel does not cover wavelengths from the red part of the visible spectrum $(\sim 600-700 \mathrm{~nm} \mathrm{~nm})$ and instead it houses the NIR light, $670-770 \mathrm{~nm}$. This means that for computing NDVI, the red channel was used for the NIR parts of the equation and the blue channel was used for VIS parts of the equation. Previous studies have found that for close range remote sensing, blue light behaves similarly to red light with respect to vegetation reflectance (Leblanc et al., 2014). Although red is more commonly used as the visible part of the NDVI equation (Rouse et al., 1974), carotenoid and chlorophyll pigments effectively absorb blue light (Knipling, 1970).

To take the photographs, a metal frame was placed on the boundary of the plot. Photos were taken in automatic mode, with the camera held level above the plot at breast height. Beside each plot, and captured in each image, were a set of three reference reflective disks with known reflectance. All images were captured in jpeg format.

Using software designed by Sylvain LeBlanc and Wenjun Chen of Natural Resources Canada, the three reference disks and metal frame were semi-automatically extracted from each image (Leblanc et al., 2014). The software used the metal frame to find the inside of each plot (Leblanc et al., 2014). The software then extracted the digital number (DN) of each pixel in the reflectance disks and used these to calibrate the transformation of the DN of each pixel in the delineated plot into a reflectance value in the blue and NIR wavebands (Leblanc et al., 2014). Canon NDVI measurements were not made at the FN site. 


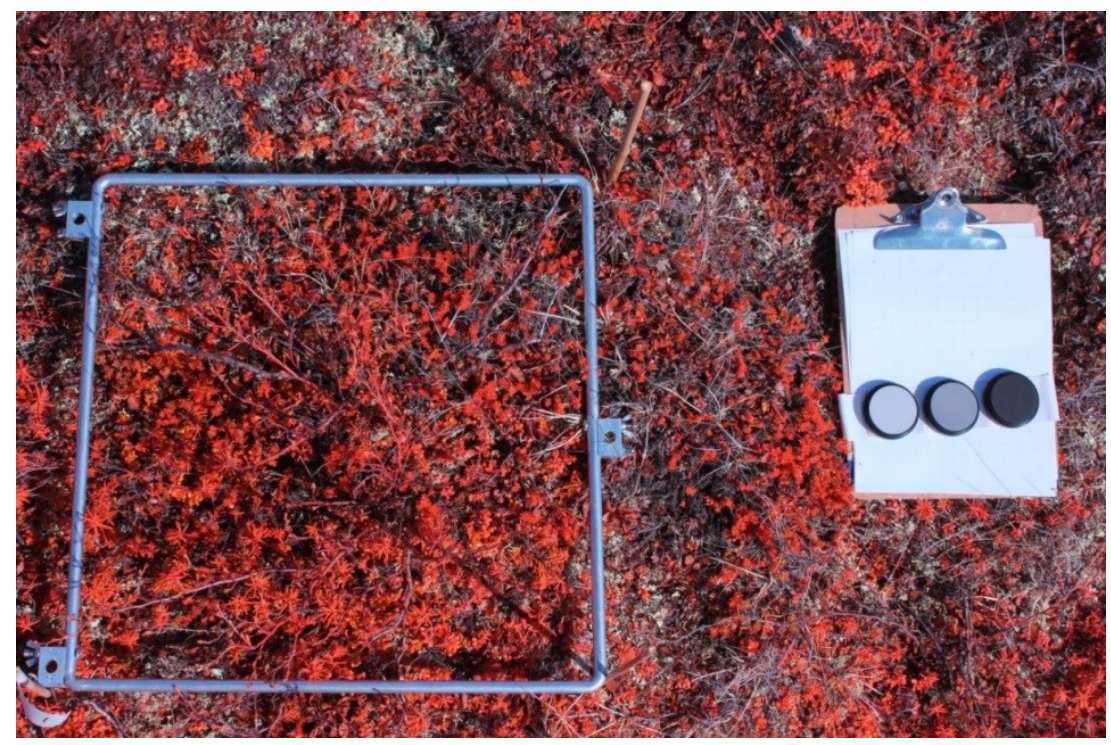

Figure 4. An image captured with the modified Canon digital camera, including the metal frame used to denote the plot and the three calibration disks used to adjust the pixel DN for the current light conditions.

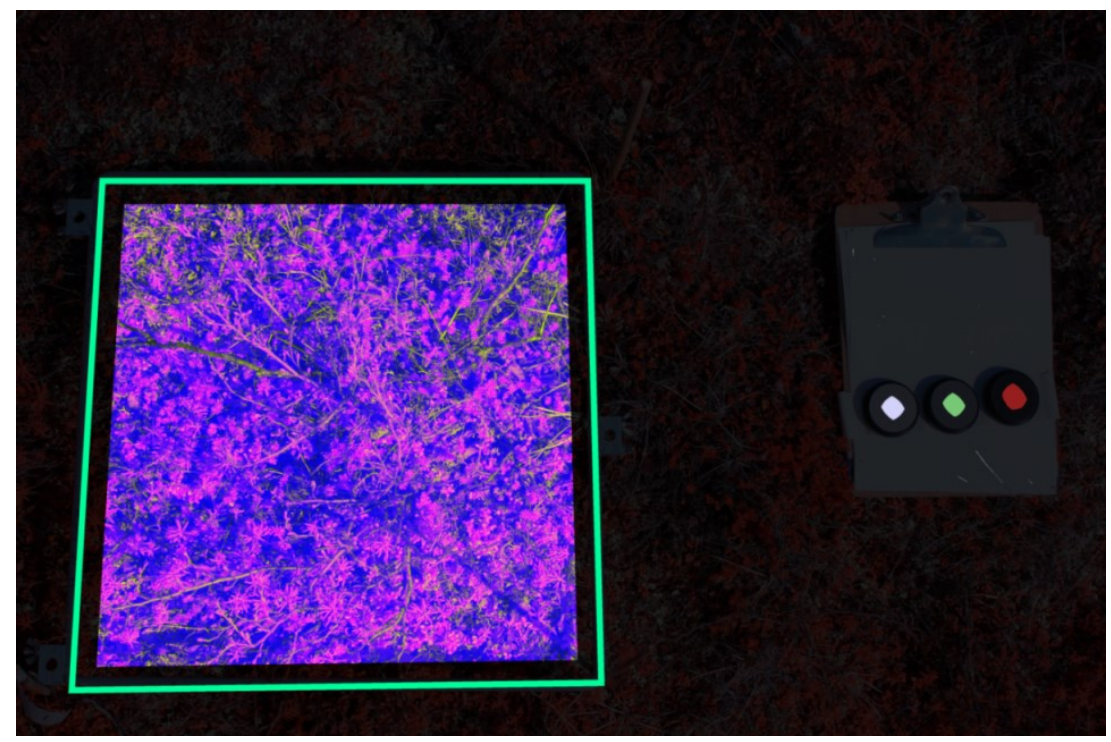

Figure 5. An image captured with the modified Canon digital camera after being run through the NRCan software that semi-automatically detects the calibration disks and frame. The highlighted area within the frame is the area of the image for which NDVI is calculated. 
For comparison to the field data, $500 \mathrm{~m}$ resolution 8 day MODIS/Terra Surface Reflectance 8-Day L3 Global 500m SIN Grid (MOD09A1) bands 02 (NIR) and 01 (red) were retrieved from the Oak Ridge National Laboratory Global Subsetting Tool: MODIS Land Products for 2014 for the pixel containing each of the three sampling sites. Growing season MODIS surface reflectance data was also selected for the $250 \mathrm{~m}$ resolution pixels using a 3 day subset provided by Agriculture and Agri-Food Canada. In both cases, NDVI was calculated using equation (1). The 3 day traces were cleaned of unreasonable NDVI values (e.g. day to day changes greater than 0.2 ). The 3 day MODIS NDVI were then linearly interpolated and correlated with the mean Tetracam and Cannon NDVI for each site.

\subsection{Leaf Area Index and Percent Vegetation Cover}

Leaf area index, measured as projected $\mathrm{m}^{2}$ leaf area per $\mathrm{m}^{2}$ ground area $\left(\mathrm{m}^{2} \mathrm{~m}^{-2}\right)$, and vascular and non-vascular vegetation cover measurements were obtained using the point quadrat method (Jonasson, 1988). This method was selected because it is non-destructive and allows for multiple LAI measurements to be taken at the same location over time. A $0.5 \mathrm{~m} \times 0.5 \mathrm{~m}$ frame with an even grid of 25 crosshairs was leveled over a sampling plot. The spacing of the crosshairs was determined to be adequate for determining leaf area and vegetation cover by Brathen and Hagberg (2004). A pin was lowered at the site of each crosshair and a count was obtained for all living leaf hits, separated by species. A description of the ground cover, lichen, moss, or bare soil was collected for each pin site as well. 


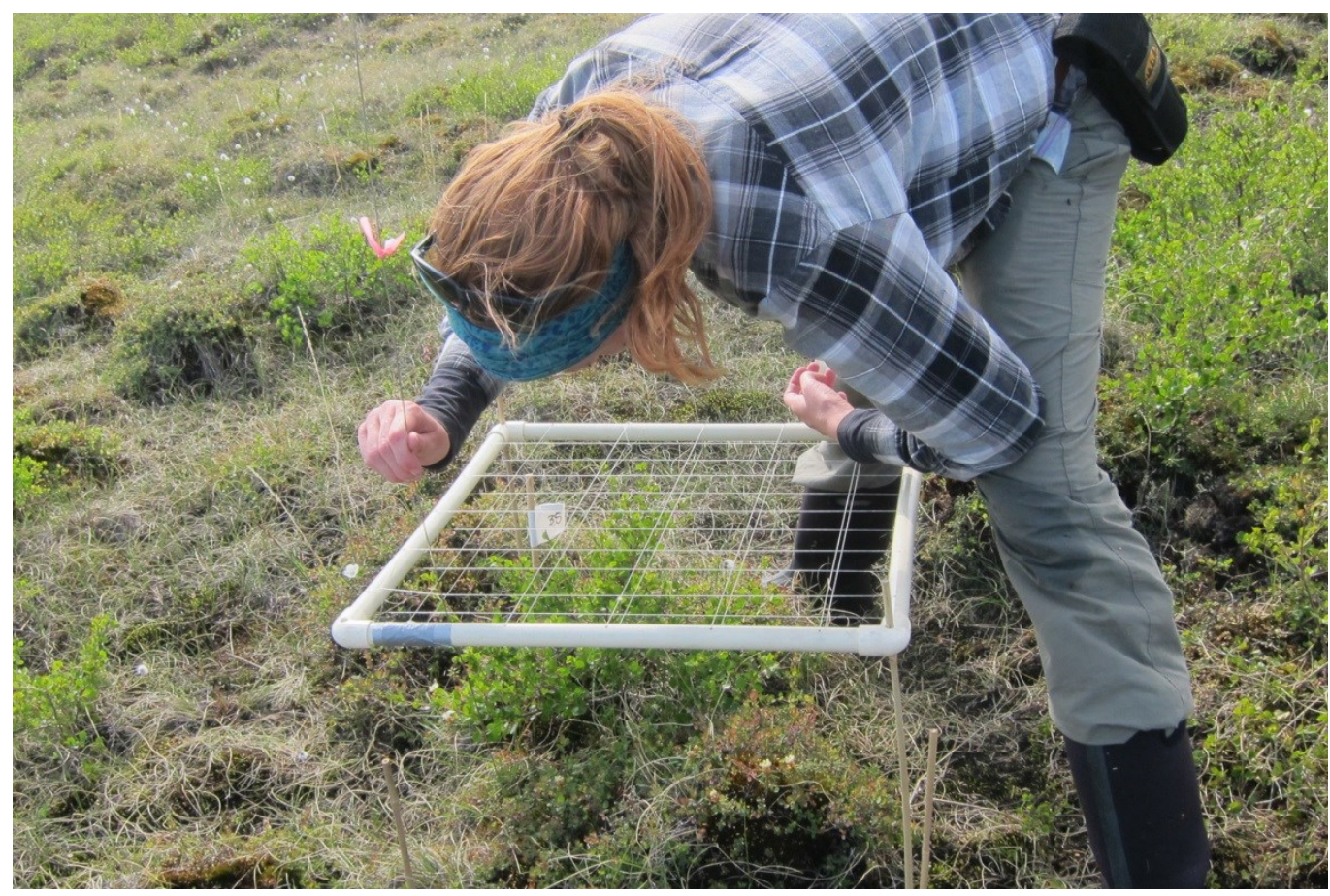

Figure 6. The point-frame method being carried out in the field.

LAI was calculated as the sum of 'hits' on green vegetation divided by the number of pin drops $(=25)$. Percent vascular vegetation cover was determined as the number of pin drops that contacted at least one living vascular plant leaf divided by 25 multiplied by $100 \%$. Similarly, percent moss and percent lichen cover were determined by the number of pin drops that contacted moss and lichen, respectively, divided by 25 and multiplied by 100\%. Effective LAI was also gathered optically using the LAI2200c sensor (LI-COR Biosciences, Lincoln NE). This method proved to be ineffective for measuring LAI at many plots, due to issues with getting the sensor under very short vegetation canopies while keeping the sensor face leveled as has been found in other studies (van Wijk \& Williams, 2005). 


\subsection{Soil Volumetric Water Content}

Volumetric Water Content (VWC) of the soil was measured by the Hydrosense II probe with the $200 \mathrm{~mm}$ CS658 water content probes (Campbell Scientific Inc, Logan, UT). Each sample includes a measurement of the period $(\mu \mathrm{s})$, a measurement of the dielectric permittivity of the soil between the sensor rods, and a computed value of the soil volumetric water content (\%) based on the default logarithmic instrument calibration. For each survey day, two measurements were taken at each plot. In cases where soil water content was high, typically in saturated peat soils, the period measured by the Hydrosense probe was outside the default calibration range. The default calibration was linearly extended based on the data available for measurements with periods $>2.5 \mu$ s and a VWC value $>40 \%$. The measurements were then separated again by site. For each plot the two measurements of VWC were averaged to create a single value for each plot on each sampling day.

\subsection{Data Analyses}

The statistical analyses used in this project were run using JMP 12 Statistical Discovery $^{\text {TM }}$ (SAS Institute Inc., Toronto ON) and Matlab (R2013a, The Mathworks Inc., Natick, MA). Significance was determined for all tests using a p-value of 0.05 . To test for temporal trends in the data, two one-way analysis of variance (ANOVA) tests were conducted on the seasonal data collected for each variable at the $0.5 \mathrm{~m}$ measurement resolution. The first ANOVA test was conducted on the first half of the seasonal measurements up to the date of the highest recorded value. This test was used to determine if there was a significant increasing trend in the data as hypothesized for the "green-up" period. The second ANOVA test was run on the data starting from the highest 
recorded value for each measurement variable and ending at the final measurement date for the season. The second ANOVA was used to determine whether there was a discernable senescence trend in the data.

A nested ANOVA helped identify when there were significant differences in the spatial variability of the measurement variables (Tetracam NDVI, Canon NDVI, LAI, percent vascular vegetation cover, lichen cover, moss cover, and soil volumetric water content) collected at peak greenness at DL and LK sites. FN site data was not included since fewer samples were collected there due to logistical constraints (the need for boardwalks). For each site, the $0.5 \mathrm{~m}$ plot measurements were nested within the $5 \mathrm{~m}$ plots, the $5 \mathrm{~m}$ within the $30 \mathrm{~m}$, the $30 \mathrm{~m}$ within the $200 \mathrm{~m}$ site footprint. At the highest level of nesting, DL and LK sites were nested within the Daring Lake research valley. This analysis will show whether there is (1) variation among $200 \mathrm{~m}$ sites (DL and LK), (2) variation among $30 \mathrm{~m}$ plots, and (3) variation among $5 \mathrm{~m}$ plots.

K-means cluster analysis using 3 clusters was used to group plots by vegetation characteristics after visually assessing the patterns using principle component analysis biplots. ANOVA with NDVI as a covariate was used to assess significance of relationships between NDVI and LAI or percent vascular vegetation cover and how these differed among sites or the 3 vegetation classifications. Least squares non-linear regression, nlinfit routine in Matlab, was used to fit a logarithmic relationship between NDVI and LAI. Orthogonal regression, with equal variance in the $\mathrm{x}$ and $\mathrm{y}$ errors, was also used to characterize the relationships between vegetation metrics, VWC, and NDVI for each measurement resolution ( $\mathrm{n}=63$ for $0.5 \mathrm{~m}, \mathrm{n}=18$ for $5 \mathrm{~m}$, and $\mathrm{n}=9$ for $30 \mathrm{~m}$ for DL and LK sites and $\mathrm{n}=21$ for 0.5 and $\mathrm{n}=6$ for $5 \mathrm{~m}$ for the FN site). This form of 
regression helps address the issue that all variables were associated with similar uncertainties and measurement error. Pearson's correlation coefficient was used to test the degree of correlation between measurement variables. For site specific analyses, plots 19 and 20 at the FN site were excluded as outliers as they were characteristic of dwarf shrub tundra rather than sedge fen but were retained for the combined site analyses. In most cases, data were normally distributed and no data transformations were done. 


\section{4: Results}

\subsection{Vegetation Metrics}

Overall the LK site had the greatest average percent vascular vegetation coverage, LAI, and NDVI at the time of peak greenness in late July 2014 (Table 1). DL site had the next greatest vascular vegetation values followed by the FN site (Table 1). Lichen was the dominant non-vascular ground cover at the DL site, which also had the lowest average soil volumetric water content. Moss was the dominant non-vascular ground cover at both the LK and FN sites, where the FN site had complete coverage in the plots sampled (Table 1). The FN site also had the greatest soil volumetric water content, followed by the LK site (Table 1). Spatial variability in these variables was greater at DL and LK compared to FN. As expected, variability decreased with coarser resolutions at all three sites (Table 1). 
Table 1. Mean plot value (Avg) and standard deviation (SD) for vegetation metrics and soil volumetric water content at DL, LK and FN sites at the end of July 2014 for the three measurement scales; $0.5 \mathrm{~m}, 5 \mathrm{~m}, 30 \mathrm{~m}$ ( $\mathrm{n}=63,18,9$, respectively).

\begin{tabular}{|c|c|c|c|c|}
\hline DL & Avg & $\begin{array}{l}\text { SD } \\
0.5 \mathrm{~m}\end{array}$ & $\begin{array}{l}\text { SD } \\
5 \mathrm{~m} \\
\end{array}$ & $\begin{array}{l}\text { SD } \\
30 \mathrm{~m} \\
\end{array}$ \\
\hline $\operatorname{LAI}\left(\mathrm{m}^{2} \mathrm{~m}^{-2}\right)$ & 1.53 & 0.65 & 0.41 & 0.31 \\
\hline Vascular Plant Percent Cover (\%) & 74 & 14 & 10 & 6 \\
\hline Lichen Cover (\%) & 49 & 29 & 21 & 13 \\
\hline Moss Cover (\%) & 19 & 26 & 20 & 13 \\
\hline Volumetric Water Content (\%) & 34 & 15 & 13 & 12 \\
\hline NDVI - Tetracam & 0.35 & 0.09 & 0.08 & 0.06 \\
\hline NDVI - Canon & 0.67 & 0.08 & 0.05 & 0.04 \\
\hline
\end{tabular}

\begin{tabular}{|l|r|r|r|r|}
\hline LK & & & & \\
\hline LAI $\left(\mathrm{m}^{2} \mathrm{~m}^{-2}\right)$ & 2.00 & 0.64 & 0.47 & 0.39 \\
\hline Vascular Plant Percent Cover (\%) & 83 & 12 & 9 & 7 \\
\hline Lichen Cover (\%) & 30 & 26 & 20 & 17 \\
\hline Moss Cover (\%) & 44 & 27 & 20 & 14 \\
\hline Volumetric Water Content (\%) & 35.8 & 10.2 & 10.4 & 6.9 \\
\hline NDVI - Tetracam & 0.41 & 0.05 & 0.04 & 0.02 \\
\hline NDVI - Canon & 0.73 & 0.15 & 0.09 & 0.07 \\
\hline
\end{tabular}

\begin{tabular}{|l|r|r|r|r|}
\hline FN & & & & \\
\hline LAI $\left(\mathrm{m}^{2} \mathrm{~m}^{-2}\right)$ & 0.85 & 0.40 & 0.25 & 0.15 \\
\hline Vascular Plant Percent Cover (\%) & 65 & 11 & 7 & 2 \\
\hline Lichen Cover (\%) & 2 & 10 & 6 & 4 \\
\hline Moss Cover (\%) & 97 & 12 & 9 & 5 \\
\hline Volumetric Water Content (\%) & 62.8 & 7.9 & 6.5 & 5.0 \\
\hline NDVI - Tetracam & 0.28 & 0.06 & 0.04 & 0.03 \\
\hline
\end{tabular}


The $0.5 \mathrm{~m}$ scale vegetation communities were then statistically separated into 3 clusters (regardless of which site they were located in) (Table $2 \&$ Appendix 4) and associated with the tundra groups in the CAVM classification scheme (Walker et al., 2005). This analysis confirmed that DL was a mixture of tundra communities (drier lichen-rich dwarf shrub and moist dwarf shrub tundra, both part of Unit S1, and sedge tundra that grouped with the FN plots although was more representative of tussock tundra, G4 than W3), while LK plots were $86 \%$ moist dwarf shrub (S1) and FN plots were $95 \%$ sedge meadow (W3).

Table 2. Selected vegetation metrics for the three communities determined using k-means cluster analysis. Plant values indicate number of pin contacts (out of a total of 25 pin drops) during point frame measurements at peak greenness. Values with subscripts $i$ indicate significant differences among groups $(p<0.05)$ using the Student's $t$ test.

\begin{tabular}{|l|l|l|l|}
\hline & $\begin{array}{l}\text { Dwarf shrub } \\
\text { tundra(S1, red } \\
\text { markers in } \\
\text { Appendix 4) }\end{array}$ & $\begin{array}{l}\text { Drier lichen-rich } \\
\text { dwarf shrub (S1, } \\
\text { green markers) }\end{array}$ & $\begin{array}{l}\text { Sedge wetland } \\
\text { tundra (W3, blue } \\
\text { markers) }\end{array}$ \\
\hline Number of plots & 84 & 23 & 40 \\
\hline Birch & 9.8 & 6.0 & 2.9 \\
\hline Labrador tea & $14.0^{\mathrm{a}}$ & $12.0^{\mathrm{a}}$ & $1.6^{\mathrm{b}}$ \\
\hline Bilberry & $6.5^{\mathrm{a}}$ & $1.4^{\mathrm{b}}$ & $1.2^{\mathrm{b}}$ \\
\hline Cranberry & $12.4^{\mathrm{a}}$ & $10.7^{\mathrm{a}}$ & $1.8^{\mathrm{b}}$ \\
\hline Crowberry & $0.2^{\mathrm{a}}$ & $6.6^{\mathrm{b}}$ & $0.1^{\mathrm{a}}$ \\
\hline Graminoid & $2.8^{\mathrm{a}}$ & $0.9^{\mathrm{b}}$ & $12.4^{\mathrm{c}}$ \\
\hline Bearberry & $0.2^{\mathrm{a}}$ & $2.7^{\mathrm{b}}$ & $0^{\mathrm{a}}$ \\
\hline Azalea & $0.2^{\mathrm{a}}$ & $2.2^{\mathrm{b}}$ & $0^{\mathrm{a}}$ \\
\hline Lichen & $9.5^{\mathrm{a}}$ & $14.6^{\mathrm{b}}$ & $0.8^{\mathrm{c}}$ \\
\hline Moss & $6.9^{\mathrm{a}}$ & $0.5^{\mathrm{b}}$ & $19.6^{\mathrm{c}}$ \\
\hline VWC (\%) & $34.6^{\mathrm{a}}$ & $26.2^{\mathrm{b}}$ & $54.8^{\mathrm{c}}$ \\
\hline LAI (m m $^{-2}$ ) & $1.94^{\mathrm{a}}$ & $1.73^{\mathrm{a}}$ & $0.95^{\mathrm{b}}$ \\
\hline $\begin{array}{l}\text { Vascular vegetation } \\
\text { cover }(\%)\end{array}$ & $81.1^{\mathrm{a}}$ & $78.1^{\mathrm{a}}$ & $65.6^{\mathrm{b}}$ \\
\hline NDVI (Tetracam) & $0.40^{\mathrm{a}}$ & $0.39^{\mathrm{a}}$ & $0.29^{\mathrm{b}}$ \\
\hline
\end{tabular}




\subsection{Temporal Variations in Vegetation Metrics}

Over the course of the growing season, percent vascular vegetation cover exhibited an increasing trend from the start of the measurement period to the final week of July followed by a decline until the end of the measurement period (Figure 3). These seasonal trends were significant at $\mathrm{DL}(\mathrm{df}=8, \mathrm{~F}=58.41, \mathrm{p}=<0.0001$ and $\mathrm{df}=3, \mathrm{~F}$ $=34.35, \mathrm{p}=<0.0001$, respectively $)$, at $\mathrm{LK}(\mathrm{df}=7, \mathrm{~F}=40.2938, \mathrm{p}=<0.0001$ and $\mathrm{df}=$ $3, \mathrm{~F}=23.9881, \mathrm{p}=<0.0001$, respectively $)$, and at $\mathrm{FN}(\mathrm{df}=8, \mathrm{~F}=55.1181, \mathrm{p}=<0.0001$ and $\mathrm{df}=2, \mathrm{~F}=8.4308, \mathrm{p}=0.0006$, respectively). There were no seasonal trends in percent lichen or moss cover (data not shown).

Similar trends were observed for the LAI (Figure 7). These early and late seasonal trends were found to be significant at $\mathrm{DL}(\mathrm{df}=8, \mathrm{~F}=35.01, \mathrm{p}=<0.0001$ and $\mathrm{df}=3, \mathrm{~F}=$ 23.52, $\mathrm{p}=<0.0001$, respectively $)$, at $\mathrm{LK}(\mathrm{df}=7, \mathrm{~F}=38.04, \mathrm{p}=<0.0001$ and $\mathrm{df}=3, \mathrm{~F}$ $=31.32, \mathrm{p}=<0.0001$, respectively $)$, and at $\mathrm{FN}(\mathrm{df}=8, \mathrm{~F}=23.35, \mathrm{p}=<0.0001$ and $\mathrm{df}=$ $2, \mathrm{~F}=4.12, \mathrm{p}=0.02$, respectively). These seasonal trends suggest that the vegetation goes through a process of leaf emergence and expansion where vegetation cover is rapidly increasing until a peak value is reached and then senescence becomes the dominant process. 

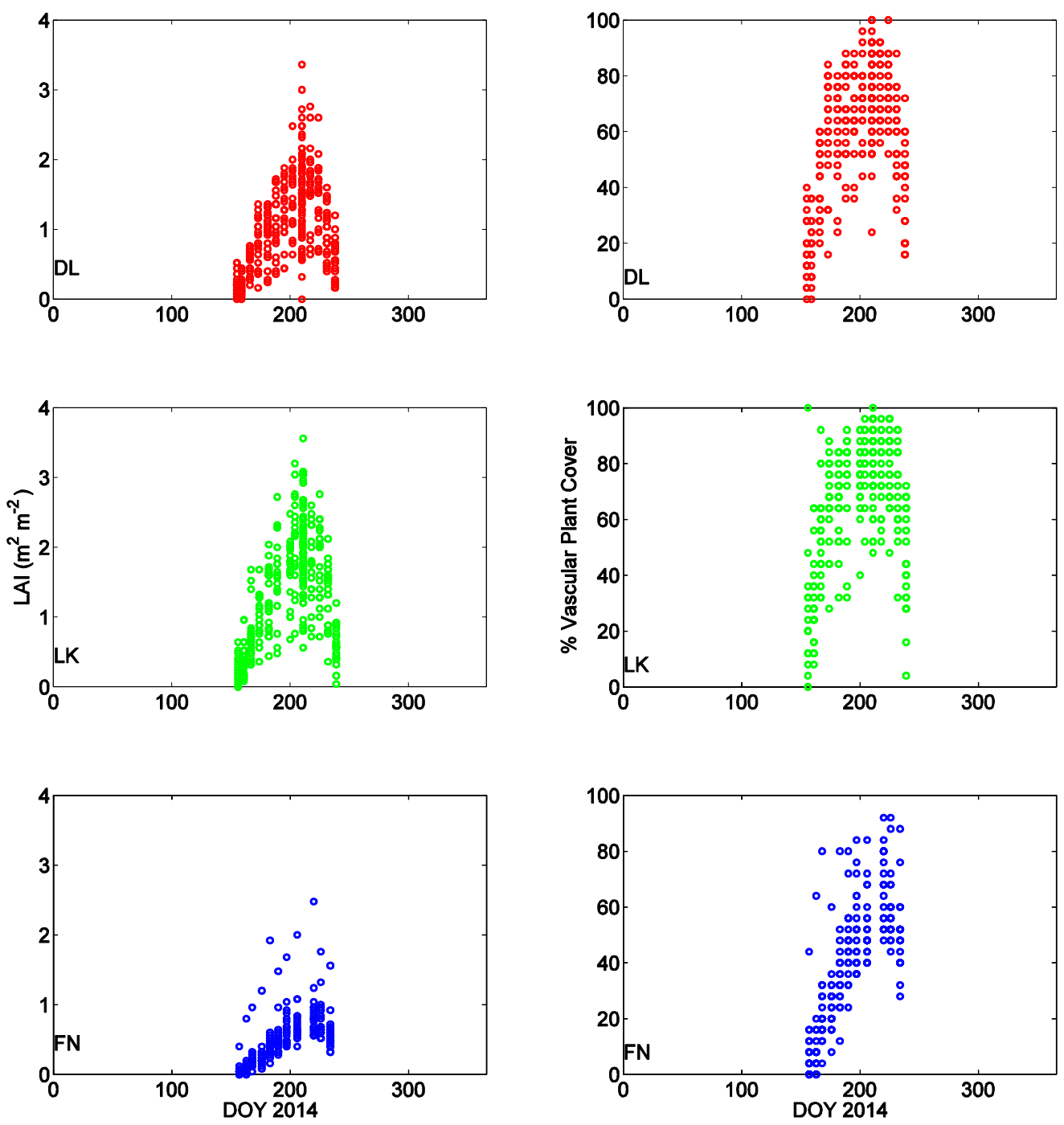

Figure 7. Percent vascular vegetation cover (right panels) and leaf area index as measured using point intercept method (left panels) at the $0.5 \mathrm{~m}$ plot scale over the course of the growing season for the DL, LK and FN sites. 
Both DL and LK sites exhibited a trend of rising Tetracam NDVI values in the early part of the growing season, peaking around the final week of July, and then following a gradual decline until then last measurements at the end of August (Figure 8). These greening trends and senescing trends were significant at DL $(\mathrm{df}=7, \mathrm{~F}=20.40, \mathrm{p}$ $=<0.0001$ for green-up and $\mathrm{df}=4, \mathrm{~F}=10.87, \mathrm{p}=<0.0001$ for senescence) and at LK $(\mathrm{df}=7, \mathrm{~F}=40.18, \mathrm{p}=<0.0001$ for green-up and $\mathrm{df}=3, \mathrm{~F}=42.04, \mathrm{p}=<0.0001$ for senescence). In contrast, the FN site had a slight increasing trend in NDVI-tetracam values but it did not decline during the period of measurement after peak greenness was reached (Figure 8). Only the green-up trend was significant $(\mathrm{df}=8, \mathrm{~F}=22.78, \mathrm{p}=<$ 0.0001 for green-up and $\mathrm{df}=3, \mathrm{~F}=1.3810, \mathrm{p}=0.25$ for senescence).

The Canon NDVI did not illustrate these seasonal trends as effectively as the Tetracam, in part due to a later start date to the measurements and some low values midseason. The change in weekly measurements for green-up at DL and LK were not significant $(\mathrm{df}=5, \mathrm{~F}=1.89, \mathrm{p}=0.10$ for $\mathrm{DL}, \mathrm{df}=7, \mathrm{~F}=1.12, \mathrm{p}=0.35$ for $\mathrm{LK})$. While there was a significant trend after peak greenness at $\mathrm{DL}(\mathrm{df}=3, \mathrm{~F}=4.50, \mathrm{p}=0.0043)$, visually it does not follow a declining senescence pattern. There was no significant senescence trend at $\mathrm{LK}(\mathrm{df}=3, \mathrm{~F}=1.97, \mathrm{p}=0.12)$.

For comparison to the field measurements, $500 \mathrm{~m}$ resolution 8 day (for the full year) and $250 \mathrm{~m}$ resolution 3 day MODIS NDVI (for the growing season) for the pixel containing each of the three sampling sites was evaluated. The $500 \mathrm{~m}$ MODIS-based NDVI demonstrated a large change from snow covered conditions to summer. The seasonal trend of the MODIS data was generally similar to that observed with the Tetracam NDVI data. The MODIS-based NDVI also placed peak greenness around the 
final week of July (Figure 9). DL site showed the strongest correlation between groundbased Tetracam NDVI and MODIS NDVI $(\mathrm{r}=0.64, \mathrm{p}=0.03$ for 3 -day, $\mathrm{r}=0.87, \mathrm{p}=$ 0.0002 for 16-day), followed by the LK site $(r=0.74, p=0.006$ for 3-day, $r=0.81, p=$ 0.001 for 16-day), and finally FN site $(r=0.65, p=0.02$ for 3 -day, $r=0.51, p=0.09$ for 16-day). The correlation may not have been significant at FN for the $500 \mathrm{~m}$ NDVI due to a mixed signal from the larger MODIS pixel, which included reflectance from other features such as the exposed bedrock lying to the south of the site (Figure 1). The spatial variation in mean growing season 3-day 250 m MODIS NDVI (between DOY 155 and 240) (standard deviations of $0.62,0.66,0.61$ at DL, LK, and FN, respectively) was smaller but generally reflected the variations obtained using the Tetracam NDVI $(0.35$, $0.41,0.28$ at DL, LK, and FN, respectively). In contrast, at the $500 \mathrm{~m}$ resolution, MODIS NDVI was larger at the FN vs. DL site $(0.60,0.65,0.62$ at DL, LK, and FN, respectively) again, likely due to the inclusion of other surface types in the pixel. 

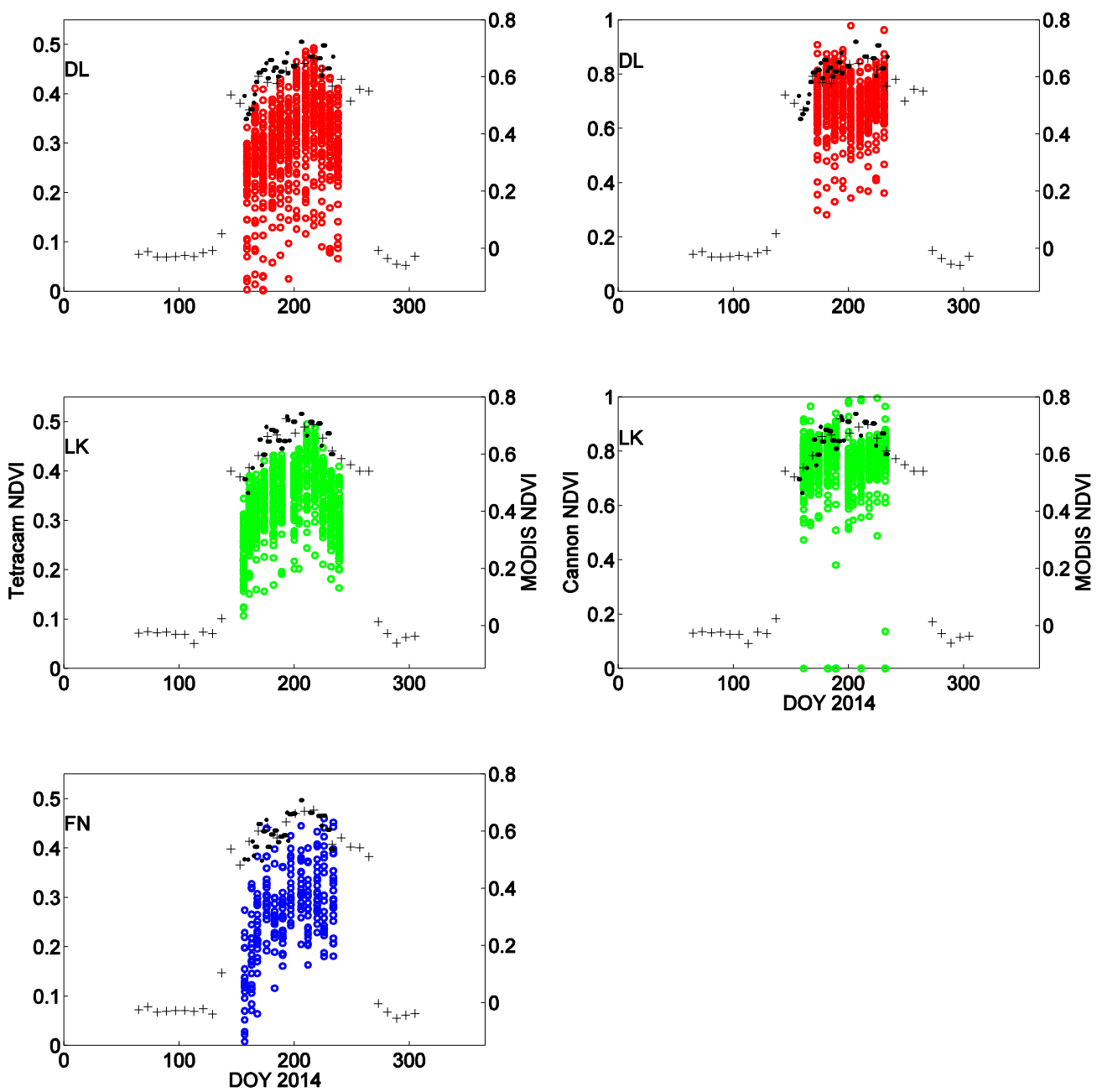

Figure 8. Tetracam NDVI (left panel) and Canon NDVI (right panel) at the $0.5 \mathrm{~m}$ plot scale over the course of the growing season for top) DL site, middle) LK site, and bottom) FN site. Note that Canon NDVI was not measured at the FN. MODIS-based NDVI is also shown on each figure (black + symbols are the $500 \mathrm{~m}$ 16-day values and black circles are the $250 \mathrm{~m}$ 3-day values). 


\subsection{Relationships Among Vegetation Metrics \& Other Variables}

When the $0.5 \mathrm{~m}$ data collected at peak greenness from all three measurement sites were grouped together, Tetracam NDVI was positively correlated with both percent vascular vegetation cover and LAI (Figure 9, Table 3). Tetracam NDVI was negatively correlated with moss cover and soil volumetric water content (Table 3). Only lichen cover did not significantly correlate with Tetracam NDVI.

Similarly Canon NDVI was positively correlated with percent vascular vegetation cover and LAI, but had no significant correlation with moss cover, soil volumetric water content, or lichen cover (Table 3).

Percent vascular vegetation cover was positively correlated with LAI, and both variables were positively correlated with moss cover and had no significant correlation with lichen cover (Table 3). Lichen cover was negatively correlated with moss cover (Table 3). Soil volumetric water was negatively correlated with all vegetation metrics with the exception of the positive correlation with moss cover (Table 3). See Appendix 1 for illustrations of the orthogonal relationships among variables listed in Table 3. 
Table 3. Pearson correlations (r) and probabilities (p) for the relationships between variables at peak greenness for DL, LK, and FN sites combined, $n=147$. Significant correlations are shaded (when $\mathrm{p}<0.05$ ).

\begin{tabular}{|c|c|c|c|c|c|c|c|c|c|c|c|c|}
\hline \multirow[t]{2}{*}{ Variable } & \multicolumn{2}{|c|}{$\begin{array}{c}\text { Percent } \\
\text { vascular } \\
\text { vegetation } \\
\text { cover }\end{array}$} & \multicolumn{2}{|c|}{ LAI } & \multicolumn{2}{|c|}{$\begin{array}{l}\text { Lichen } \\
\text { Cover }\end{array}$} & \multicolumn{2}{|c|}{$\begin{array}{l}\text { Moss } \\
\text { Cover }\end{array}$} & \multicolumn{2}{|c|}{$\begin{array}{c}\text { Tetracam } \\
\text { NDVI }\end{array}$} & \multicolumn{2}{|c|}{$\begin{array}{l}\text { Canon } \\
\text { NDVI }\end{array}$} \\
\hline & $\mathrm{r}$ & $\mathrm{P}$ & $\mathrm{r}$ & $\mathrm{p}$ & $\mathrm{R}$ & $\mathrm{p}$ & $\mathrm{r}$ & $\mathrm{p}$ & $\mathrm{r}$ & $\mathrm{p}$ & $\mathrm{r}$ & $\mathrm{p}$ \\
\hline VWC & -0.27 & 0.001 & -0.43 & $\begin{array}{r}< \\
0.0001\end{array}$ & -0.40 & $\begin{array}{r}<< \\
0.0001\end{array}$ & 0.63 & $\begin{array}{r}r< \\
0.0001\end{array}$ & -0.50 & $\begin{array}{r}< \\
0.0001\end{array}$ & -0.09 & 0.32 \\
\hline $\begin{array}{l}\text { Percent vascular } \\
\text { vegetation cover }\end{array}$ & & & 0.80 & $\begin{array}{r}< \\
0.0001 \\
\end{array}$ & -0.01 & 0.87 & -0.22 & 0.008 & 0.64 & $\begin{array}{r}< \\
0.0001 \\
\end{array}$ & 0.43 & $\begin{array}{r}< \\
0.0001 \\
\end{array}$ \\
\hline LAI & & & & & 0.08 & 0.39 & -0.30 & 0.0002 & 0.66 & $\begin{array}{r}<< \\
0.0001 \\
\end{array}$ & 0.40 & $\begin{array}{r}< \\
0.0001\end{array}$ \\
\hline Lichen Cover & & & & & & & -0.78 & $\begin{array}{r}< \\
0.0001\end{array}$ & 0.14 & 0.10 & -0.12 & 0.17 \\
\hline Moss Cover & & & & & & & & & -0.24 & 0.004 & 0.07 & 0.41 \\
\hline
\end{tabular}



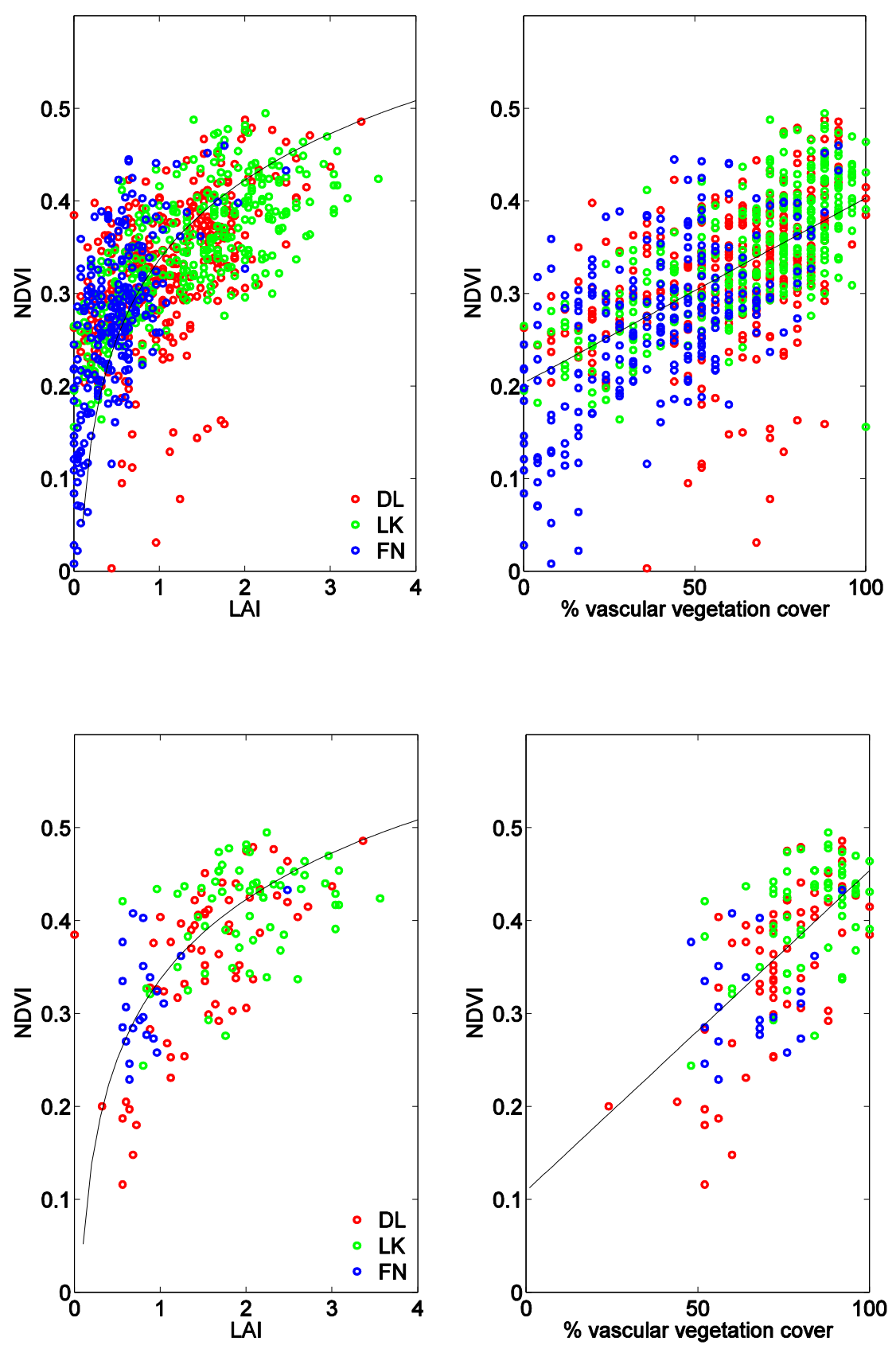

Figure 9. NDVI measured using the Tetracam vs. LAI (left) and vs. percent vascular vegetation cover (right) for the three research sites at Daring Lake at the $0.5 \mathrm{~m}$ resolution for all measurement dates (top) and peak greenness (below). The relationship between NDVI and LAI is modified from Shaver et al. (2007) where modelled NDVI is reduced by 0.4 . The relationship between NDVI and \% cover is the orthogonal regression with slope $=0.002$ and offset of 0.2032 (for all measurement dates) (top). 
The orthogonal relationships between the measures of NDVI and LAI or percent vascular vegetation cover were not identical at the three sites (Appendix 2) suggesting there may be community-specific relationships. For example, a group of plots at DL with low NDVI $(<0.2)$ resulted in a greater slope between Tetracam NDVI and LAI (Appendix 2). In contrast, Tetracam NDVI was higher at FN and LK for plots with similar LAI ( $\sim 1$ or less) and $\%$ vascular vegetation cover $(\sim 50 \%)$. These plots at DL were associated with a higher percentage graminoid cover associated with tussock microforms and had higher soil volumetric water content than at other plots at DL (Appendix 3). Nevertheless, using only the measurements from the peak greenness period, there was no significant interaction between NDVI and site suggesting the linear relationships between NDVI and LAI were not significantly different among sites ( $\mathrm{F}=$ $1.13, \mathrm{df}=2, \mathrm{p}=0.33)$ while both Site $(\mathrm{F}=6.6, \mathrm{df}=2, \mathrm{p}=0.002)$ and NDVI $(\mathrm{F}=22.1, \mathrm{df}$ $=1, \mathrm{p}<0.0001)$ had significant effects (ANOVA with NDVI as a covariate, Site as a fixed effect, and LAI as the response variable). Similarly, there was no difference in the LAI-NDVI relationships when grouped using the three tundra classifications determined using k-means cluster analysis (Section 4.1 and Appendix 4) $(\mathrm{F}=1.62, \mathrm{df}=2, \mathrm{p}=0.20)$. This was also the case for $\%$ vascular vegetation cover and NDVI $(F=0.61, \mathrm{df}=2, \mathrm{p}$ $=0.55)$. In contrast, the relationship between FN \% vascular vegetation cover and NDVI was significantly different than at the other two sites $(\mathrm{F}=4.24, \mathrm{df}=2, \mathrm{p}=0.016)$ in that there was no significant relationship at that site.

Using forward stepwise linear regression, the model that best fit the Tetracam NDVI at DL included lichen cover, soil volumetric water content, and LAI with a coefficient of determination $\left(\mathrm{R}^{2}\right)$ of 0.44 and a RMSE of 0.057 . With only LAI in the 
model, $\mathrm{R}^{2}$ was 0.26 and RMSE of 0.065 . For the LK site, the model included LAI, percent vascular vegetation cover and moss cover for an $\mathrm{R}^{2}$ of 0.46 and a RMSE of 0.046. This was only a slight improvement to using LAI alone where $\mathrm{R}^{2}$ was 0.43 and RMSE was 0.047 . For the FN site, using only LAI resulted in a poorly fitting (but significant with $\mathrm{p}=0.009$ ) model with $\mathrm{R}^{2}$ of 0.06 and a RMSE of 0.056 . No additional variables improved the model.

With all sites combined, the best model included LAI, moss cover and soil volumetric water content with $\mathrm{R}^{2}$ of 0.42 and a RMSE of 0.054 . This is in contrast to a model with LAI alone with $\mathrm{R}^{2}$ of 0.36 and a RMSE of 0.057 .

The modified logarithmic relationship of Shaver et al (2007) reflects the tendency for NDVI to saturate as LAI increases beyond a value of $\sim 1.5$ (Figure 9). When visually assessed, all three datasets (over all measurement dates and at peak greenness) appear to follow a similar logarithmic relationship between LAI and Tetracam-based NDVI, particularly if the low NDVI plots at DL were excluded (Figure 9). The modified logarithmic relationship of Shaver et al. (2008), LAI $=0.0026 \mathrm{e}(8.0783 \mathrm{NDVI}+0.4)$, resulted in a RMSE of 0.087 . A logarithmic relationship fit specifically to this dataset resulted in the following model, $\mathrm{LAI}=0.0032 \mathrm{e}(17.2143 \mathrm{NDVI})$ with a $\mathrm{R}^{2}=0.43$ and $\mathrm{a}$ $\mathrm{RMSE}=0.061$ for all the measurement sites and dates. This was a slight improvement over the simple orthogonal regression with $\mathrm{R}^{2}=0.40$ and a $\mathrm{RMSE}=0.060$ shown in Figure 9. 


\subsection{Effects of Measurement Scale}

For all measurement variables, with the exception of soil volumetric water content, there was significant variation among DL and LK research sites $(200 \mathrm{~m})$ (Table 4). Percent vascular vegetation cover and moss cover variation was not significant at the $30 \mathrm{~m}$ resolution and only Tetracam NDVI variation was significant at the $5 \mathrm{~m}$ resolution (Table 4).

Table 4. F-statistics (F) and probabilities (p) for all measurement variables analysed with nested ANOVA for the three measurement resolutions $(200 \mathrm{~m}, 30 \mathrm{~m}$, and $5 \mathrm{~m})$ at combined DL and LK sites (FN site was not included due to a lack of replication at the 30 m resolution).

\begin{tabular}{|l|r|r|r|r|r|r|}
\hline & \multicolumn{2}{|c|}{$200 \mathrm{~m}$} & \multicolumn{2}{c|}{$30 \mathrm{~m}$} & \multicolumn{2}{c|}{$5 \mathrm{~m}$} \\
\hline Variable & F & p & F & p & F & p \\
\hline Tetracam - NDVI & $\mathbf{3 4 . 5 2}$ & $<0.001$ & $\mathbf{6 . 1 8}$ & $<0.001$ & $\mathbf{2 . 3 5}$ & 0.03 \\
\hline Canon - NDVI & $\mathbf{4 . 8 6}$ & 0.03 & $\mathbf{1 . 9 2}$ & 0.04 & 0.50 & 0.86 \\
\hline LAI & $\mathbf{1 5 . 2 4}$ & 0.003 & $\mathbf{2 . 2 4}$ & 0.02 & 1.91 & 0.07 \\
\hline $\begin{array}{l}\text { Percent vascular } \\
\text { vegetation cover }\end{array}$ & $\mathbf{1 0 . 2 0}$ & 0.003 & 1.48 & 0.18 & 0.69 & 0.87 \\
\hline Lichen cover & $\mathbf{1 9 . 0 9}$ & $<0.001$ & $\mathbf{2 . 6 1}$ & 0.006 & 2.13 & 0.05 \\
\hline Moss cover & $\mathbf{2 3 . 3 1}$ & $<0.001$ & 1.73 & 0.08 & 0.81 & 0.61 \\
\hline $\begin{array}{l}\text { Soil volumetric } \\
\text { water content }\end{array}$ & 1.45 & 0.23 & $\mathbf{7 . 1 2}$ & $<0.001$ & 1.93 & 0.07 \\
\hline
\end{tabular}

Using DL data only, the slope of the orthogonal relationships for Tetracam and CCRS NDVI vs. percent vascular vegetation cover and LAI tended to show greatest responses (greatest slopes) for the $5 \mathrm{~m}$ plot scale (Figure 10). The one exception was a slight increase in slope at the $30 \mathrm{~m}$ plots scale for the Canon NDVI vs. percent vascular vegetation cover. These correlations were all significant at DL, with the exception of Tetracam NDVI vs percent vascular vegetation cover at the $30 \mathrm{~m}$ measurement resolution. 
At LK site both the 5 and $30 \mathrm{~m}$ scales did not have significant correlations (Table 6). There were no significant correlations between Tetracam NDVI and either percent vascular vegetation cover or LAI at FN site at any measurement resolution (Table 7).

Although Canon NDVI did not represent the temporal variations in vegetation leaf area and cover as well as the Tetracam NDVI, it had a better correlation to LAI and percent vascular vegetation cover than the Tetracam at DL for all three measurement resolutions at peak greenness (Table 5). However at LK, the correlations between Canon NDVI were insignificant for all measurement resolutions (Table 6).

See Appendix 2 for graphs illustrating the orthogonal relationships among variables at the $0.5 \mathrm{~m}$ resolution and listed in Tables 5-7. 

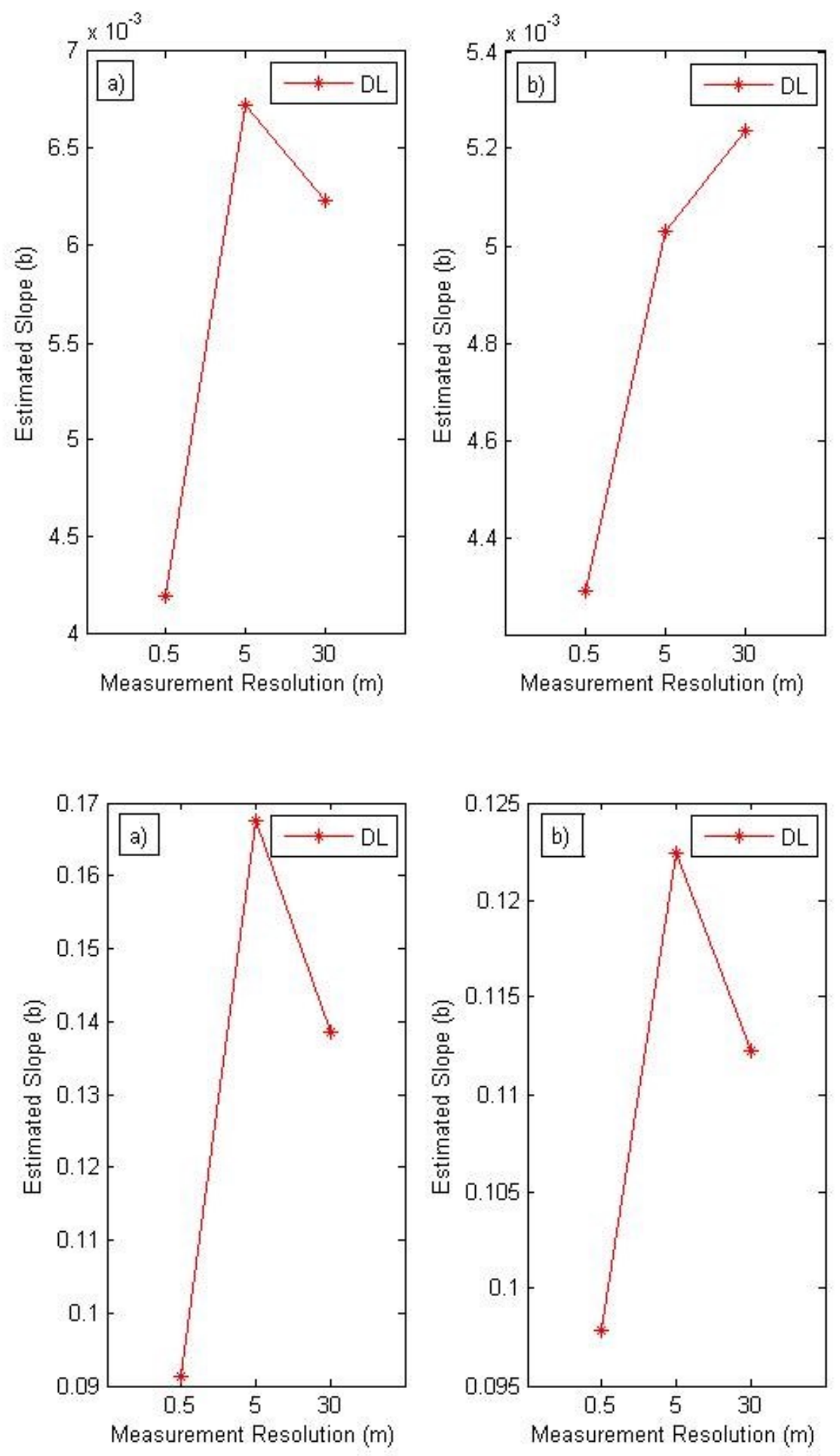

Figure 10. The slopes of the orthogonal regressions for percent vascular vegetation cover [x variable] and Tetracam NDVI [y variable] (a) and Canon NDVI [y variable] (b) (top panels) and LAI [x variable] vs. Tetracam NDVI [y variable] (a) and Canon NDVI [y variable] (b) (bottom panels). 
At peak greenness, the response of Tetracam NDVI and Canon NDVI to changes in soil volumetric water content was greatest at the $5 \mathrm{~m}$ resolution at DL (Figure 11) while correlations were greatest at the $30 \mathrm{~m}$ resolution (Table 5). This reflected the signficant decrease in leaf area with wetter soil conditions at DL at all resolutions (Table $5)$.

At the LK and FN sites, no vegetation metrics were significantly correlated to soil volumetric water content at any resolution (Tables $6 \& 7$ ) likely due to the smaller amount of spatial variation in soil moisture at these two sites (Table 1).
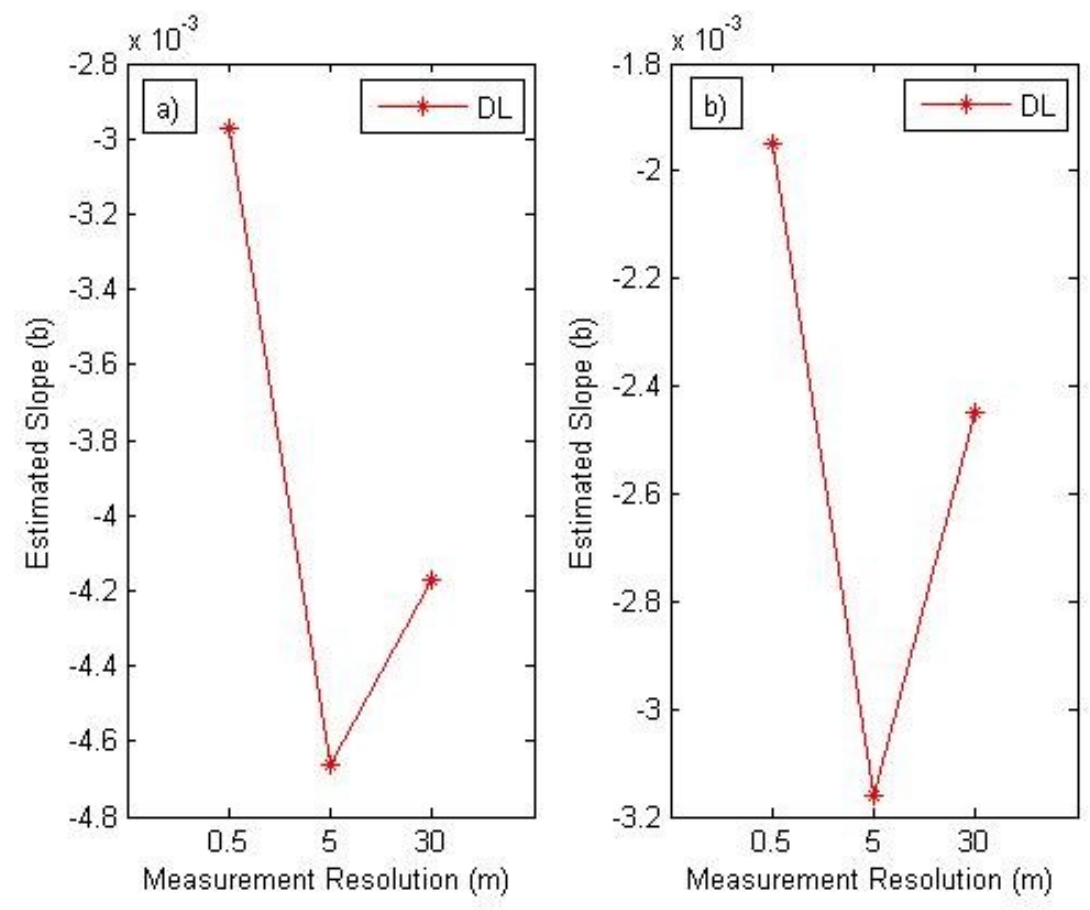

Figure 11. The slopes of the orthogonal regressions for soil volumetric water content $[\mathrm{x}$ variable] and (a) Tetracam NDVI [ $\mathrm{x}$ variable] and (b) Canon NDVI [ $\mathrm{x}$ variable] at DL.

Although lichen cover did not correlate negatively with soil volumetric water content at any measurement resolution at either DL or LK (Tables 5 and 6) like it did 
when all sites were combined (Table 3), it was significantly negatively correlated with moss cover at both sites. Lichen cover was entirely absent from all plots at the FN site.

In contrast to the site-wide significant negative correlation between moss cover and Tetracam NDVI, moss cover did not correlate to either measure of NDVI at DL or FN at any resolution (Tables $5 \& 7$ ) but did correlate positively at $5 \mathrm{~m}$ at LK when using the Tetracam (Table 6). When all sites were combined, lichen did not correlate to any measure of NDVI (Table 3) but it was weakly negative and significant at LK at the 0.5 and $5 \mathrm{~m}$ resolution using the Tetracam (Table 6). Because non-vascular vegetation are strictly ground cover, it was expected that these measures of cover could potentially explain some spatial variability in NDVI values, particularly at low NDVI. However, trends in residual NDVI at the $0.5 \mathrm{~m}$ resolution were best identified using soil moisture rather than percent cover of moss or lichen and as noted earlier, and may have been related to the presence of tussock formations (Appendix 3). 
Table 5. Pearson correlations (r) and calculated probabilities (p) for relationships between variables at DL site. A p-value $<0.05$ determines significance.

\begin{tabular}{|c|c|c|c|c|c|c|c|c|c|c|c|c|c|c|c|}
\hline \multirow[t]{2}{*}{ Resolution } & \multirow[t]{2}{*}{ Variable } & \multicolumn{2}{|c|}{ Percent Cover } & \multicolumn{2}{|c|}{ LAI } & \multicolumn{2}{|c|}{ Lichen Cover } & \multicolumn{2}{|c|}{ Moss Cover } & \multicolumn{2}{|c|}{$\begin{array}{c}\text { Volumetric } \\
\text { Water } \\
\text { Content } \\
\end{array}$} & \multicolumn{2}{|c|}{$\begin{array}{c}\text { Tetracam } \\
\text { NDVI }\end{array}$} & \multicolumn{2}{|c|}{$\begin{array}{l}\text { Canon } \\
\text { NDVI }\end{array}$} \\
\hline & & $\mathrm{r}$ & $\mathrm{P}$ & $\mathrm{r}$ & $\mathrm{P}$ & $\mathrm{r}$ & $\mathrm{p}$ & $\mathrm{r}$ & $\mathrm{p}$ & $\mathrm{r}$ & $\mathrm{p}$ & $\mathrm{r}$ & $\mathrm{p}$ & $\mathrm{r}$ & $\mathrm{p}$ \\
\hline 0.5 & \multirow{3}{*}{$\begin{array}{l}\text { Percent } \\
\text { Cover }\end{array}$} & & & 0.72 & $<0.0001$ & 0.01 & 0.93 & -0.19 & 0.3 & -0.21 & 0.09 & 0.69 & $<0.0001$ & 0.76 & $<0.0001$ \\
\hline 5 & & & & 0.91 & $<0.0001$ & 0.13 & 0.62 & -0.23 & 0.35 & -0.64 & 0.005 & 0.80 & $<0.0001$ & 0.90 & $<0.0001$ \\
\hline 30 & & & & 0.71 & 0.0314 & 0.31 & 0.42 & -0.63 & 0.07 & -0.57 & 0.11 & 0.59 & 0.10 & 0.79 & 0.01 \\
\hline 0.5 & \multirow{3}{*}{ LAI } & & & & & 0.04 & 0.77 & -0.15 & 0.24 & -0.36 & 0.004 & 0.67 & $<0.0001$ & 0.78 & $<0.0001$ \\
\hline 5 & & & & & & 0.23 & 0.36 & -0.34 & 0.17 & -0.75 & 0.0003 & 0.83 & $<0.0001$ & 0.922 & $<0.0001$ \\
\hline 30 & & & & & & 0.37 & 0.32 & -0.50 & 0.17 & -0.77 & 0.01 & 0.71 & 0.03 & 0.94 & 0.0002 \\
\hline 0.5 & \multirow{3}{*}{$\begin{array}{l}\text { Lichen } \\
\text { Cover }\end{array}$} & & & & & & & -0.65 & $<0.0001$ & -0.24 & 0.06 & 0.22 & 0.09 & -0.07 & 0.52 \\
\hline 5 & & & & & & & & -0.76 & 0.0003 & -0.40 & 0.10 & 0.36 & 0.14 & 0.09 & 0.71 \\
\hline 30 & & & & & & & & -0.70 & 0.04 & -0.49 & 0.18 & 0.58 & 0.10 & 0.35 & 0.36 \\
\hline 0.5 & \multirow{3}{*}{$\begin{array}{l}\text { Moss } \\
\text { Cover }\end{array}$} & & & & & & & & & 0.44 & 0.0003 & -0.21 & 0.10 & -0.006 & 0.95 \\
\hline 5 & & & & & & & & & & 0.65 & 0.004 & -0.29 & 0.25 & -0.24 & 0.33 \\
\hline 30 & & & & & & & & & & 0.66 & 0.05 & -0.48 & 0.19 & -0.51 & 0.16 \\
\hline 0.5 & \multirow{3}{*}{$\begin{array}{c}\text { Volumetric } \\
\text { Water } \\
\text { Content }\end{array}$} & & & & & & & & & & & -0.50 & $<0.0001$ & -0.38 & 0.0003 \\
\hline 5 & & & & & & & & & & & & -0.74 & 0.0004 & -0.75 & 0.0003 \\
\hline 30 & & & & & & & & & & & & -0.84 & 0.0049 & -0.79 & 0.01 \\
\hline 0.5 & \multirow{3}{*}{$\begin{array}{l}\text { Tetracam } \\
\text { NDVI }\end{array}$} & & & & & & & & & & & & & 0.76 & $<0.0001$ \\
\hline 5 & & & & & & & & & & & & & & 0.85 & $<0.0001$ \\
\hline 30 & & & & & & & & & & & & & & 0.76 & 0.02 \\
\hline
\end{tabular}


Table 6. Pearson correlations (r) and probabilities (p) for relationships between variables at LK site. A p-value $<0.05$ determines significance.

\begin{tabular}{|c|c|c|c|c|c|c|c|c|c|c|c|c|c|c|c|}
\hline \multirow[t]{2}{*}{ Resolution } & \multirow[t]{2}{*}{ Variable } & \multicolumn{2}{|c|}{ Percent Cover } & \multicolumn{2}{|c|}{ LAI } & \multicolumn{2}{|c|}{ Lichen Cover } & \multicolumn{2}{|c|}{ Moss Cover } & \multicolumn{2}{|c|}{$\begin{array}{c}\text { Volumetric } \\
\text { Water } \\
\text { Content } \\
\end{array}$} & \multicolumn{2}{|c|}{$\begin{array}{c}\text { Tetracam } \\
\text { NDVI }\end{array}$} & \multicolumn{2}{|c|}{$\begin{array}{l}\text { Canon } \\
\text { NDVI }\end{array}$} \\
\hline & & $\mathrm{r}$ & $\mathrm{P}$ & $\mathrm{r}$ & $\mathrm{P}$ & $\mathrm{r}$ & $\mathrm{p}$ & $\mathrm{r}$ & $\mathrm{p}$ & $\mathrm{r}$ & $\mathrm{p}$ & $\mathrm{r}$ & $\mathrm{p}$ & $\mathrm{r}$ & $\mathrm{p}$ \\
\hline 0.5 & \multirow{3}{*}{$\begin{array}{l}\text { Percent } \\
\text { Cover }\end{array}$} & & & 0.78 & $<0.0001$ & -0.32 & 0.01 & -0.07 & 0.57 & 0.12 & 0.36 & 0.43 & 0.0004 & 0.19 & 0.07 \\
\hline 5 & & & & 0.90 & $<0.0001$ & -0.45 & 0.06 & 0.19 & 0.44 & 0.21 & 0.401 & 0.28 & 0.26 & 0.13 & 0.61 \\
\hline 30 & & & & 0.91 & 0.0007 & -0.37 & 0.32 & -0.0000 & 1.0000 & 0.23 & 0.55 & -0.11 & 0.78 & -0.10 & 0.80 \\
\hline 0.5 & \multirow{3}{*}{ LAI } & & & & & -0.24 & 0.07 & -0.16 & 0.22 & -0.01 & 0.93 & 0.34 & 0.006 & 0.14 & 0.19 \\
\hline 5 & & & & & & -0.21 & 0.41 & -0.08 & 0.75 & 0.07 & 0.80 & 0.15 & 0.55 & 0.07 & 0.80 \\
\hline 30 & & & & & & -0.13 & 0.74 & -0.26 & 0.51 & 0.05 & 0.89 & -0.29 & 0.45 & 0.09 & 0.94 \\
\hline 0.5 & \multirow{3}{*}{$\begin{array}{l}\text { Lichen } \\
\text { Cover }\end{array}$} & & & & & & & -0.72 & $<0.0001$ & 0.07 & 0.60 & -0.33 & 0.009 & -0.02 & 0.88 \\
\hline 5 & & & & & & & & -0.81 & $<0.0001$ & 0.14 & 0.59 & -0.47 & 0.05 & -0.02 & 0.93 \\
\hline 30 & & & & & & & & -0.83 & 0.006 & 0.25 & 0.52 & -0.29 & 0.45 & 0.21 & 0.59 \\
\hline 0.5 & \multirow{3}{*}{$\begin{array}{l}\text { Moss } \\
\text { Cover }\end{array}$} & & & & & & & & & 0.24 & 0.06 & 0.15 & 0.23 & -0.07 & 0.54 \\
\hline 5 & & & & & & & & & & 0.25 & 0.32 & 0.51 & 0.023 & 0.01 & 0.97 \\
\hline 30 & & & & & & & & & & -0.07 & 0.86 & 0.57 & 0.11 & -0.15 & 0.69 \\
\hline 0.5 & \multirow{3}{*}{$\begin{array}{c}\text { Volumetric } \\
\text { Water } \\
\text { Content }\end{array}$} & & & & & & & & & & & -0.03 & 0.84 & 0.03 & 0.78 \\
\hline 5 & & & & & & & & & & & & -0.05 & 0.84 & 0.17 & 0.51 \\
\hline 30 & & & & & & & & & & & & 0.09 & 0.82 & 0.19 & 0.62 \\
\hline 0.5 & \multirow{3}{*}{$\begin{array}{l}\text { Tetracam } \\
\text { NDVI }\end{array}$} & & & & & & & & & & & & & 0.17 & 0.18 \\
\hline 5 & & & & & & & & & & & & & & 0.04 & 0.87 \\
\hline 30 & & & & & & & & & & & & & & -0.44 & 0.23 \\
\hline
\end{tabular}


Table 7. Pearson correlations (r) and probabilities (p) for the relationships between variables at FN site. A p-value $<0.05$ determines significance.

\begin{tabular}{|c|c|c|c|c|c|c|c|c|c|c|c|c|c|}
\hline \multirow[t]{2}{*}{ Resolution } & \multirow[t]{2}{*}{ Variable } & \multicolumn{2}{|c|}{ Percent Cover } & \multicolumn{2}{|c|}{ LAI } & \multicolumn{2}{|c|}{ Lichen Cover } & \multicolumn{2}{|c|}{ Moss Cover } & \multicolumn{2}{|c|}{$\begin{array}{c}\text { Volumetric } \\
\text { Water } \\
\text { Content } \\
\end{array}$} & \multicolumn{2}{|c|}{$\begin{array}{c}\text { Tetracam } \\
\text { NDVI }\end{array}$} \\
\hline & & $\mathrm{r}$ & P & $\mathrm{r}$ & $\mathrm{P}$ & $\mathrm{r}$ & P & $\mathrm{r}$ & $\mathrm{p}$ & $\mathrm{r}$ & $\mathrm{p}$ & $\mathrm{r}$ & $\mathrm{p}$ \\
\hline 0.5 & \multirow{2}{*}{$\begin{array}{l}\text { Percent } \\
\text { Cover }\end{array}$} & & & 0.80 & $<0.0001$ & & & & & 0.21 & 0.39 & -0.35 & 0.14 \\
\hline 5 & & & & 0.89 & 0.04 & & & & & 0.09 & 0.88 & -0.79 & 0.11 \\
\hline 0.5 & \multirow{2}{*}{ LAI } & & & & & & & & & 0.22 & 0.37 & -0.34 & 0.16 \\
\hline 5 & & & & & & & & & & -0.22 & 0.73 & -0.72 & 0.17 \\
\hline 0.5 & \multirow{2}{*}{$\begin{array}{l}\text { Lichen } \\
\text { Cover }\end{array}$} & & & & & & & & & & & & \\
\hline 5 & & & & & & & & & & & & & \\
\hline 0.5 & \multirow{2}{*}{$\begin{array}{l}\text { Moss } \\
\text { Cover }\end{array}$} & & & & & & & & & & & & \\
\hline 5 & & & & & & & & & & & & & \\
\hline 0.5 & \multirow{2}{*}{$\begin{array}{c}\text { Volumetric } \\
\text { Water } \\
\text { Content }\end{array}$} & & & & & & & & & & & -0.37 & 0.12 \\
\hline 5 & & & & & & & & & & & & -0.49 & 0.41 \\
\hline
\end{tabular}




\section{5: Discussion}

\subsection{The Relations between Vegetation Metrics and NDVI}

The goal of this study was to evaluate how tundra vegetation metrics were characterized using ground-based NDVI sensors. Past work on this topic was carried out at the Daring Lake site by Dagg and Lafleur (2010) who examined relationships between NDVI, LAI, biomass, and $\mathrm{CO}_{2}$ exchange on $400.4 \mathrm{~m}$ plots in and around the DL site in 2008. Tetracam NDVI ranged from approximately 0.1 to 0.6 during the measurement period, with peak greenness being reached near the final week of July, similar to the results of this study, and was shown to represent $25 \%$ of the variance in LAI for all plots combined (Dagg \& Lafleur, 2010). When broken down by community, the NDVI - LAI relationship was only significant for some groups, and NDVI explained a range in the variation of LAI from just over 10\% to just over $50 \%$ (Dagg \& Lafleur 2010). NDVI was found to be significantly correlated to both total biomass and moss biomass, but no relationship was found between NDVI and lichen biomass (Dagg \& Lafleur, 2010). The current study expanded this earlier work by increasing the number of plots, further developing on the contrasts between vegetation communities and examining differences in measurement scales. The issue of scale was examined to better understand how satellite-based NDVI at much coarser resolutions might represent LAI, vegetation cover, and their temporal patterns in Southern Arctic tundra.

With respect to the first hypothesis of this study, LAI was found to be the leading variable controlling variations in NDVI, as found in a number of other studies (Chen \& Chilar, 1996; Van Wijk \& Williams, 2005; Street et al., 2007; Williams et al., 2008; Dagg \& Lafleur, 2010; among others). LAI alone explained 36\% of the variance in 
NDVI when all sites were combined over all measurement dates. The $\mathrm{R}^{2}$ at $\mathrm{DL}$ at the 0.5 m measurement scale $(0.26)$ was the same as what was found in an earlier study by Dagg and Lafleur (2010) at the same site using the same sensor.

Although LAI was most closely related to NDVI, \% vascular vegetation cover correlated to NDVI at all but the FN site. Similarly, Laidler et al. (2008) found a significant linear relationship between NDVI and percent cover at $0.5 \mathrm{~m}$ (surface spectroradiometer measurement), the $5 \mathrm{~m}$ resolution (IKONOS data) and $30 \mathrm{~m}$ resolution (Landsat ETM 6+ data). However a strong relationship between NDVI and vascular percent cover is not as beneficial for deriving NPP/GPP as a strong NDVI - LAI relationship, since both sunlit and shaded leaves contribute to carbon exchange and most models of carbon exchange need estimate of leaf area to represent the photosynthetic capacity/potential of a surface (Breda, 2003).

There was no relationship between NDVI and LAI at the FN site likely due to the small range in LAI at this site. There also may have been issues related to the reflectance of water saturated moss cover impacting the reflectance. In future studies, it may be worth investigating the effects of non-nadir viewing angles on vegetation reflectance and NDVI measurements as did Tittebrand et al (2009), in order to lessen the effect of ground cover reflectance at the $\mathrm{FN}$ site. Increasing the viewing angle of the NDVI sensor from $0^{\circ}$ has the effect of creating a more closed canopy, increasing the radiation path length and the volume scattering from the vegetation thus increasing NIR reflectance, and increasing NDVI values (Tittebrand et al., 2009).

The correlations and regressions noted above assume a linear relationship, but as noted by a number of other studies (Curran, 1983; Carlson and Ripley, 2007; Ferrara et 
al. 2010), NDVI and LAI have a near linear relationship before reaching an upper asymptote at a threshold value of LAI. This threshold LAI value has been reported to be in the range of 2 to 4 , though it has been shown that for short crop plants, such as corn sorghum and wheat, the threshold value range was closer to 3 to 4 (Curran, 1983; Carlson \& Ripley, 1997). Other work on crop plants by Ferrara et al. (2010) found that the NDVILAI relationship saturated at a threshold value nearer to 1.5. At all three research sites there was a linear relationship at the $0.5 \mathrm{~m}$ measurement scale with the relationship levelling off at a threshold somewhere in the range of 1.5 to 2 . In this study, a logarithmic relationship such as the one developed by Shaver et al. (2007) improved the $\mathrm{R}^{2}$ value only marginally and did not improve the RMSE over the multiple linear regression or simple orthogonal regression between NDVI and LAI.

The second hypothesis of this thesis was that the relationship between NDVI and LAI is community specific. There were some differences in the NDVI - LAI relationship between the three sites with lichen cover, moss cover and soil volumetric water content slightly improving linear models differently at the three sites. However, when analyzed with a common version of the Shaver et al. (2007) model, the three sites did not appear to differ greatly.

Street et al. (2007) found that while combining data for all vegetation communities of interest lead to a strong correlation between NDVI and LAI $\left(\mathrm{R}^{2}\right.$ of 0.75$)$, applying the regression equation to NDVI data for the individual communities lead to biased estimates of LAI. Similarly, though Dagg and Lafleur (2010) found a significant relationship between NDVI and LAI for all plots combined, the relationship between NDVI and LAI was only significant for 5 of the 7 communities when individually 
separated. Likewise, this study found that the combined sites regression of NDVI and LAI at the $0.5 \mathrm{~m}$ resolution compared well with the $0.5 \mathrm{~m}$ regression results from the DL site individually, but not for the LK and FN sites. This was likely in large part due to the larger range in communities present at DL.

In the case of the FN site, some standing dead vegetation may be decreasing the overall greenness of the plots, thus lowering the NDVI measurements. As expressed above, the nadir viewing angle of the NDVI sensor and high moss cover and water content could be pulling down the overall reflectance of the plot, leading to overall lower NDVI (Tittebrand et al., 2009). This theory is supported by plots 34 and 45 at DL, which also showed higher percentage graminoid cover, and higher soil volumetric water content, and lower overall NDVI for a given leaf area. These results show that there is a need to increase the sample size at peak greenness at the FN site to confirm whether the lack of correlation holds.

Both 3-day and 16-day MODIS-based NDVI correlated well with the seasonal trend in NDVI at the three sites but did not reproduce the same relative differences in NDVI among the sites. Although the spatial variations in NDVI were significant at the $200 \mathrm{~m}$ scale, they were likely subtle and at larger scales, such as $500 \mathrm{~m}$ resolution, the inclusion of non-target surface types likely confounded the results.

For the third hypothesis, this study confirms that measurement scale was an important and sometimes crucial factor in characterizing some vegetation metrics, with scale-dependent relationships noted for a number of variables (Table 4; Table 5; Table 6). In most cases, studies only investigate ecological traits and relationships at one focal scale, discounting how traits and relationships may differ at other measurement scales 
leading to many knowledge gaps (Messier et al., 2010). Assessing variables at multiple scales may help to determine which scales are most important for the characterization of the chosen phenomena or process of interest (Messier et al., 2010).

At the DL site, relationships between LAI and NDVI and vascular percent cover and NDVI were very similar across measurement scales. There were some small differences in the sensitivity of NDVI to changes in LAI between measurement scales. Williams et al. (2008) also found the spatially averaged relationship between NDVI and LAI did not vary with scale for all nested measurements between $1.5 \mathrm{~m}$ and $9 \mathrm{~m}$ for the Swedish taiga-tundra border characterized by birch forest, heath, and mire vegetation communities. In contrast, the relationships between LAI and NDVI and vascular percent cover and NDVI were only significant at the $0.5 \mathrm{~m}$ measurement scale at the LK site. This may have been due to a relatively larger decrease in variation in NDVI at LK as the measurement resolution decreased from 0.5 to $30 \mathrm{~m}$.

\subsection{The Relations between Vegetation and Soil Moisture}

For tundra vegetation communities, soil moisture has been named as the critical limiting factor for determining vegetation productivity and growth (Laidler et al., 2008; Gamon et al., 2013). Gamon et al. (2013) found that in areas with low soil moisture, such as areas of high microtopographical relief, NDVI-measured productivity was low. The results from this study did not support this, though this could be because the plots sampled at Daring Lake were overall wetter (Table 1) than those sampled by Gamon et al. (2013), where average growing season soil volumetric water content was approximately $18 \%$. All vegetation metrics (except moss cover) correlated negatively with soil volumetric water content across the sites. At the FN site, average soil 
volumetric water content was high but there was a lower percent vascular vegetation cover and LAI than either LK or DL. The FN site is a peatland characterized by saturated and acidic organic soils and in this case, may be limited by other factors including nutrient availability and saturated conditions typical of tundra sedge meadows

(Verhoeven et al., 1996). At the DL site, NDVI was found to be most sensitive to changes in soil moisture at the smallest measurement resolution and again, the general trend was one where wetter sites had lower values for the various vegetation metrics. However, among the three clustered vegetation communities, the moist dwarf shrub tundra had the highest values for the various vegetation metrics compared to the drier dwarf shrub and wetter sedge wetland communities. Similar to the findings by Gamon et al. (2013), soil moisture was most variable at small, microtopographical resolutions at any given site. However, the nested ANOVA analysis concluded there was significant variation in soil moisture only at the $30 \mathrm{~m}$ resolution when examining the measurements from LK and DL only. If the FN replicates had been sufficient to be included in this analysis, the $200 \mathrm{~m}$ resolution may also have been significant.

\subsection{The Differences between the Tetracam and Canon NDVI}

Two ground-based NDVI sensors were used in this study; the Tetracam and the Canon camera. While both cameras were similar in size and ease of use, they differed in the spectral information they collected and in their results. The Tetracam used spectral reflectance data collected in the red and NIR portions of the electromagnetic spectrum to create a traditional NDVI measurement. In contrast, the Canon camera, a modified traditional digital camera, collected blue/green and NIR reflectance data for the NDVI calculation. Earlier work with the Canon camera by Leblanc et al. (2014), found that 
NDVI measurements at Daring Lake in 2013 displayed a seasonal trend, with peak NDVI in late July and lower values at the beginning and end of the measurement season in June and August, respectively. However, these results required the use of corrections for solar zenith angle on all plots (Leblanc et al., 2014). These corrections were not applied in this study and may be why we did not find similar trends. Leblanc et al. (2014) applied corrections for solar zenith angle in order to reveal these seasonal trends were found, with peak greenness at the end of July, for tussock vegetation communities at Daring Lake. Future studies should consider applying solar angle corrections should the Canon camera be used for seasonal NDVI measurements.

Though the Canon NDVI's use of blue/green light may be unconventional, blue/green light has been shown to be sensitive to vegetation dynamics. In terms of its use in vegetation studies, Wang et al. (2007), reported that both blue and red light were most sensitive to LAI for values under 3, and that NDVI using a combination of blue and green reflectance for the visual reflectance part of the equations had better performance in predicting LAI than typical red NDVI in rice fields. At the DL site, Canon NDVI did have a stronger correlation with LAI at peak greenness than Tetracam NDVI at all three measurement resolutions. This was also the case for the correlation between Canon NDVI and percent vascular vegetation cover. However at LK site, Canon NDVI was not significantly correlated with any vegetation metric, including LAI.

\subsection{The Effects of Non-vascular Vegetation on NDVI}

In regions with a high prevalence of non-vascular vegetation cover, the use of NDVI and other spectral vegetation indices developed for vascular vegetation may not be as appropriate as compared to regions with little non-vascular vegetation cover. On the 
tundra, differing vegetation communities will have distinct non-vascular vegetation assemblages, with related differences in productivity, carbon storage and carbon cycling. Directly relating NDVI, or derived LAI, to GPP or NPP may lead to erroneous conclusions without first characterizing the impact of the non-vascular vegetation on the spectral reflectance measurements, and determining the contribution of the non-vascular vegetation on the storage and exchange of carbon (Street et al., 2013).

The typical spectral reflectance curves for sphagnum mosses, such as Sphagnum fallax, will differ from vascular vegetation in both the visible and NIR portion of the electromagnetic spectrum (Bubier et al., 1997). Most notably, there is a decreased NIR reflectance due to water absorption as a result of greater foliar water content in moss (Bubier et al., 1997). As well, where vascular vegetation exhibits a distinct peak in the green portion of the visible reflectance spectrum, sphagnum mosses tend to have an extended green peak that also falls into the yellow and orange regions of the visible spectrum (Bubier et al., 1997).

Because of the differences in spectral reflectance between vascular vegetation and moss, a study in the Hudson Bay Lowlands found that for moss-dominated vegetation communities, NDVI was a deficient tool for estimating carbon exchange (Whiting, 1994). In contrast, Kross et al., (2013) found that MODIS NDVI data was able to capture a range of variation, $25-71 \%$, in ground-based flux tower measurements of GPP and NEP across 4 distinct northern peatlands, but differed in its ability to capture year to year variations in annual peak GPP and NEP at each site. The FN site at Daring Lake would be categorized as a peatland and moss-dominated community, thus NDVI alone may be unable to fully represent productivity. Instead of using the typical broad red and NIR 
bandwidths for moss-dominated communities, Bubier et al. (1997) recommend that computing NDVI with narrower, site-specific and non-vascular species specific bandwidths for red and NIR wavelengths could properly characterize the contributions of moss without adversely affecting the NDVI values of vascular plants.

Lichens have a smaller ratio of visible spectrum reflectance to NIR reflectance, as compared to vascular vegetation reflectance, due to their relative lack of chlorophyll (Bubier et al., 1997). One study found lower overall temporal trends in NDVI in lichendominated communities as compared to communities dominated by vascular vegetation (Olthof et al., 2008). Although lichen cover did not correlate with LAI at any of the sites or across all the sites combined, the more lichen-dominated DL site had lower average NDVI than at LK site, it improved the multiple linear regression model of NDVI at the DL site, and lichen cover negatively correlated with NDVI at the LK site at the 0.5 and 5 $\mathrm{m}$ resolutions. In contrast, Dagg and Lafleur (2010) did not find a relation between NDVI and lichen biomass for all sampled vegetation communities near DL.

\subsection{The Effects of View Angle and Atmospheric Conditions}

The method of image capture for this study involved a remote sensing camera being held over the vegetation plot with the camera's sensor at nadir. This method mirrored those used by Laidler et al. (2008), Dagg and Lafleur (2010), and Gamon et al. (2012). A similar study that instead had various cameras mounted on eddy covariance flux towers, found that using off-nadir camera measurements improved estimates of vegetation phenology (Eklundh et al., 2008). This is due to the minimization of soil and ground cover reflectance and the creation of a closed canopy effect from overlapping vegetation at viewing angles greater than $0^{\circ}$ (Tittebrand et al., 2009). 
The 2014 field season at Daring Lake included prolonged smoky periods as a result of forest fires in the region. A concern for remote sensing measurements taken in smoky conditions is radiation scattering by the smoke aerosols. When Mount Pinatubo in the Philippines erupted in June of 1991, researchers found that NDVI in the areas impacted by the eruption decreased by 0.15 in part due to the aerosols settling in the troposphere (Vermote et al., 1997). The dust particles emitted by Pinatubo were approximately $500 \mathrm{~nm}$ in width, which falls within the visible spectrum wavelength bands (Vermote et al., 1997). The Tyndall and Rayleigh scattering caused by these particles were a source of the immediate drop in NDVI values. A correction that accounted for the aerosols and the optical thickness of the atmosphere between the sensor and the ground surface was developed (Vermote et al., 1997). The ground-based NDVI sensors used in this thesis may be relatively unaffected by forest fire introduced aerosols due to their design. The sensor measures surface reflectance relative to calibration plates that account for the magnitude of incoming light thus in part accounting for any attenuation due to sky conditions. 


\section{6: Conclusion}

After relating NDVI from two different ground-based sensors to LAI, percent vascular vegetation cover, moss cover, lichen cover, and soil volumetric water content at different sites, vegetation communities and measurement resolutions, the following conclusions for the three central hypotheses were drawn:

1. LAI was a dominant control on NDVI for all sites combined at peak greenness and throughout the growing season. Other variables, including percent vascular vegetation cover, soil volumetric water content and lichen and moss cover were also shown to improve LAI-NDVI models but not in the same way at each site. Non-vascular vegetation cover alone was not strongly correlated with NDVI, which confirms that NDVI, as a measure of chlorophyll reflectance spectra, works best for vascular vegetation whose reflectance spectra differs from both lichen and moss reflectance. Should future researchers intend to use NDVI as an input to models of GPP or NPP, alternative means to assess the role of non-vascular plants on carbon exchange will be necessary, for instance by first identifying the specific reflectance spectra of the non-vascular plants within the sampling site, with tools other than the Tetracam and Canon cameras. Street et al. (2013) demonstrated that non-vascular plants play a significant role in carbon uptake and retention, and this study, along with those by Bubier et al. (1997) and Olthof et al. (2008), did not find NDVI was able to capture the variability in non-vascular cover.

2. LAI and NDVI measurements, along with percent vascular vegetation cover, lichen cover, and moss cover were significantly different between the DL and LK sites. The DL site had the strongest correlation between the LAI and NDVI, 
followed by the LK site. The FN site did not have a significant correlation between NDVI and LAI. Despite distinct models that best represented NDVI at each site, a single logarithmic relationship between NDVI and LAI gave satisfactory results for each site.

3. The relationship between NDVI and LAI, and well as NDVI and vascular percent cover, tended to have greatest sensitivity at $5 \mathrm{~m}$ resolution. Nevertheless, the strong relationships between seasonal MODIS NDVI at the 250 and $500 \mathrm{~m}$ resolutions and the seasonal ground-based Tetracam NDVI measurements at 200 $\mathrm{m}$ resolution demonstrated that there is potential to scale the relationship up to satellite-based measurements. In addition, the Tetracam's reflectance bandwidths are comparable to Landsat bandwidths, and may be used for scaling studies. However, many satellites do not have a blue reflectance band that approximates the blue band of the Canon camera, thus it may be difficult to find an appropriate satellite NDVI datasets at various resolutions for scaling with the Canon camera. Consideration of the effects of aerosols from regional forest fires and other sources on vegetation reflectance retrievals may be required depending on the conditions of the season, especially if comparing or calibrating satellite-based measurements to data collected at ground level. In addition, since spatial variations were less successfully reproduced than temporal variations in this study, this may suggest that care will be needed in interpreting long-term variations in NDVI signals at a given site and across regions in Canada's Southern Arctic. 


\section{Appendices}

\section{Appendix A}

\section{A.1 Orthogonal Regressions, Combined Sites, Peak Greenness}

Slopes (m) and offsets (b) for the orthogonal regressions between variables at peak greenness for combined sites. Bold values imply significance ( $\mathrm{p}$-value $<0.05)$.

\begin{tabular}{|c|c|c|c|c|c|c|c|c|c|c|c|c|c|c|c|}
\hline \multirow[t]{2}{*}{ "Resolution" } & \multirow[t]{2}{*}{ Variable } & \multicolumn{2}{|c|}{ Percent Cover } & \multicolumn{2}{|c|}{ LAI } & \multicolumn{2}{|c|}{ Lichen Cover } & \multicolumn{2}{|c|}{ Moss Cover } & \multicolumn{2}{|c|}{$\begin{array}{c}\text { Volumetric } \\
\text { Water } \\
\text { Content } \\
\end{array}$} & \multicolumn{2}{|c|}{ Tetracam NDVI } & \multicolumn{2}{|c|}{ Canon NDVI } \\
\hline & & $\mathrm{M}$ & $\mathrm{b}$ & $\mathrm{m}$ & $\mathrm{B}$ & $\mathrm{m}$ & $\mathrm{b}$ & $\mathrm{m}$ & $\mathrm{b}$ & $\mathrm{m}$ & $\mathrm{b}$ & $\mathrm{m}$ & $\mathrm{b}$ & $\mathrm{m}$ & $\mathrm{b}$ \\
\hline 0.5 & Percent Cover & & & 0.04 & -1.43 & -0.0003 & 0.37 & -0.005 & 0.82 & -0.74 & 105.91 & 0.004 & 0.08 & 0.004 & 0.4 \\
\hline 0.5 & LAI & & & & & 0.04 & 0.28 & -0.19 & 0.72 & -0.02 & 2.41 & 0.08 & 0.24 & 0.08 & 0.57 \\
\hline 0.5 & Lichen Cover & & & & & & & -1.24 & $\mathbf{0 . 8 3}$ & -0.008 & 0.64 & 0.04 & 0.35 & -0.07 & 0.73 \\
\hline 0.5 & Moss Cover & & & & & & & & & 0.02 & -0.15 & -0.06 & 0.39 & 0.04 & 0.69 \\
\hline 0.5 & Volumetric Water Content & & & & & & & & & & & -0.003 & 0.47 & -0.0009 & 0.73 \\
\hline 0.5 & Tetracam NDVI & & & & & & & & & & & & & 2.65 & -0.31 \\
\hline
\end{tabular}



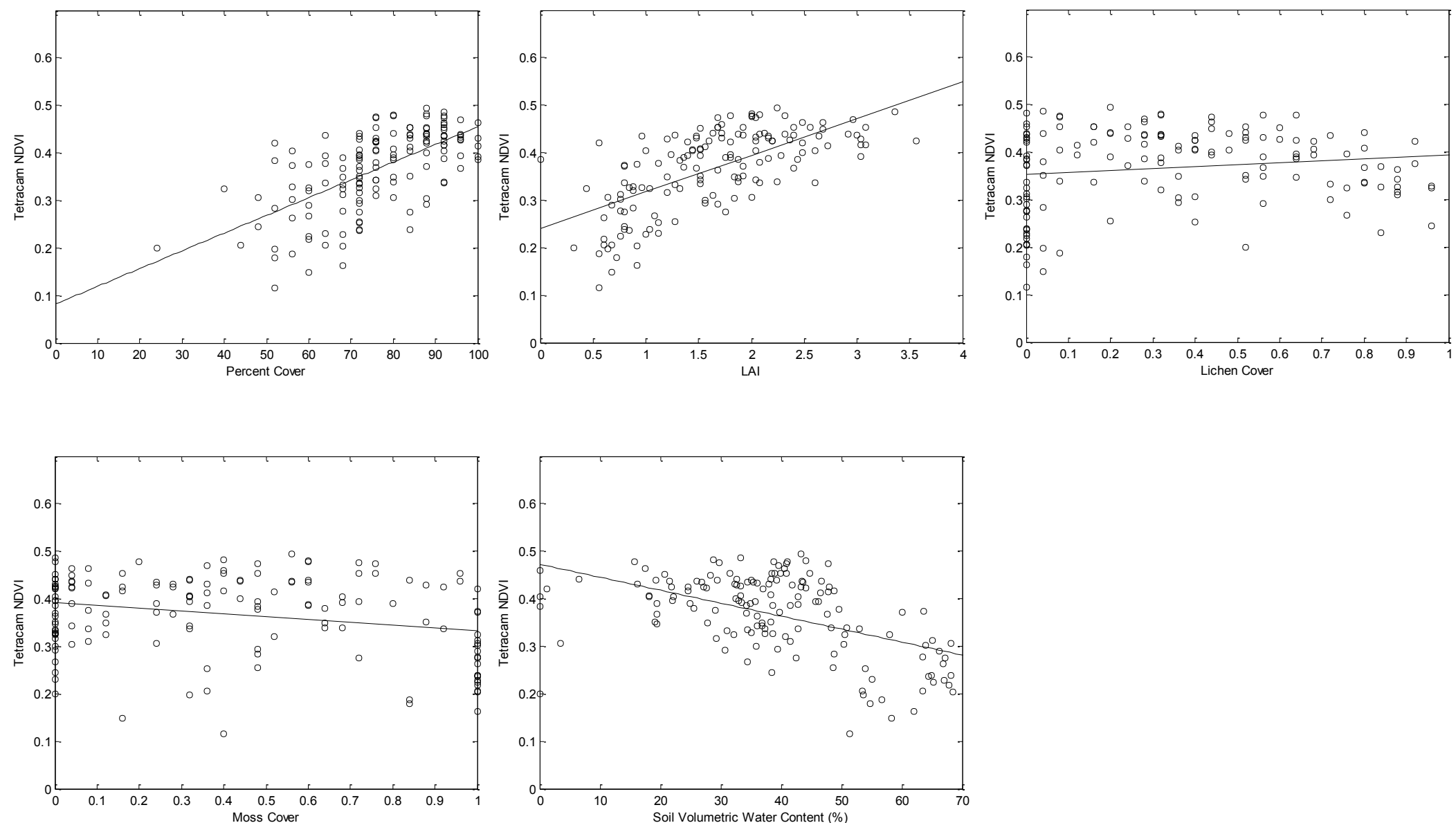

Orthogonal regressions, combined sites, peak greenness. 

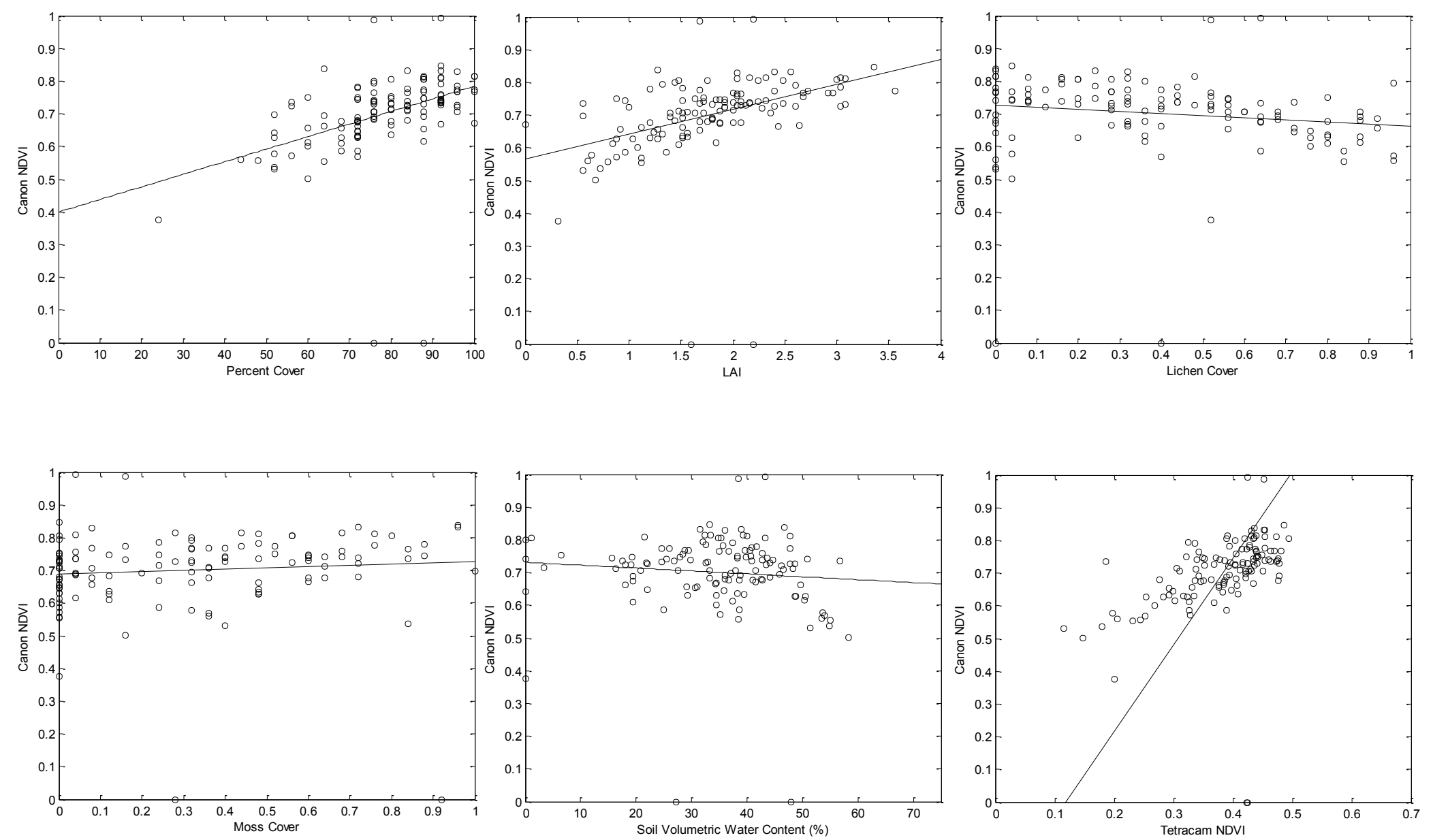

Orthogonal regressions, combined sites, peak greenness. 

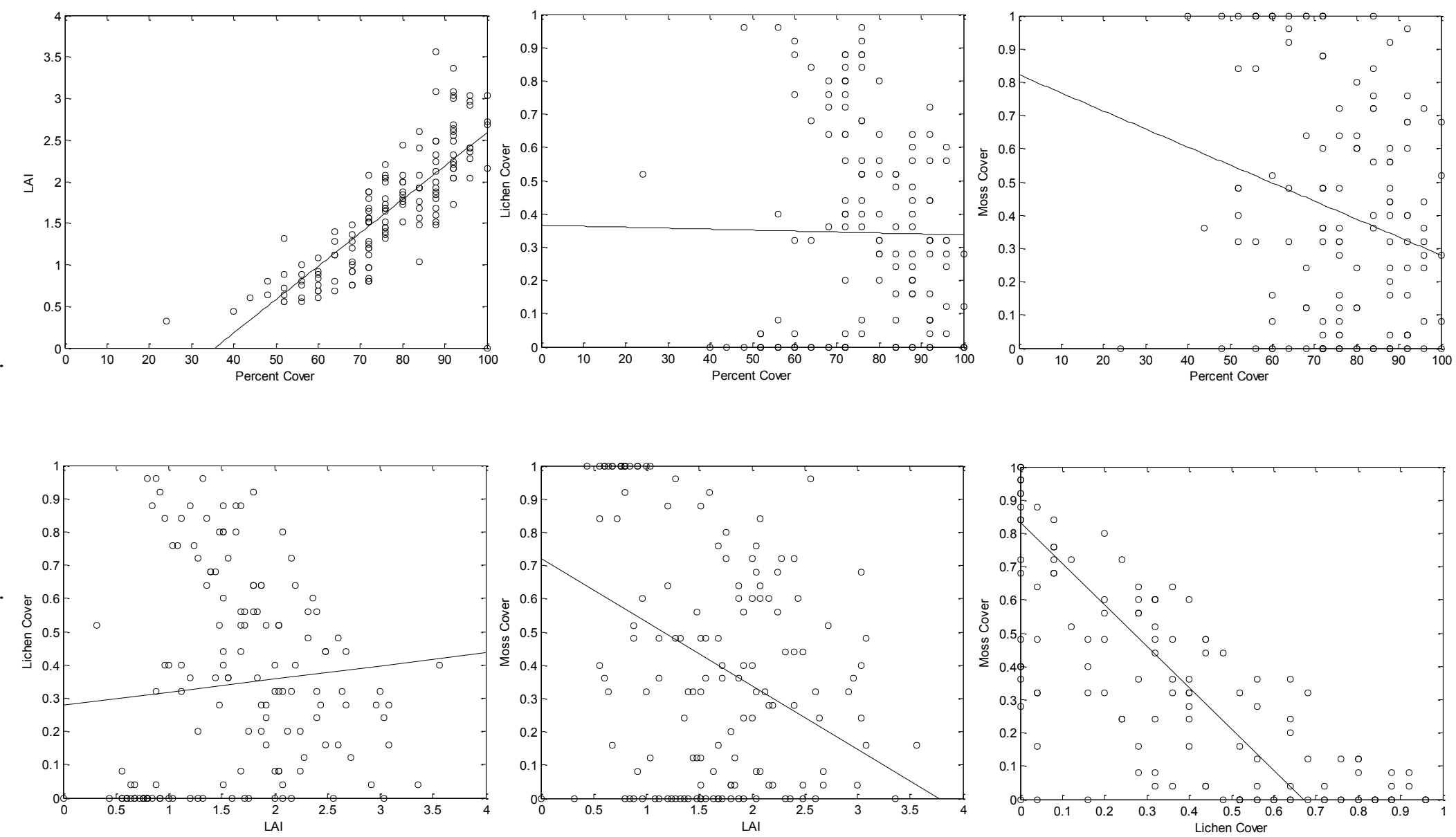

Orthogonal regressions, combined sites, peak greenness. 

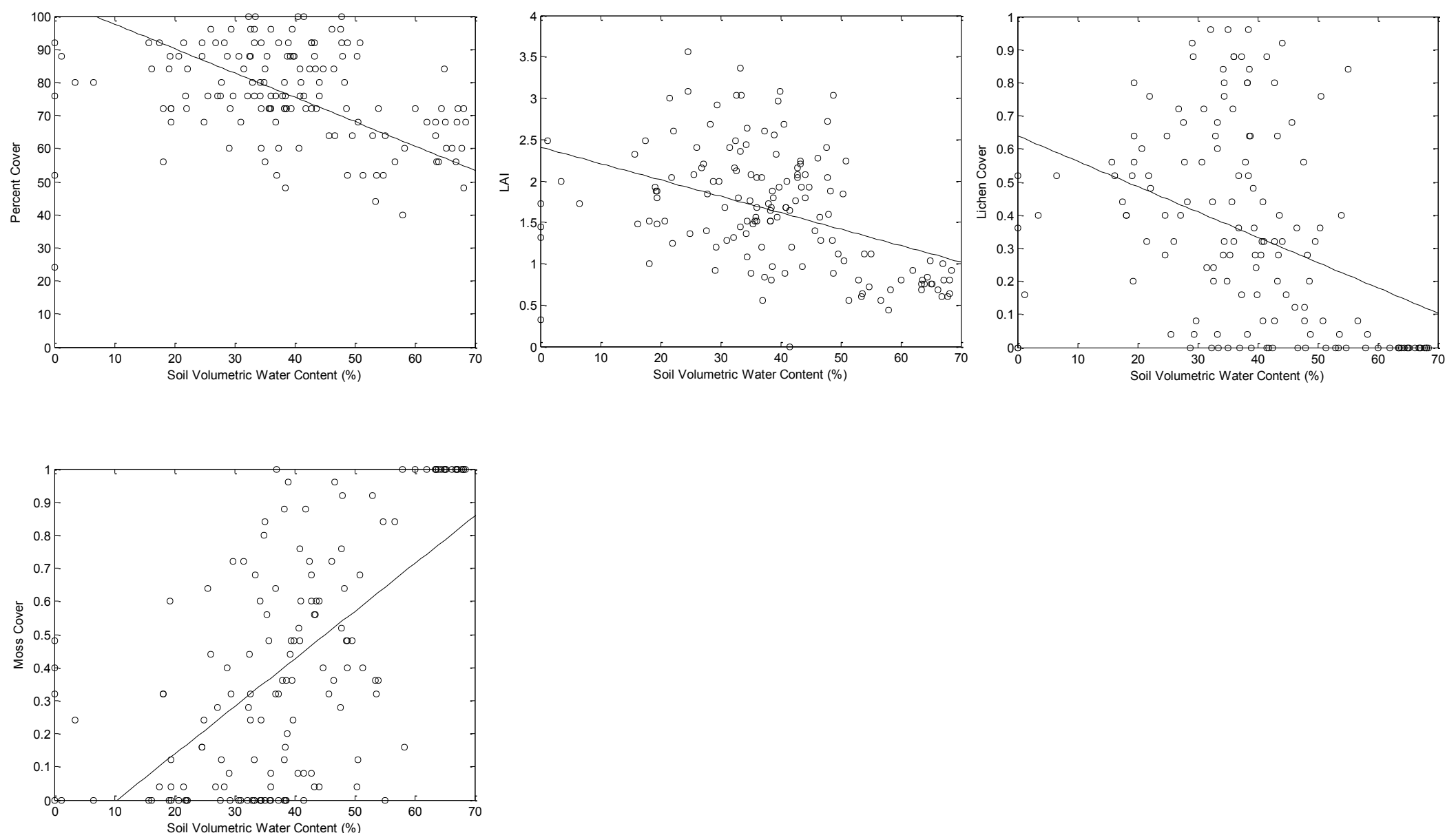

Orthogonal regressions, combined sites, peak greenness. 


\section{A.2 Orthogonal Regressions, Individual Sites, Peak Greenness}

Table A.2.1 Slopes (m) and offsets (b) for the orthogonal regressions between variables at peak greenness for DL site. Bold values imply significance $(\mathrm{p}$-value $<0.05)$.

\begin{tabular}{|c|c|c|c|c|c|c|c|c|c|c|c|c|c|c|c|}
\hline \multirow[t]{2}{*}{ "Resolution" } & \multirow[t]{2}{*}{ Variable } & \multicolumn{2}{|c|}{ Percent Cover } & \multicolumn{2}{|c|}{ LAI } & \multicolumn{2}{|c|}{ Lichen Cover } & \multicolumn{2}{|c|}{ Moss Cover } & \multicolumn{2}{|c|}{$\begin{array}{c}\text { Volumetric } \\
\text { Water } \\
\text { Content } \\
\end{array}$} & \multicolumn{2}{|c|}{ Tetracam NDVI } & \multicolumn{2}{|c|}{ Canon NDVI } \\
\hline & & $\mathrm{m}$ & $\mathrm{b}$ & $\mathrm{m}$ & $\mathrm{b}$ & $\mathrm{M}$ & $\mathrm{b}$ & $\mathrm{m}$ & $\mathrm{b}$ & $\mathrm{m}$ & $\mathrm{b}$ & $\mathrm{m}$ & $\mathrm{b}$ & $\mathrm{m}$ & $\mathrm{b}$ \\
\hline 0.5 & \multirow{3}{*}{$\begin{array}{l}\text { Percent } \\
\text { Cover }\end{array}$} & & & 0.03 & -0.87 & 0.0002 & 0.47 & -0.003 & 0.45 & -0.91 & 104.47 & 0.004 & 0.04 & 0.004 & 0.35 \\
\hline 5 & & & & 0.04 & -1.32 & 0.003 & 0.3 & -0.005 & 0.56 & -0.64 & 96.56 & 0.01 & 0.15 & 0.01 & 0.3 \\
\hline 30 & & & & 0.04 & -1.38 & 0.01 & -0.04 & -0.01 & 1.25 & -0.34 & 84.09 & 0.01 & -0.11 & 0.001 & 0.28 \\
\hline 0.5 & \multirow{3}{*}{ LAI } & & & & & 0.02 & 0.46 & -0.07 & 0.3 & -0.02 & 2.08 & 0.09 & 0.21 & 0.1 & 0.52 \\
\hline 5 & & & & & & 0.15 & 0.27 & -0.2 & 0.52 & -0.02 & 2.38 & 0.17 & 0.09 & 0.12 & 0.48 \\
\hline 30 & & & & & & 0.19 & 0.21 & -0.23 & 0.54 & -0.02 & 2.21 & 0.14 & 0.14 & 0.11 & 0.5 \\
\hline 0.5 & \multirow{3}{*}{$\begin{array}{l}\text { Lichen } \\
\text { Cover }\end{array}$} & & & & & & & -0.83 & 0.60 & -0.005 & 0.65 & 0.06 & 0.32 & -0.02 & 0.68 \\
\hline 5 & & & & & & & & -0.94 & 0.68 & -0.01 & 0.71 & 0.17 & 0.27 & 0.03 & 0.66 \\
\hline 30 & & & & & & & & -0.93 & 0.65 & -0.01 & 0.68 & 0.29 & 0.21 & 0.1 & 0.62 \\
\hline 0.5 & \multirow{3}{*}{$\begin{array}{l}\text { Moss } \\
\text { Cover }\end{array}$} & & & & & & & & & 0.01 & -0.07 & -0.08 & 0.37 & -0.002 & 0.67 \\
\hline 5 & & & & & & & & & & 0.01 & -0.12 & -0.14 & 0.38 & -0.07 & 0.69 \\
\hline 30 & & & & & & & & & & 0.007 & -0.05 & -0.27 & 0.4 & -0.16 & 0.7 \\
\hline 0.5 & \multirow{3}{*}{$\begin{array}{c}\text { Volumetric } \\
\text { Water } \\
\text { Content }\end{array}$} & & & & & & & & & & & -0.003 & 0.45 & -0.002 & 0.74 \\
\hline 5 & & & & & & & & & & & & -0.005 & 0.51 & -0.003 & 0.78 \\
\hline 30 & & & & & & & & & & & & -0.004 & 0.49 & -0.002 & 0.75 \\
\hline 0.5 & \multirow{3}{*}{$\begin{array}{c}\text { Tetracam } \\
\text { NDVI }\end{array}$} & & & & & & & & & & & & & 1.1 & $\begin{array}{r}-0.39 \\
\end{array}$ \\
\hline 5 & & & & & & & & & & & & & & 1.61 & -0.73 \\
\hline 30 & & & & & & & & & & & & & & 1.84 & -0.88 \\
\hline
\end{tabular}


Table A.2.2 Slopes (m) and offsets (b) for the orthogonal regressions between variables at peak greenness for LK site. Bold values imply significance ( $p$-value $<0.05$ ).

\begin{tabular}{|c|c|c|c|c|c|c|c|c|c|c|c|c|c|c|c|}
\hline \multirow[t]{2}{*}{ "Resolution" } & \multirow[t]{2}{*}{ Variable } & \multicolumn{2}{|c|}{ Percent Cover } & \multicolumn{2}{|c|}{ LAI } & \multicolumn{2}{|c|}{ Lichen Cover } & \multicolumn{2}{|c|}{ Moss Cover } & \multicolumn{2}{|c|}{$\begin{array}{c}\text { Volumetric } \\
\text { Water } \\
\text { Content } \\
\end{array}$} & \multicolumn{2}{|c|}{ Tetracam NDVI } & \multicolumn{2}{|c|}{ Canon NDVI } \\
\hline & & $\mathrm{m}$ & $\mathrm{b}$ & $\mathrm{m}$ & $\mathrm{b}$ & $\mathrm{m}$ & $\mathrm{b}$ & $\mathrm{m}$ & $\mathrm{b}$ & $\mathrm{m}$ & $\mathrm{b}$ & $\mathrm{m}$ & $\mathrm{b}$ & $\mathrm{m}$ & $\mathrm{b}$ \\
\hline 0.5 & \multirow{3}{*}{$\begin{array}{l}\text { Percent } \\
\text { Cover }\end{array}$} & & & 0.04 & -1.39 & -0.01 & 0.86 & -0.002 & 0.57 & 3.38 & -38.49 & 0.002 & 0.25 & 0.002 & 0.54 \\
\hline 5 & & & & 0.05 & -2.08 & -0.01 & 1.16 & 0.004 & 0.09 & 0.43 & 66.31 & 0.001 & 0.31 & 0.001 & 0.61 \\
\hline 30 & & & & 0.05 & -2.38 & -0.01 & 1.1 & $<0.0001$ & 0.43 & 0.88 & 51.33 & -0.0003 & 0.44 & -0.0001 & 0.82 \\
\hline 0.5 & \multirow{3}{*}{ LAI } & & & & & -0.12 & 0.53 & -0.08 & 0.6 & -0.001 & 2.02 & 0.03 & 0.35 & 0.03 & 0.66 \\
\hline 5 & & & & & & -0.11 & 0.51 & -0.04 & 0.54 & 0.003 & 1.87 & 0.01 & 0.39 & 0.01 & 0.7 \\
\hline 30 & & & & & & -0.07 & 0.44 & -0.1 & 0.64 & 0.003 & 1.89 & -0.01 & 0.44 & 0.01 & 0.72 \\
\hline 0.5 & \multirow{3}{*}{$\begin{array}{l}\text { Lichen } \\
\text { Cover }\end{array}$} & & & & & & & -1.08 & 0.77 & 0.002 & 0.24 & -0.07 & 0.43 & -0.01 & 0.73 \\
\hline 5 & & & & & & & & -0.99 & 0.76 & 0.002 & 0.2 & -0.1 & 0.44 & -0.01 & 0.73 \\
\hline 30 & & & & & & & & -0.77 & 0.67 & 0.01 & 0.08 & 0.1 & 0.7 & 0.01 & 0.7 \\
\hline 0.5 & \multirow{3}{*}{$\begin{array}{l}\text { Moss } \\
\text { Cover }\end{array}$} & & & & & & & & & 0.01 & 0.21 & 0.03 & 0.4 & -0.05 & 0.75 \\
\hline 5 & & & & & & & & & & 0.005 & 0.29 & 0.11 & 0.37 & 0.01 & 0.72 \\
\hline 30 & & & & & & & & & & -0.001 & 0.48 & -0.1 & 0.78 & -0.01 & 0.78 \\
\hline 0.5 & \multirow{3}{*}{$\begin{array}{c}\text { Volumetric } \\
\text { Water } \\
\text { Content }\end{array}$} & & & & & & & & & & & -0.0001 & 0.42 & 0.0004 & 0.72 \\
\hline 5 & & & & & & & & & & & & -0.0002 & 0.42 & 0.001 & 0.67 \\
\hline 30 & & & & & & & & & & & & 0.0002 & 0.4 & 0.002 & 0.66 \\
\hline 0.5 & \multirow{3}{*}{$\begin{array}{l}\text { Tetracam } \\
\text { NDVI }\end{array}$} & & & & & & & & & & & & & 0.07 & 0.36 \\
\hline 5 & & & & & & & & & & & & & & 0.02 & 0.4 \\
\hline 30 & & & & & & & & & & & & & & -0.12 & 0.5 \\
\hline
\end{tabular}


Table A.2.3 Slopes (m) and offsets (b) for the orthogonal regressions between variables at peak greenness for FN site. Bold values imply significance $(\mathrm{p}$-value $<0.05)$.

\begin{tabular}{|c|c|c|c|c|c|c|c|c|c|c|c|c|c|}
\hline \multirow[t]{2}{*}{ "Resolution" } & \multirow[t]{2}{*}{ Variable } & \multicolumn{2}{|c|}{ Percent Cover } & \multicolumn{2}{|c|}{ LAI } & \multicolumn{2}{|c|}{ Lichen Cover } & \multicolumn{2}{|c|}{ Moss Cover } & \multicolumn{2}{|c|}{$\begin{array}{c}\text { Volumetric } \\
\text { Water } \\
\text { Content } \\
\end{array}$} & \multicolumn{2}{|c|}{ Tetracam NDVI } \\
\hline & & $\mathrm{m}$ & $\mathrm{b}$ & $\mathrm{m}$ & $\mathrm{b}$ & $\mathrm{m}$ & $\mathrm{b}$ & $\mathrm{m}$ & $\mathrm{b}$ & $\mathrm{m}$ & $\mathrm{b}$ & $\mathrm{m}$ & $\mathrm{b}$ \\
\hline 0.5 & \multirow{2}{*}{ Percent Cover } & & & 0.01 & 0.3 & & & & & 15.88 & -967.50 & -0.002 & 0.39 \\
\hline 5 & & & & 0.01 & -0.16 & & & & & -32.09 & -2020.44 & -0.005 & 0.58 \\
\hline 0.5 & \multirow{2}{*}{ LAI } & & & & & & & & & 0.01 & 0.04 & -0.15 & 0.38 \\
\hline 5 & & & & & & & & & & -0.01 & 1.53 & -0.30 & 0.50 \\
\hline 0.5 & \multirow{2}{*}{ Lichen Cover } & & & & & & & & & & & & \\
\hline 5 & & & & & & & & & & & & & \\
\hline 0.5 & \multirow{2}{*}{ Moss Cover } & & & & & & & & & & & & \\
\hline 5 & & & & & & & & & & & & & \\
\hline 0.5 & \multirow{2}{*}{$\begin{array}{l}\text { Volumetric } \\
\text { Water } \\
\text { Content }\end{array}$} & & & & & & & & & & & -0.01 & 0.76 \\
\hline 5 & & & & & & & & & & & & -0.01 & 0.94 \\
\hline
\end{tabular}



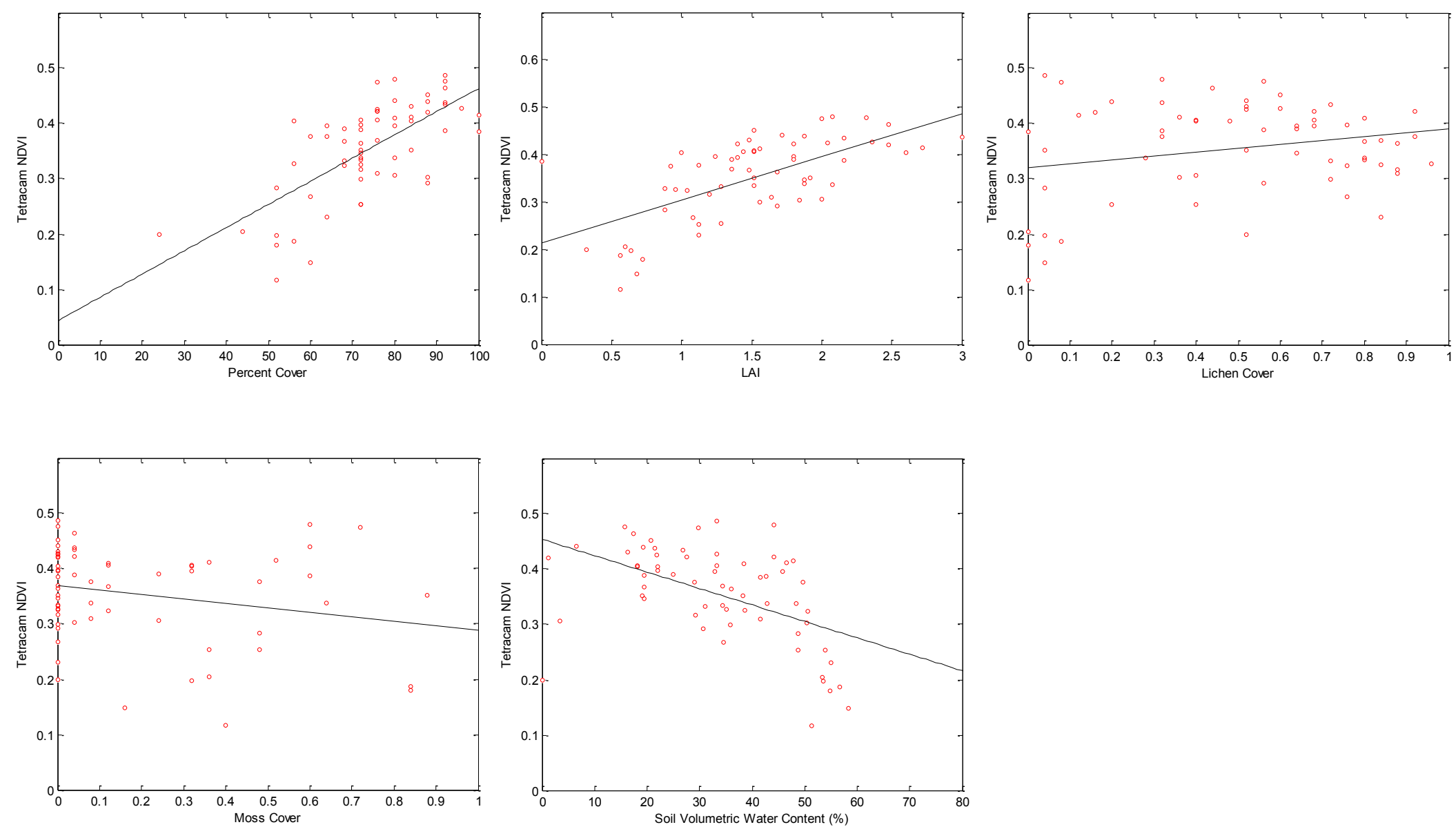

Orthogonal regressions, DL site, peak greenness. 

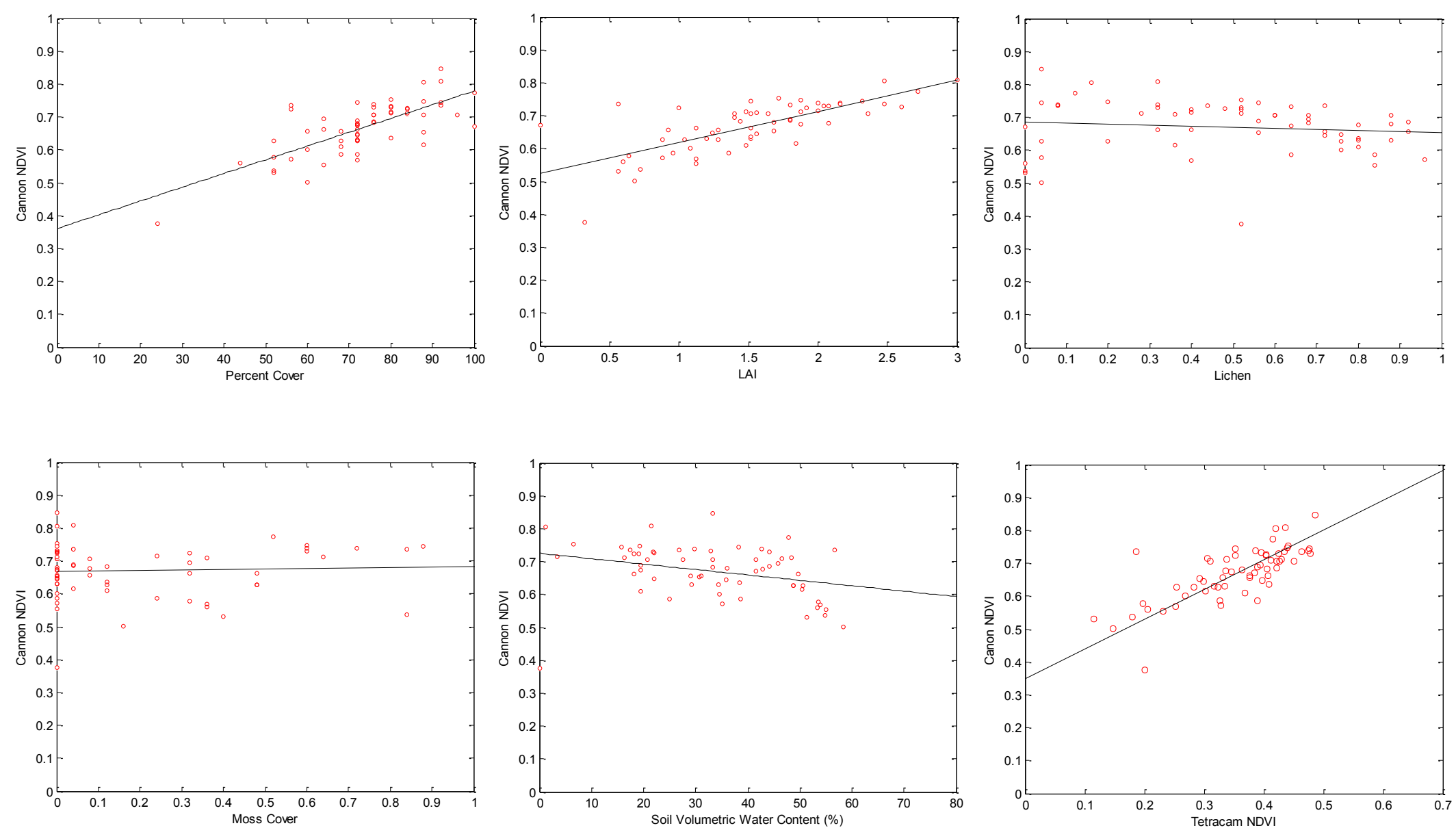

Orthogonal regressions, DL site, peak greenness. 

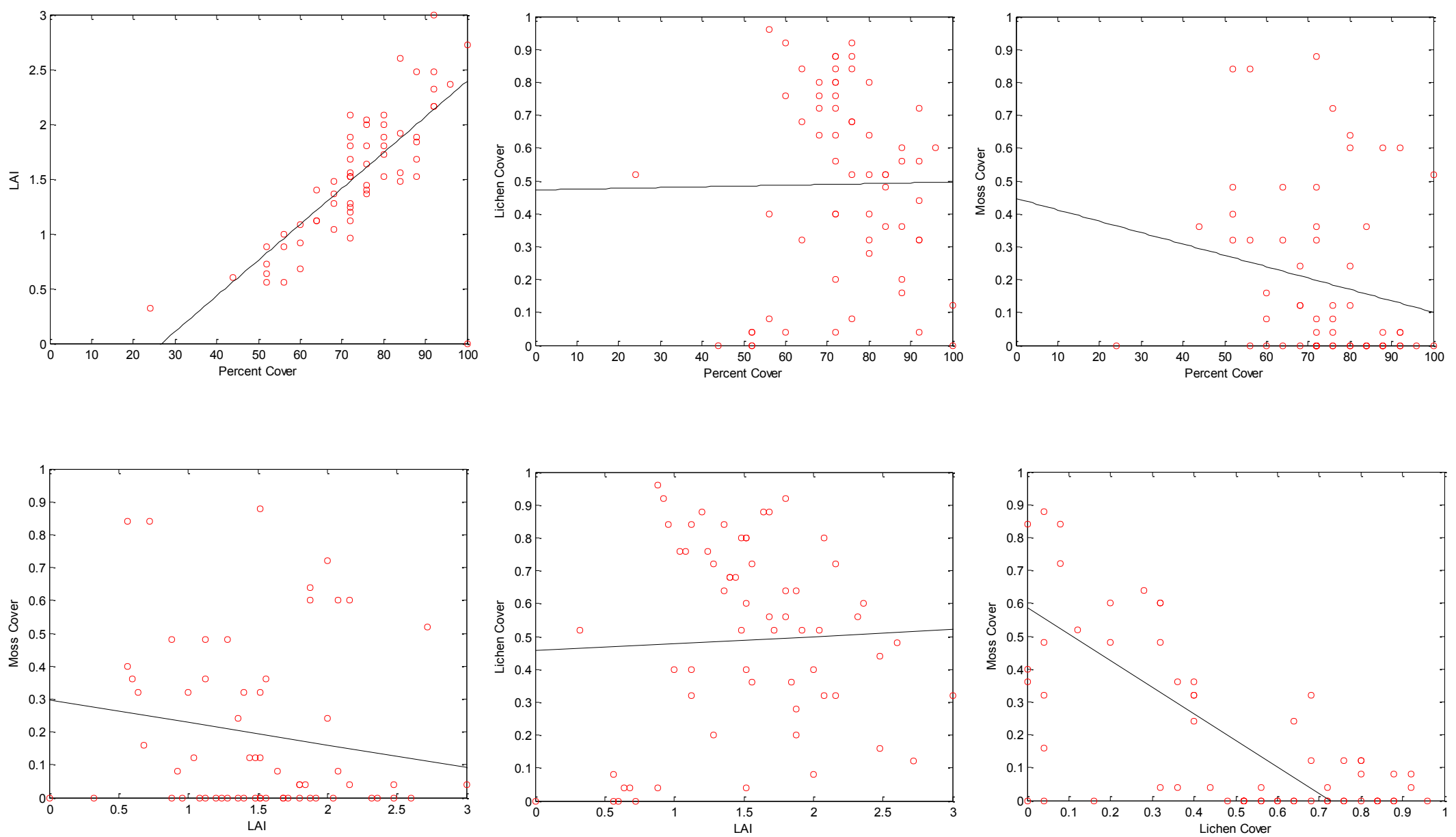

Orthogonal regressions, DL site, peak greenness. 

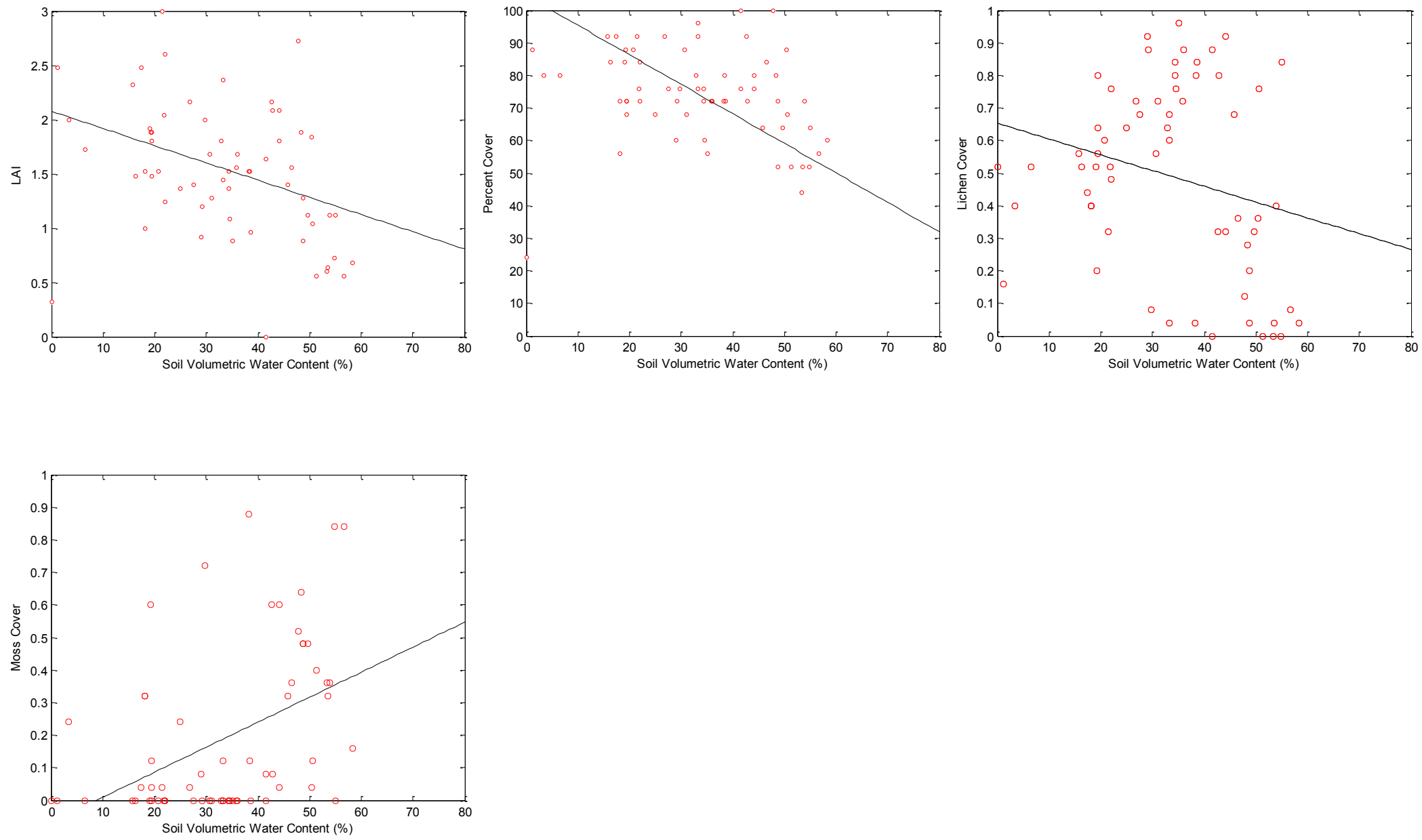

Orthogonal regressions, DL site, peak greenness.

87 

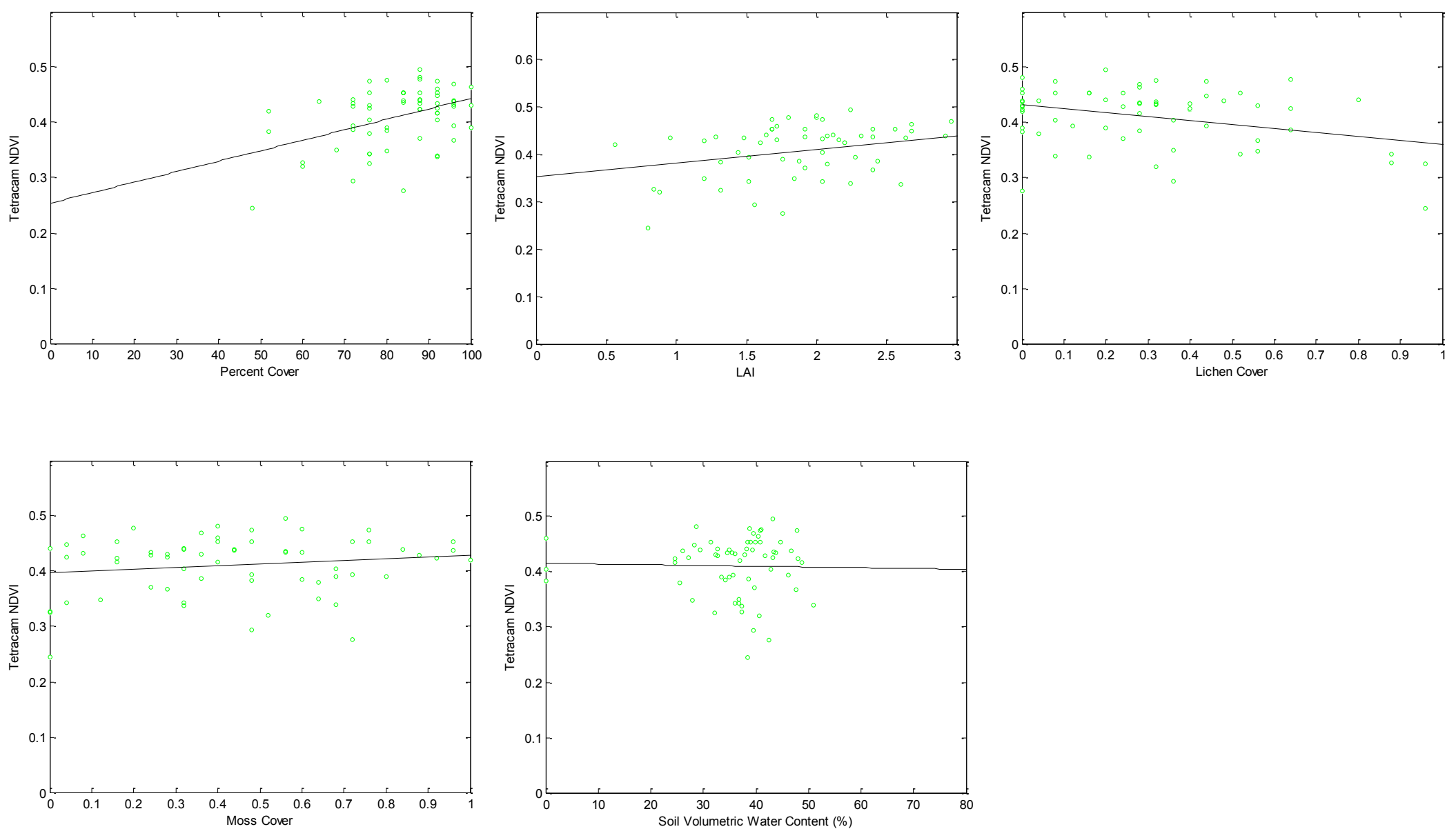

Orthogonal regressions, LK site, peak greenness. 

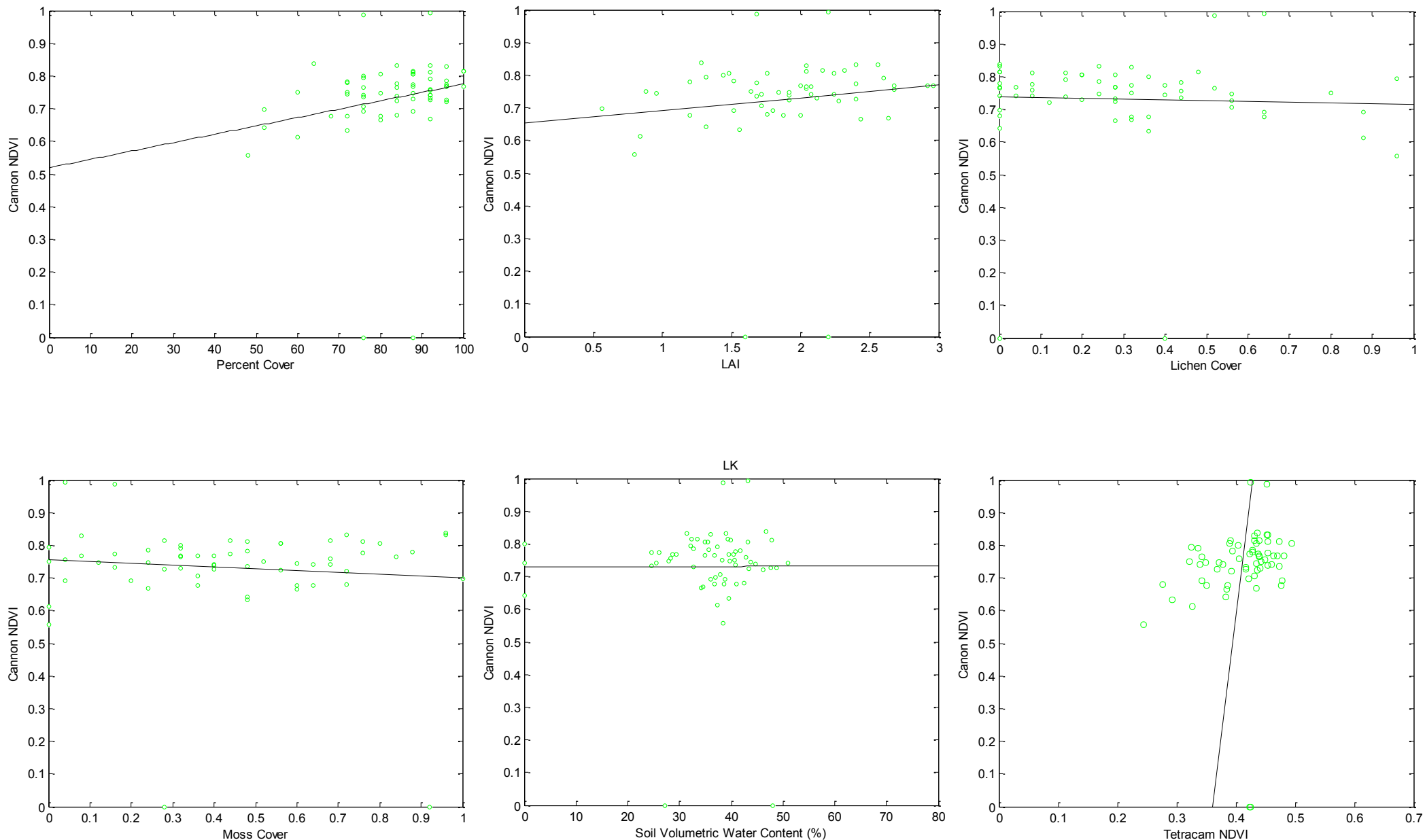

Orthogonal regressions, LK site, peak greenness. 

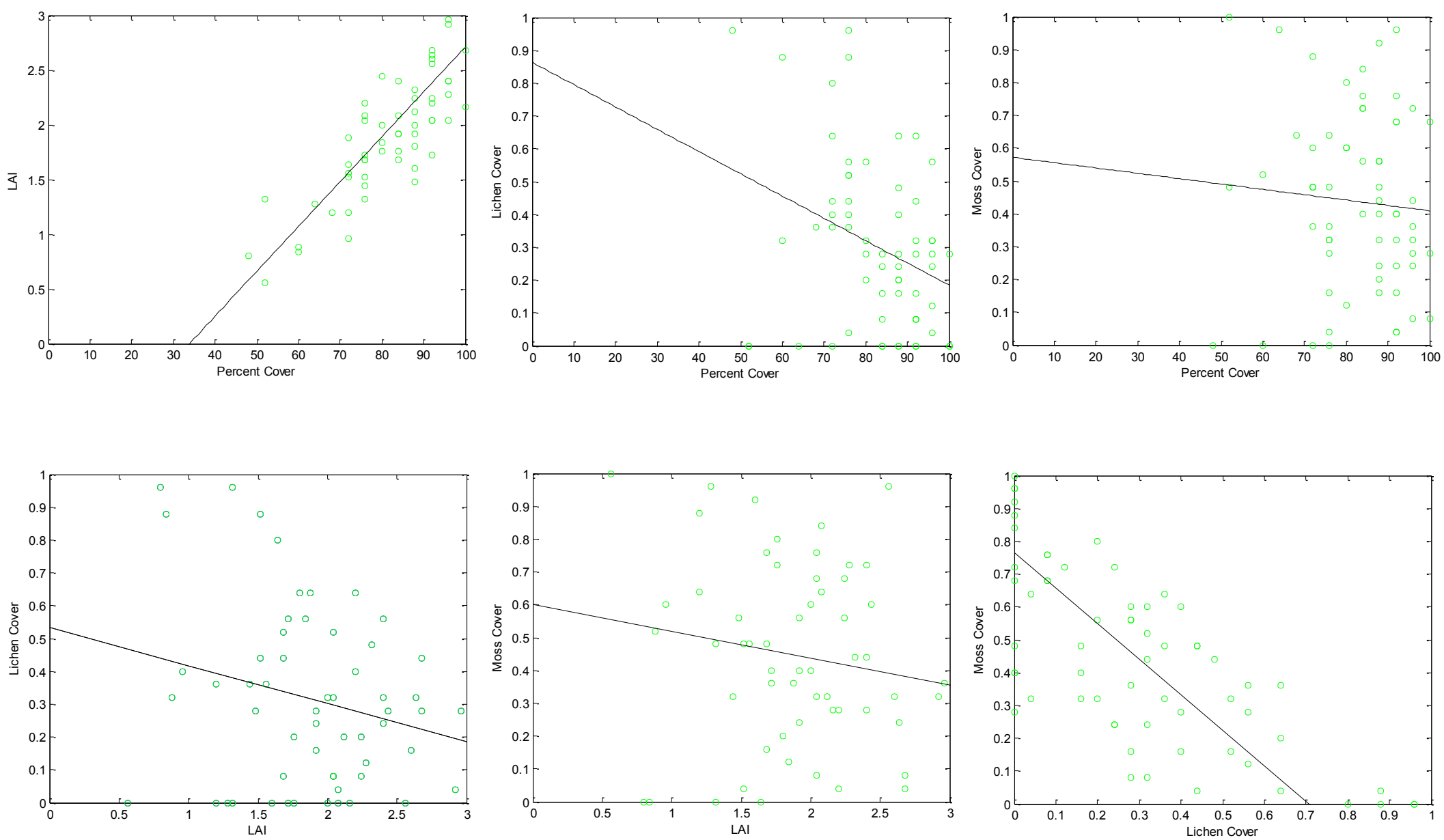

Orthogonal regressions, LK site, peak greenness. 

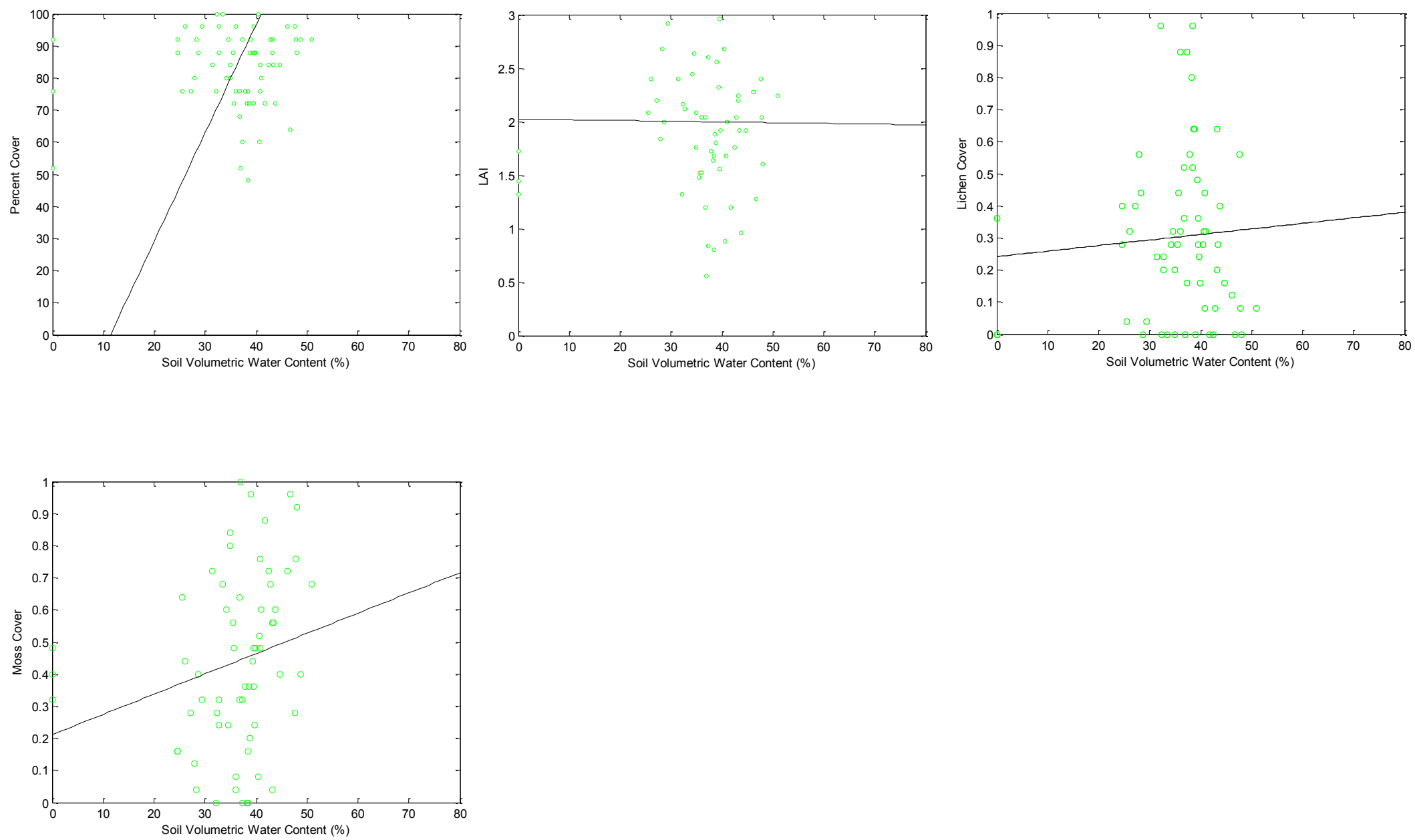

Orthogonal regressions, LK site, peak greenness.

91 

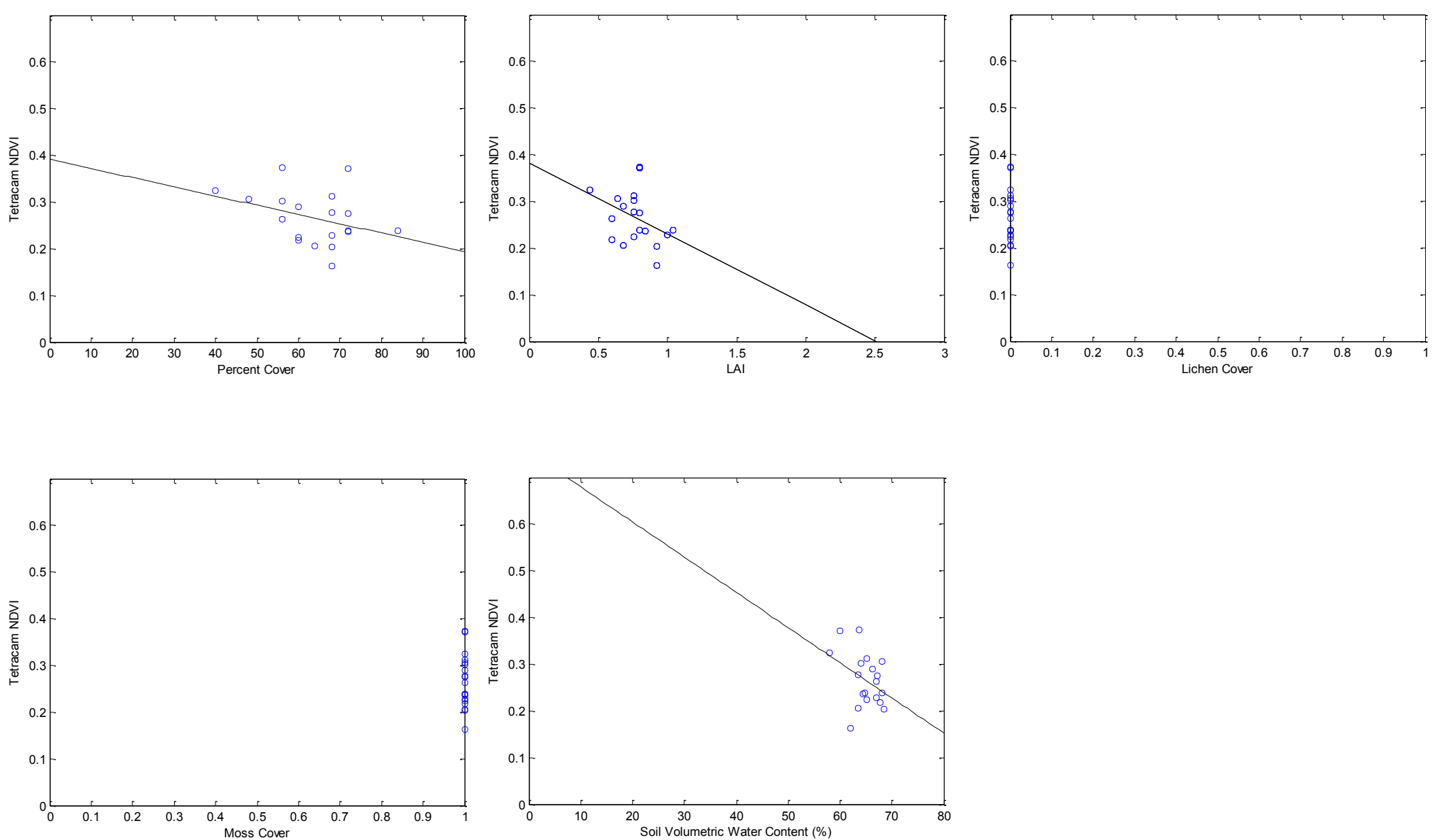

Orthogonal regressions, FN site, peak greenness. 

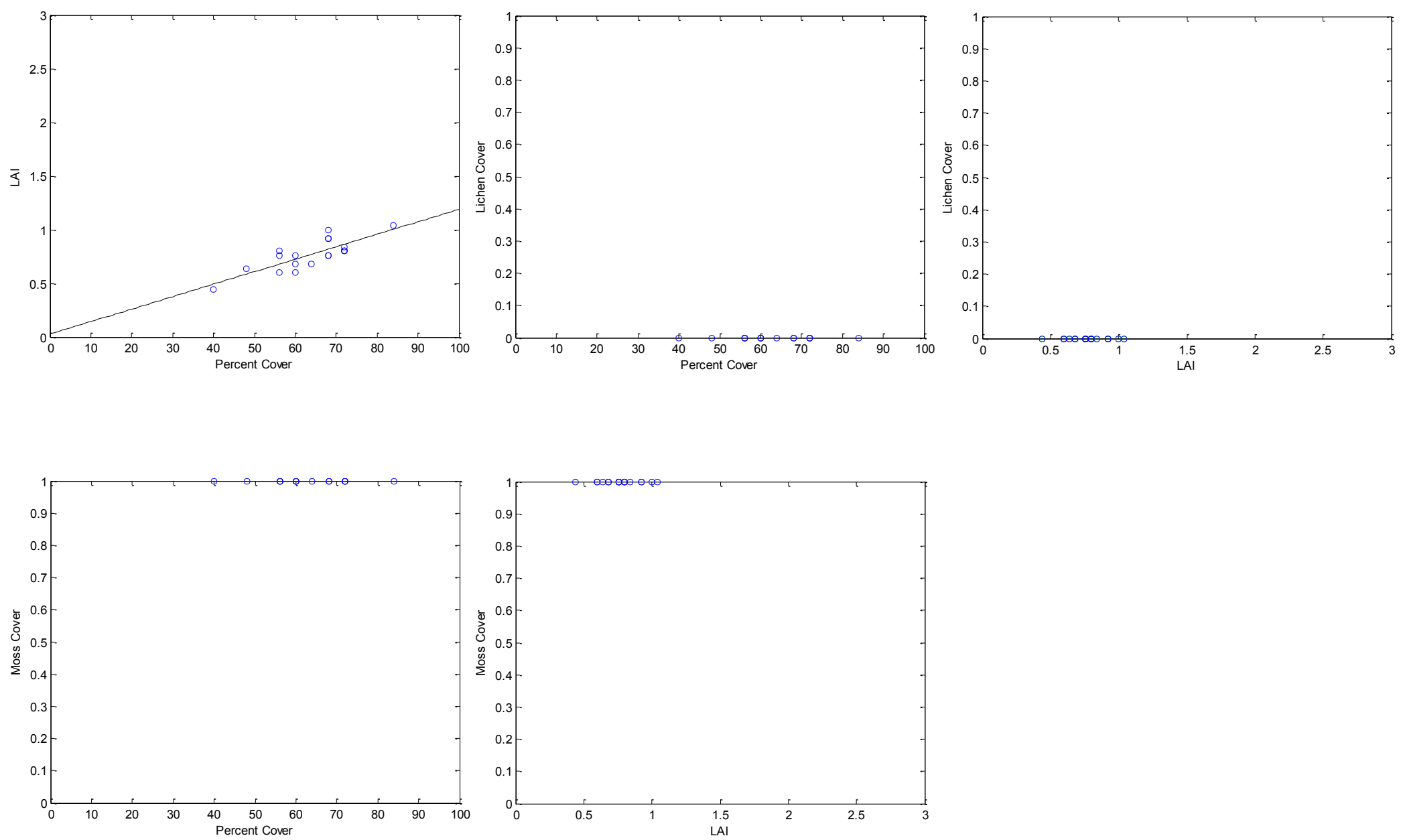

Orthogonal regressions, FN site, peak greenness. 

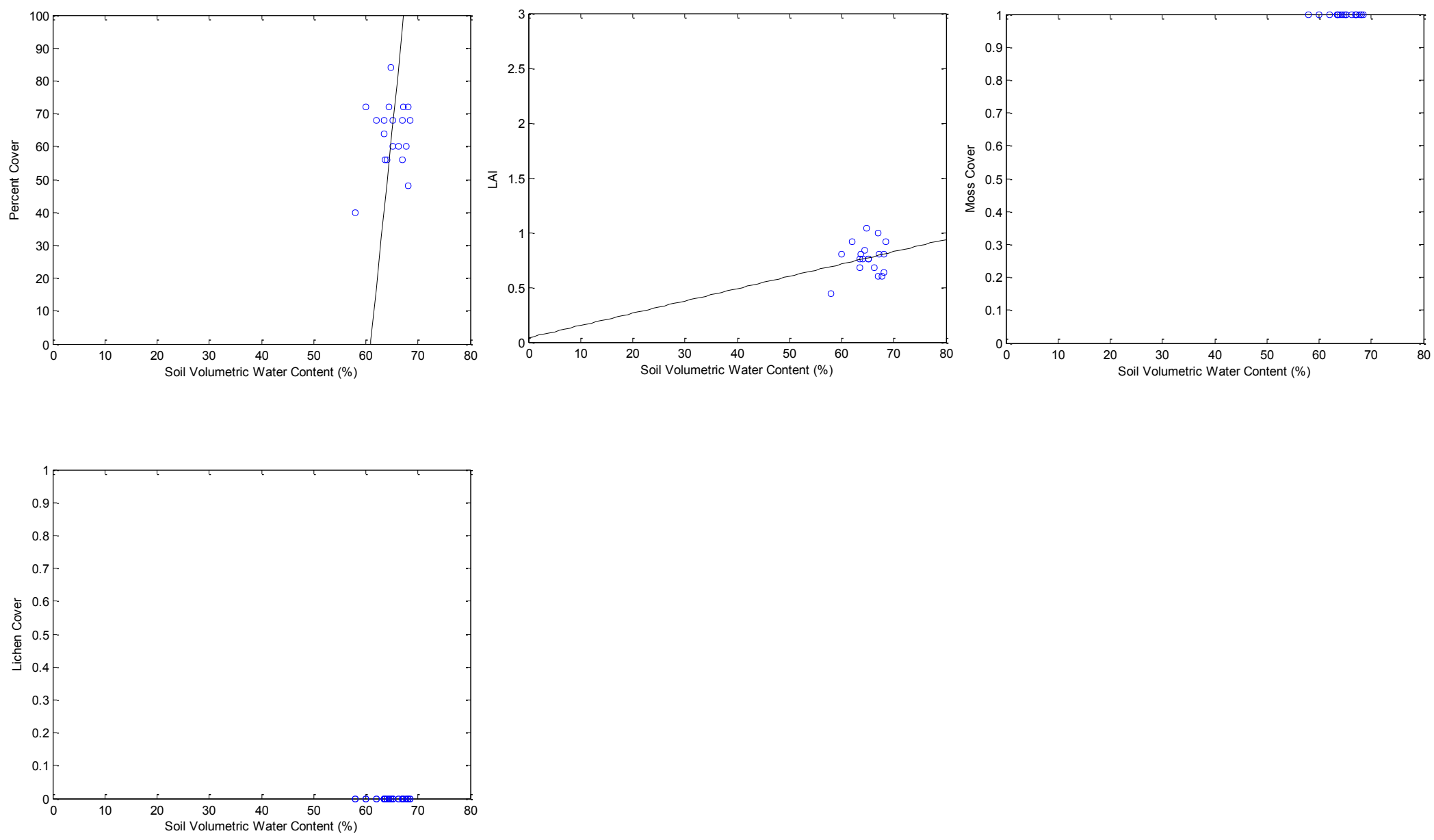

Orthogonal regressions, FN site, peak greenness.

94 


\section{A.3 Analysis of NDVI residuals from above orthogonal regression against LAI}

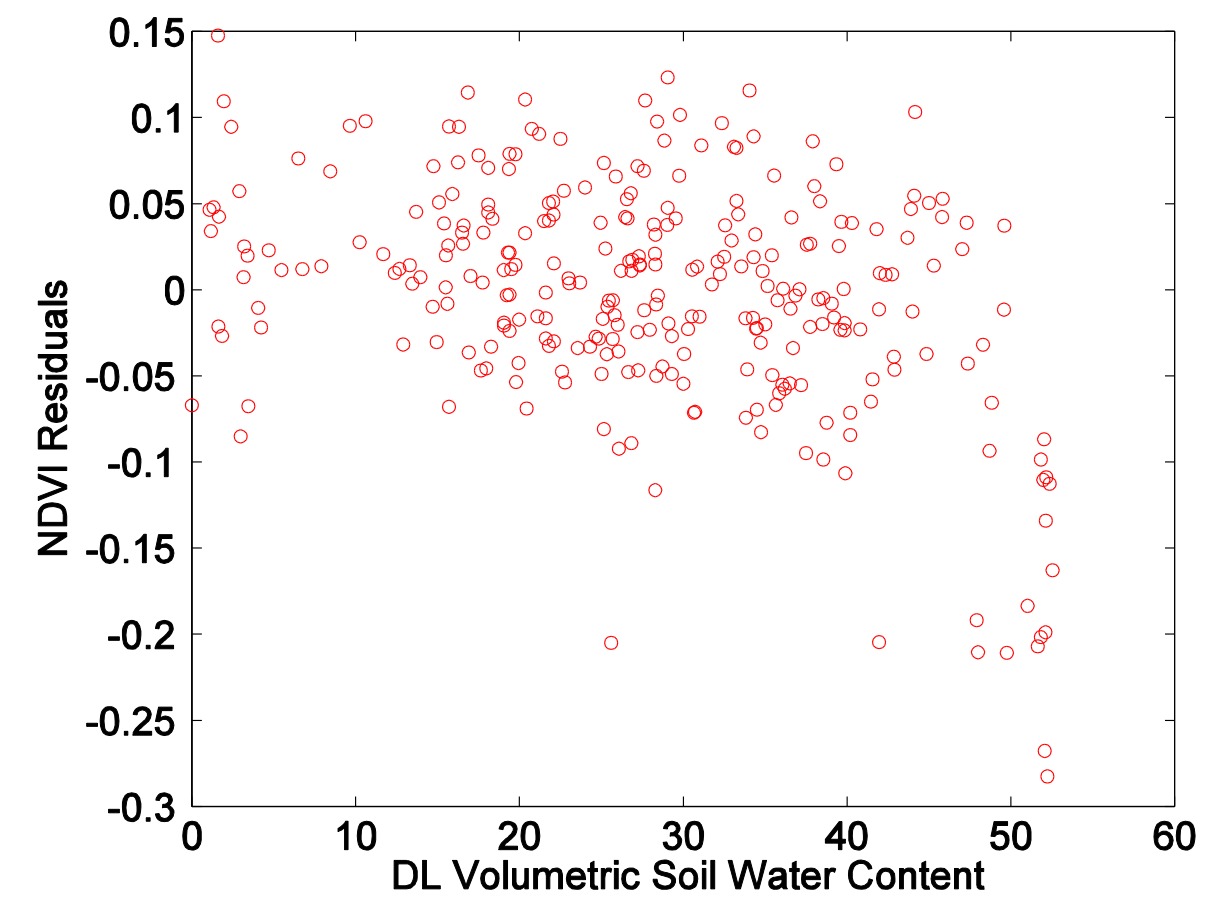

DL site residuals for the logarithmic NDVI-LAI model fit to the three sites at Daring Lake, LAI $=0.0032 \mathrm{e}(17.2143 \mathrm{NDVI})$ plotted against volumetric water content. 


\section{A.4 Plant community analysis}

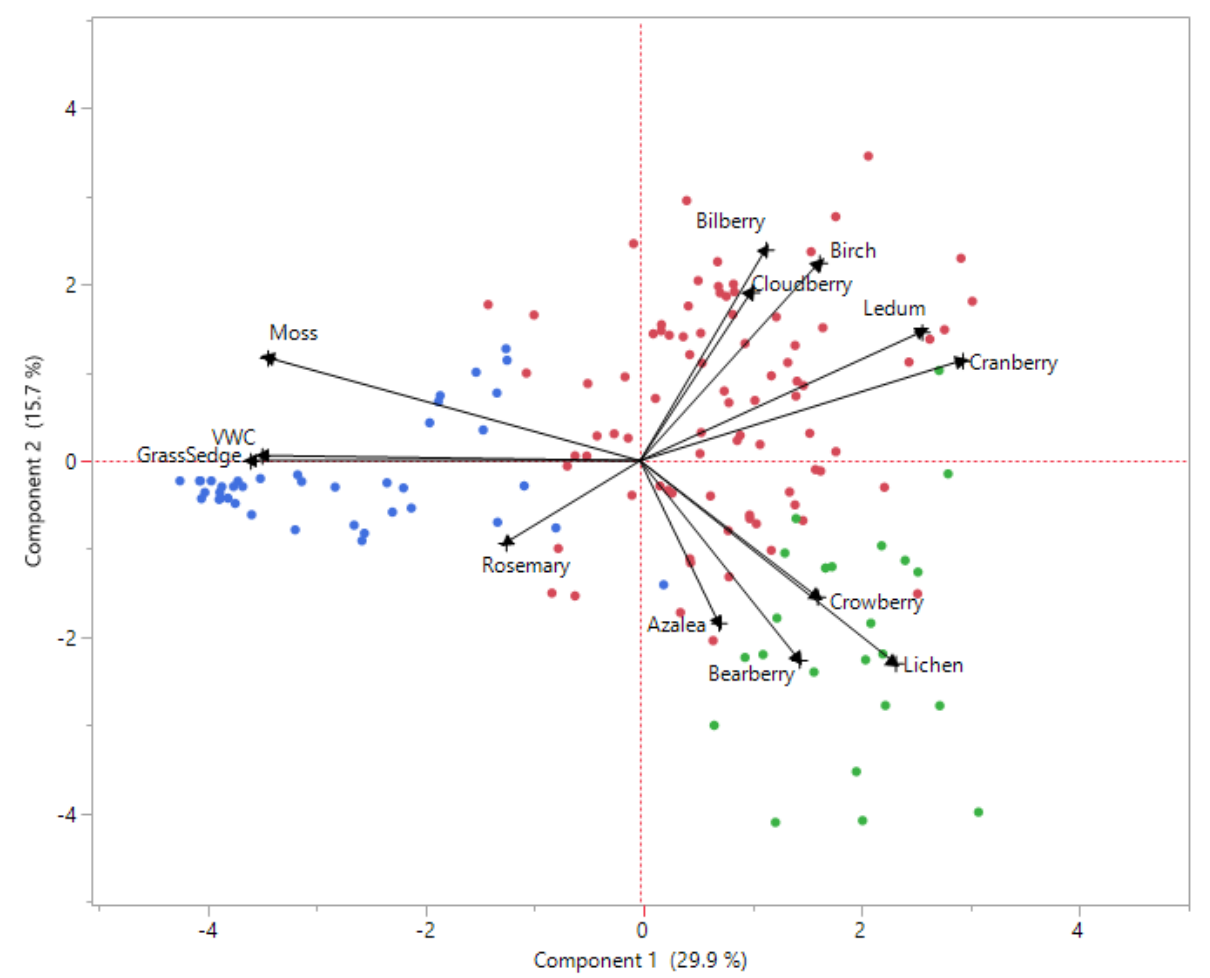

Principle component analysis of vegetation community composition from the $0.5 \mathrm{~m}$ plot point frame data and soil volumetric water content (VWC) measurements made during peak greeness. Colours reflect the three plant communities identified using k-means cluster analysis $($ dwarf shrub $=$ red, dwarf shrub/heath $=$ green, and sedge communities $=$ blue $)$. The proportion of plots of each type at DL are 46, 37, and $17 \%$ (dwarf shrub, dwarf shrub/heath, and sedge communities, respectively), at LK are $86 \%$ dwarf shrub and $14 \%$ sedge, and $95 \%$ sedge at FN with 1 plot characterized as dwarf shrub. 


\section{A.5 MODIS footprint}

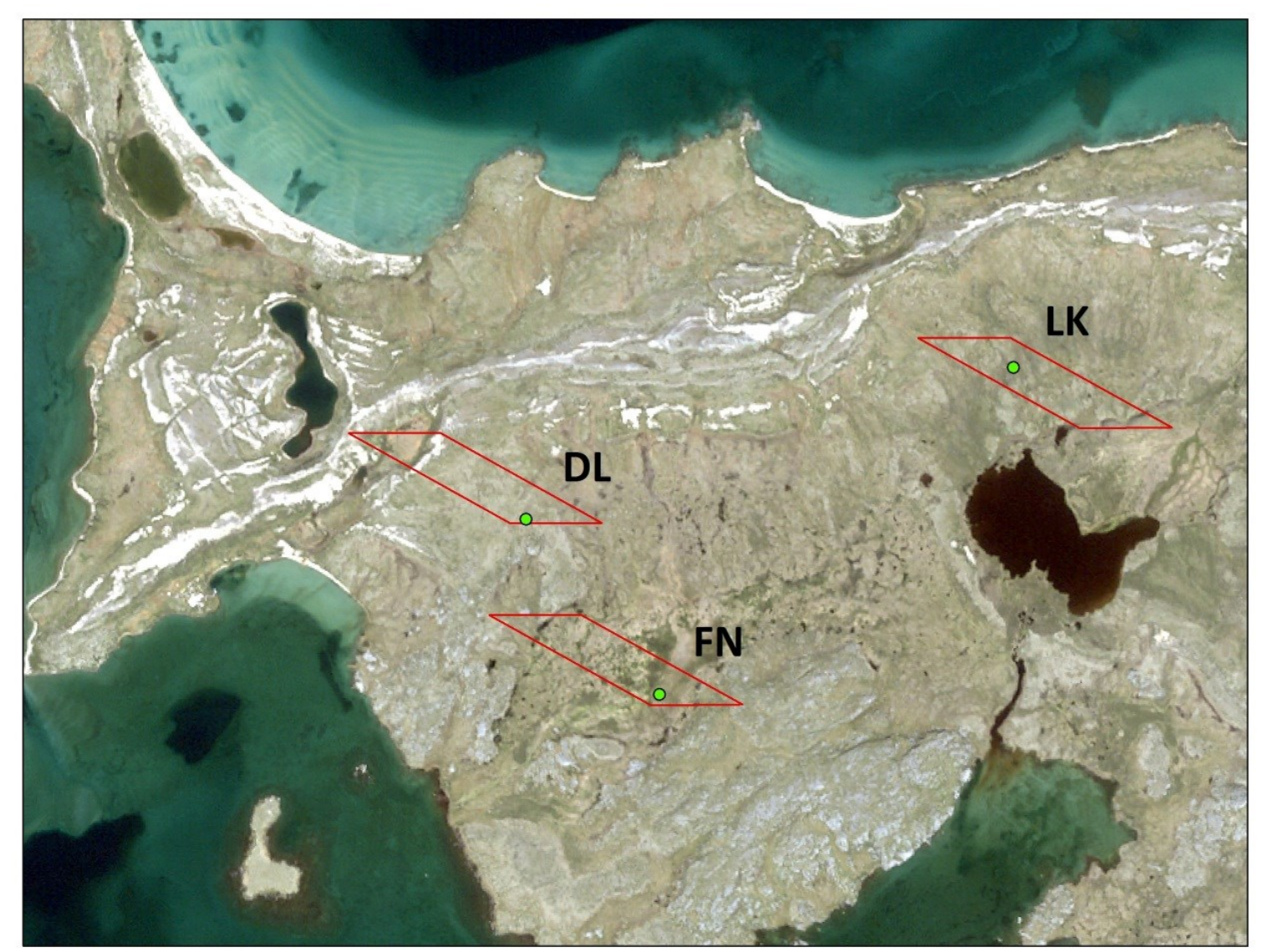

The footprints of the MODIS pixels (outlined in red) that best contained the DL, LK, and FN eddy covariance flux towers (green dots) and sampling plots. 


\section{A.6 Site Images}

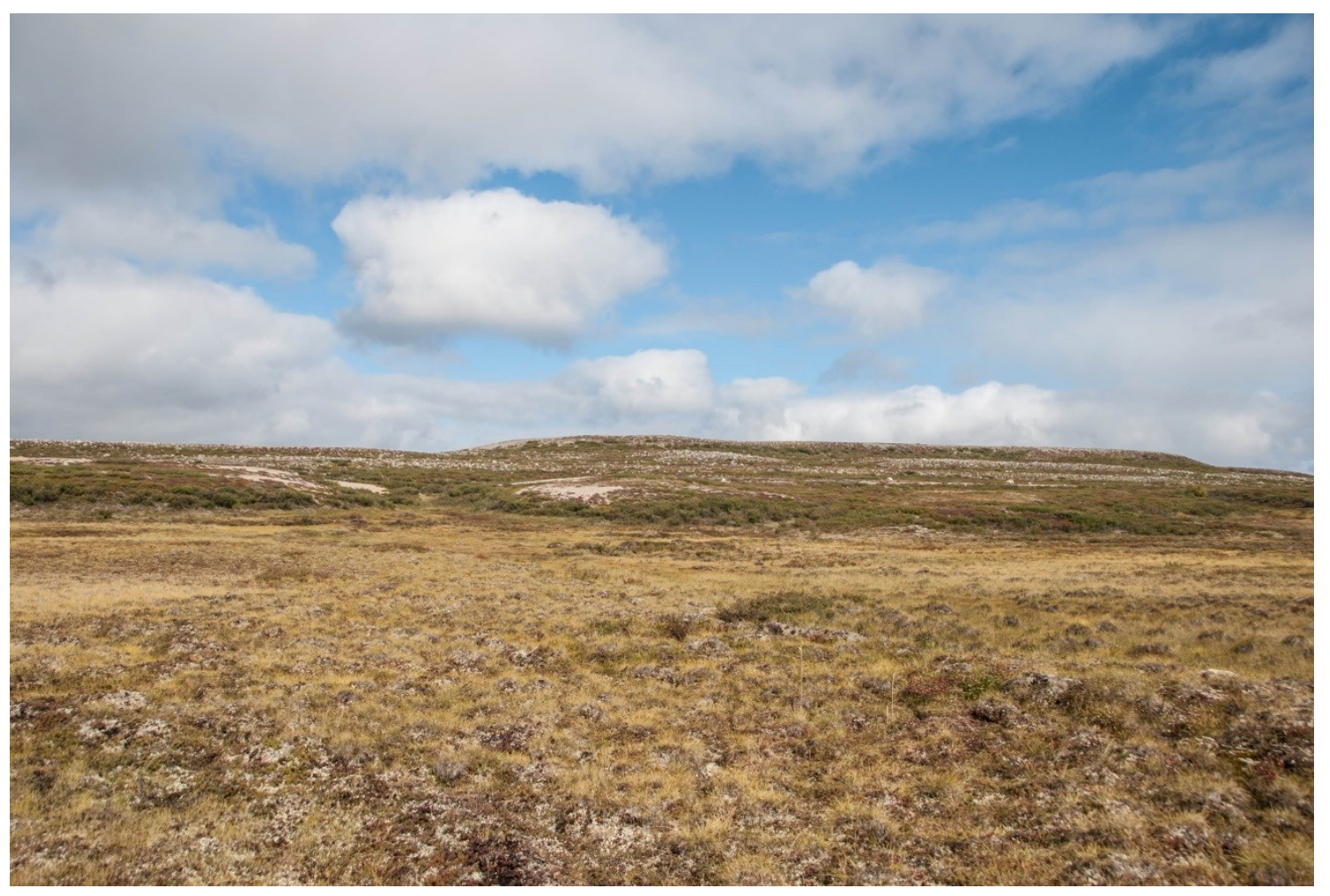

DL Site 


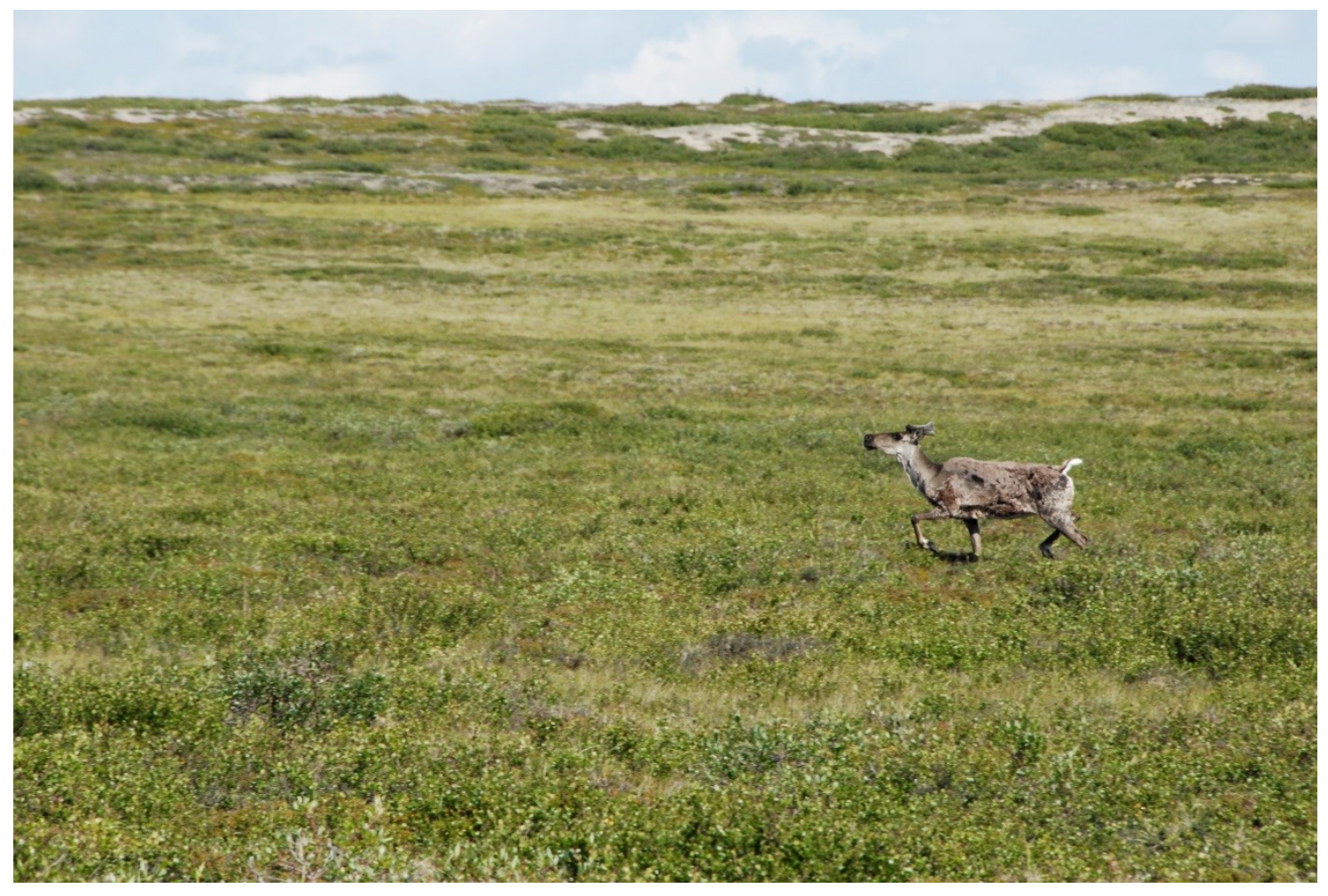

LK Site 


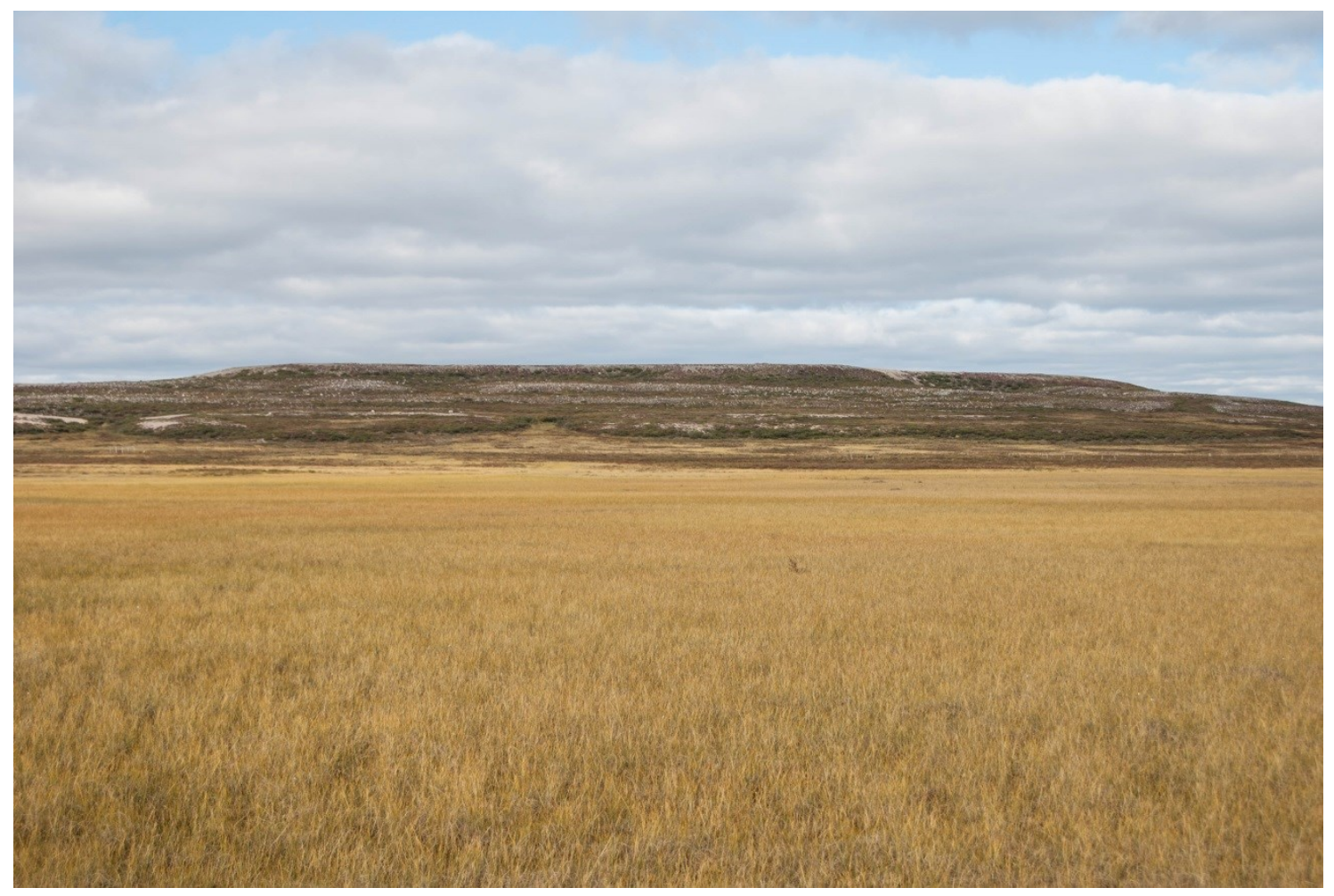

FN Site 


\section{References}

Asner, G. P., \& Warner, A. S. (2003). Canopy shadow in IKONOS satellite observations of tropical forests and savannas. Remote Sensing of Environment, 87, 521-533. doi:10.1016/j.rse.2003.08.006

Atwell, B.J., Kriedemann, P.E., \& Turnbull, C.G.N. (Eds.) (1999). Plants in action: Adaptation in Nature, performance in cultivation. Melbourne, Australia: Macmillan Education Australia Pty Ltd

Bliss, L.C. (1997). Arctic ecosystems of North America. In: Wielgolaski, F.E. (ed.) Polar and alpine tundra, pp. 551- 683. Elsevier, Amsterdam, NL.

Boelman, N. T., Stieglitz, M., Rueth, H. M., Sommerkorn, M., Griffin, K. L., Shaver, G. R., \& Gamon, J. a. (2003). Response of NDVI, biomass, and ecosystem gas exchange to long-term warming and fertilization in wet sedge tundra. Oecologia, 135(3), 414-21. doi:10.1007/s00442-003-1198-3

Boelman, N.T., Stieglitz, M., Griffin, K.L., and Shaver, G.R. 2005. Interannual variability of NDVI in response to long-term warming and fertilization in wet sedge and tussock tundra. Oecologia, Vol. 143, No. 4, pp. 588-597.

Brathen, K.A., \& Hagberg, O. (2004). More efficient estimation of plant biomass. Journal of Vegetation Science, 15(5), 653-660.

Bubier, J. L., Rock, B. N., \& Crill, P. M. (1997). Spectral reflectance measurements of boreal wetland and forest mosses. Journal of Geophysical Research, 102(D24), 29483-29494.

Burn, C. R., \& Kokelj, S. V. (2009). The Environment and permafrost of the Mackenzie Delta area. Permafrost and Periglacial Processes, 105, 83-105. doi:10.1002/ppp

Carlson, T. N., \& Ripley, D. A. (1997). On the relation between NDVI, fractional vegetation cover, and leaf area index. Remote Sensing of Environment. 62(35), 241252

Chen, J. M., \& Cihlar, J. (1996). Retrieving Leaf Area Index of boreal conifer forests using Landsat TM images. Remote Sensing of Environment, 55, 153-162.

Chen, J. M., Pavlic, G., Brown, L., Cihlar, J., Leblanc, S. G., White, H. P., ... Pellikka, P. K. E. (2002). Derivation and validation of Canada-wide coarse-resolution leaf area index maps using high-resolution satellite imagery and ground measurements. Remote Sensing of Environment, 80, 165-184.

Climatic Atlas of Canada (1984). Map Series $1 \& 2$. Ottawa, ON: Government of Canada 
Curran, P. J. (1983). Multispectral remote sensing for the estimation of green leaf area index. Philosophical Transactions of the Royal Society of London, 309, 257-270.

Dagg, J., \& Lafleur, P. (2010). An application of plot-scale NDVI in predicting carbon dioxide exchange and leaf area index in heterogeneous subarctic tundra. Canadian Journal of Remote Sensing, 36(1), 111-123.

Davidson, A., \& Csillag, F. (2001). The influence of vegetation index and spatial resolution on a two-date remote sensing- derived relation to $\mathrm{C} 4$ species Coverage. Remote Sensing of Environment, (75), 138-151.

Dorian, M., Lagagneux, P., Gauthier, G., \& Levesque, E. (2013). Broad-scale satellite normalized difference vegetation index data predict plant biomass and peak date of nitrogen concentration in Arctic tundra vegetation. Applied Vegetation Science, 16, 343-351.

Dredge, L. A., Kerr, D. E., \& Wolfe, S. A. (1999). Surficial materials and related ground ice conditions, Slave Province, N.W.T., Canada. Canadian Journal of Earth Science, 36, 1227-1238.

Ecosystem Classification Group. (2012). Ecological regions of the Northwest Territoriessouthern Arctic. Department of Environment and Natural Resources, Government ofthe Northwest Territories, Yellowknife, NT, Canada. $\mathrm{x}+170$ pp. + insert map.

Edlund, S.A. \& Alt, B.T. (1989). Regional congruence of vegetation and summer climate patterns in the Queen Elizabeth Islands, Northwest Territories, Canada. Arctic, 42, 3- 23.

Eklundh, L., Hongxiao, J., Schubert, P., Guzinski, R., \& Heliasz, M. (2011). An optical sensor network for vegetation phenology. Sensors, 11, 7678-7709.

doi:10.3390/s110807678

Ferrara, R. M., Fiorentino, C., Martinelli, N., Garofalo, P., \& Rana, G. (2010). Comparison of different ground-based NDVI measurement methodologies to evaluate crop biophysical properties. Italian Journal of Agronomy, 5, 145-154.

Fox, A. M., Huntley, B., Lloyd, C. R., Williams, M., \& Baxter, R. (2008). Net ecosystem exchange over heterogeneous Arctic tundra: Scaling between chamber and eddy covariance measurements. Global Biogeochemical Cycles, 22, GB2027. doi:10.1029/2007GB003027

Fraser, R. H., Lantz, T. C., Olthof, I., Kokelj, S. V, \& Sims, R. A. (2014). Warminginduced shrub expansion and lichen decline in the western Canadian Arctic, 11511168. doi:10.1007/s10021-014-9783-3 
Gamon, J. a., Field, C. B., Goulden, M. L., Griffin, K. L., Hartley, A. E., Joel, G., ... Valentini, R. (1995). Relationships between NDVI, canopy structure, and photosynthesis in three Californian vegetation types. Ecological Applications, 5(1), $28-41$.

Gamon, J. A., Huemmrich, K. F., Stone, R. S., \& Tweedie, C. E. (2013). Spatial and temporal variation in primary productivity (NDVI) of coastal Alaskan tundra: Decreased vegetation growth following earlier snowmelt. Remote Sensing of Environment, 129, 144-153. doi:10.1016/j.rse.2012.10.030

Gamon, J. A. (2015). Reviews and Syntheses: Optical sampling of the flux tower footprint. Biogeosciences, 12(14), 4509-4523. doi:10.5194/bg-12-4509-2015

Goetz, S.J., Bunn, A.G., Fiske, G.J., \& Houghton, R.A. (2005). Satellite- observed photosynthetic trends across boreal North America associated with climate and fire disturbance. Proceedings of the National Academy of Sciences, 102, 13521-13525.

Goswami, S., Gamon, J. A., \& Tweedie, C. E. (2011). Surface hydrology of an arctic ecosystem: Multiscale analysis of a flooding and draining experiment using spectral reflectance. Journal of Geophysical Research: Biogeosciences, 116(1), 1-14. doi:10.1029/2010JG001346

Goward, S.N., Markham, B., and Dye, D.G. 1991. Normalized Difference Vegetation Index measurements from the Advanced Very High Resolution Radiometer. Remote Sensing of Environment, Vol. 35, No. 2- 3, pp. 257-277.

Gower, S. T., Kucharik, C. J., \& Norman, J. M. (1995). Direct and Indirect Estimation of Leaf Area Index, f APAR, and Net Primary Production of Terrestrial Ecosystems. Remote Sensing of Environment, 4257(99), 29-51.

Hugelius, G., Strauss, J., Zubrzycki, S., Harden, J. W., Schuur, E. A. G., Ping, C., ... Kuhry, P. (2014). Estimated stocks of circumpolar permafrost carbon with quantified. Biodiversity, 11, 6573-6593. doi:10.5194/bg-11-6573-2014

Humphreys, E. R., \& Lafleur, P. M. (2011). Does earlier snowmelt lead to greater CO 2 sequestration in two low Arctic tundra ecosystems? Geophysical Research Letters, 38, L09703. doi:10.1029/2011GL047339

Jia, G.J., Epstein, H.E., and Walker, D.A. (2002). Spatial characteristics of AVHRRNDVI along latitudinal transects in northern Alaska. Journal of Vegetation Science, 13(3), 315-326.

Jia, G.J., Epstein, H.E., and Walker, D.A. (2006). Spatial heterogeneity of tundra vegetation response to recent temperature changes. Global Change Biology, 12(1), $42-55$. 
Jiang, Z., Huete, A. R., Chen, J., Chen, Y., Li, J., Yan, G., \& Zhang, X. (2006). Analysis of NDVI and scaled difference vegetation index retrievals of vegetation fraction. Remote Sensing of Environment, 101(3), 366-378. doi:10.1016/j.rse.2006.01.003

Jonasson, S. (1998). Evaluation of the point intercept method for the estimation of plant biomass. Oikos, 52(1), pp. 101-106.

Jones, H.G. \& Vaughan, R.A. (2010). Remote Sensing of Vegetation: Principles, Techniques, and Applications. New York, NY: Oxford University Press.

Knipling, E. B. (1970). Physical and physiological basis for the reflectance of visible and near-infrared radiation from vegetation. Remote Sensing of Biomass - Principles and Applications, 1, 155-159.

Kross, A., Seaquist, J. W., Roulet, N. T., Fernandes, R., \& Sonnentag, O. (2013). Estimating carbon dioxide exchange rates at contrasting northern peatlands using MODIS satellite data. Remote Sensing of Environment, 137, 234-243. doi:10.1016/j.rse.2013.06.014

Lafleur, P. M., \& Humphreys, E. R. (2007). Spring warming and carbon dioxide exchange over low Arctic tundra in central Canada. Global Change Biology, 14(4), 740-756. doi:10.1111/j.1365-2486.2007.01529.x

Lafleur, P. M., Humphreys, E. R., St Louis, V. L., Myklebust, M. C., Papakyriakou, T., Poissant, L., ... Swystun, K. A. (2012). Variation in peak growing season net ecosystem production across the Canadian Arctic. Environmental Science \& Technology, 46(15), 7971-7977. doi:10.1021/es300500m

Laidler, G. J., Treitz, P. M., \& Atkinson, D. M. (2008). Remote Sensing of Arctic Vegetation : Relations between the NDVI, Spatial Resolution and Vegetation Cover on Boothia Peninsula, Nunavut. Arctic, 61(1), 1-13.

La Puma, I. P., Philippi, T. E., \& Oberbauer, S. F. (2007). Relating NDVI to ecosystem $\mathrm{CO} 2$ exchange patterns in response to season length and soil warming manipulations in arctic Alaska. Remote Sensing of Environment, 109(2), 225-236. doi:10.1016/j.rse.2007.01.001

Loranty, M. M., Goetz, S.J., Rastetter, E.B., Rocha, A.V., Shaver, G.R., Humphreys, E.R., and Lafleur, P.M. 2011. Scaling an instantaneous model of tundra NEE to the Arctic landscape. Ecosystems, 14: 76-93

Lawrence, D. M., \& Slater, A. G. (2005). A projection of severe near-surface permafrost degradation during the 21st century. Geophysical Research Letters, 32(24), L24401. doi:10.1029/2005GL025080 
Leblanc, S. G., Chen, W., Maloley, M., Humphreys, E., \& Elliott, C. (2014). NDVI digital camera for monitoring Arctic vegetation. IGARSS 2014 \& 35th Canadian Symposium on Remote Sensing, Quebec, Canada

Marceau, D. J., \& Hay, G. J. (1999). Remote sensing contributions to the scale issue. Canadian Journal of Remote Sensing, 25(4), 357-366.

McGuire, a D., Macdonald, R. W., Schuur, E. A., Harden, J. W., Kuhry, P., Hayes, D. J., ... Heimann, M. (2010). The carbon budget of the northern cryosphere region. Current Opinion in Environmental Sustainability, 2(4), 231-236. doi:10.1016/j.cosust.2010.05.003

McGuire, a. D., Christensen, T. R., Hayes, D., Heroult, a., Euskirchen, E., Kimball, J. S., ... \& Yi, Y. (2012). An assessment of the carbon balance of Arctic tundra: comparisons among observations, process models, and atmospheric inversions. Biogeosciences, 9(8), 3185-3204. doi:10.5194/bg-9-3185-2012

McMichael, C. E., Hope, A. S., Stow, D. A., Fleming, J. B., Vourlitis, G., \& Oechel,W. C (1999). Estimating CO2 exchange at two sites in Arctic tundra ecosystems during the growing season using a spectral vegetation index. International Journal of Remote Sensing. International Journal of Remote Sensing, 20, 638-698.

Messier, J., McGill, B. J., \& Lechowiicz, M. J. (2010). How do traits vary across ecological scales? A case for trait-based ecology. Ecology Letters, 13, 838-848. doi:10.1111/j.1461-0248.2010.01476.x

Middleton, M., Huemmrich, K.F., Cheng, Y., \& Margolis, H.A. (2012). Spectral bioindicators of photosynthetic efficiency and vegetation stress. In P.S. Thenkabail, J.G. Lyon, \& L. Huete (Eds.), Hyperspectral Remote Sensing of Vegetation. Boca Raton, FL: CRC Press

Monteith, J. T. (1972). Solar Radiation and Productivity in Tropical Ecosystems. Journal of Applied Ecology, 9(3), 747-766.

Monteith, J. T. (1977). Climate and the Efficiency of Crop Production in Britain. Philosophical Transactions of the Royal Society of London, 281(980), 277-294.

Oechel, W. C., Hastings, S. J., Vourlitis, G., Jenkins, M., Riechers, G., \& Grulke, N. (1993). Recent change of Arctic tundra ecosystems from a net carbon dioxide sink to a source. Nature (London). (361)6412. p.520 - 523.

Olthof, I., Pouliot, D., Latifovic, R., \& Chen, W. (2008). Recent (1986-2006) vegetationspecific NDVI trends in northern Canada from satellite data. Arctic, 61(4), 381-394. 
Osterkamp, T. E., \& Romanovsky, V. E. (1999). Evidence for warming and thawing of discontinuous permafrost in Alaska. Permafrost and Periglacial Processes, 10, 1737.

Peltoniemi, J. I., Suomalainen, J., Puttonen, E., \& Näränen, J. (2008). Reflectance properties of selected arctic-boreal land cover types : field measurements and their application in remote sensing. Biogeosciences Discussions, 5, 1069-1095.

Peng, D., Zhang, B., Liu, L., Fang, H., Chen, D., Hu, Y., \& Liu, L. (2012). Characteristics and drivers of global NDVI-based FPAR from 1982 to 2006. Global Biogeochemical Cycles, 26(GB3015). doi:10.1029/2011GB004060

Post, W. M., Emanuel, W. R., Zinke, P. J., \& Stangenberger, A. G. (1982). Soil carbon pools and world life zones. Nature, 298, 156-159.

Rocha, A. V, \& Shaver, G. R. (2009). Agricultural and Forest Meteorology Advantages of a two band EVI calculated from solar and photosynthetically active radiation fluxes. Agricultural and Forest Meteorology, 149, 1560-1563. doi:10.1016/j.agrformet.2009.03.016

Rouse, J.W., Haas, R.H., Schell, J.A., and Deering, D.W. 1974. Monitoring vegetation systems in the Great Plains with ERTS. In: Freden, S.C., Mercanti, E.P., and Becker, M.A., eds. Third Earth Resources Technology Satellite-1 Symposium. Proceedings from a conference held 10-14 December 1974 at the National Aeronautics and Space Administration, Scientific and Technical Information Office, Goddard Space Flight Centre, Washington, D.C. 309-317Rothrock, D. A., Yu, Y., \& Maykut, G. A. (1999). Thinning of the Arctic sea-ice cover. Geophysical Monograph Series, 26(23), 3469-3472.

Running, S. W., Nemani, R. R., Heinsch, F. A., Zhao, M., Reeves, M., \& Hashimoto, H. (2004). A continuous satellite-derived measure of global terrestrial primary production. BioScience, 54(6), 547-560.

Serreze, M. C., Holland, M. M., Stroeve, J., Serreze, M. C., Holland, M. M., \& Stroeve, J. (2007). Perspectives on the Arctic's shrinking sea-ice cover. Science, 315(5818), $1533-1536$.

Shaver, G. R., Street, L. E., Rastetter, E. B., Van Wijk, M. T., \& Williams, M. (2007). Functional convergence in regulation of net $\mathrm{CO} 2$ flux in heterogeneous tundra landscapes in Alaska and Sweden. Journal of Ecology, 95(4), 802-817. doi:10.1111/j.1365-2745.2007.01259.x

Sims, D. A., \& Gamon, J. A. (2002). Relationships between leaf pigment content and spectral reflectance across a wide range of species, leaf structures and developmental stages. Remote Sensing of Environment, 81, 337-354. 
Solomon, S., Qin, D., Manning, M., Alley, R.B., Berntsen, T., Bindoff, N.L., Chen, Z.,Chidthaisong, A., Gregory, J.M., Hegerl, C.G., Heimann, M., Hewitson, B., Hoskins,B.J., Joos, F., Jouzel, J., Kattsov, V., Lohmann, U., Matsuno, T., Molina, M., Nicholls, N., Overpeck, J., Raga, G., Ramaswamy, V., Ren, J., Rusticucci, M., Somerville, R., Stocker, T.F., Whetton, P., Wood, R.A., and Wratt, D. 2007. Technical Summary. In Climate Change 2007: The Physical Science Basis. Contribution of Working Group I to the Fourth Assessment Report of the Intergovernmental Panel on Climate Change. Cambridge University Press, Cambridge. pp. 36-77

Steinberg, D. C., \& Goetz, S. (2009). Assessment and extension of the MODIS FPAR products in temperate forests of the eastern United States. International Journal of Remote Sensing, 30(1-2), 169-187. doi:10.1080/01431160802244276

Stow, D. A., Hope, A., Mcguire, D., Verbyla, D., Gamon, J., Huemmrich, F., ... Myneni, R. (2004). Remote sensing of vegetation and land-cover change in Arctic Tundra Ecosystems. Remote Sensing of Environment, 89, 281-308. doi:10.1016/j.rse.2003.10.018

Street, L. E., Shaver, G. R., Williams, M., \& Van Wijk, M. T. (2007). What is the relationship between changes in canopy leaf area and changes in photosynthetic $\mathrm{CO}$ 2 flux in arctic ecosystems? Journal of Ecology, 95(1), 139-150. doi:10.1111/j.1365-2745.2006.01187.x

Street, L. E., Subke, J.-A., Sommerkorn, M., Sloan, V., Ducrotoy, H., Phoenix, G. K., \& Williams, M. (2013). The role of mosses in carbon uptake and partitioning in arctic vegetation. The New Phytologist, 199(1), 163-75. doi:10.1111/nph.12285

Sturm, M., Schimel, J., Michaelson, G., Welker, J. M., Oberbauer, S. F., Liston, G. E., Fahnestock, J., \& Vladimir, E. (2005). Winter biological processes could help convert Arctic tundra to shrubland. BioScience, 55(1), 17-26.

Tape, K., Sturm, M., \& Racine, C. (2006). The evidence for shrub expansion in northern Alaska and the Pan-Arctic. Global Change Biology, 12, 686-702. doi:10.1111/j.1365-2486.2006.01128.x

Tarnocai, C., Canadell, J. G., Schuur, E. A. G., Kuhry, P., Mazhitova, G., \& Zimov, S. (2009). Soil organic carbon pools in the northern circumpolar permafrost region. Global Biogeochemical Cycles, 23, 1-11. doi:10.1029/2008GB003327

Tetracam Inc. (2011). Agricultural Digital Camera User's Guide. Retrieved from http:/www.tetracam.com/PDFs/ADC\%20Users\%20Guide\%20V2.3.pdf

Tittebrand, A., Spank, U., \& Bernhofer, C. H. (2009). Comparison of satellite- and ground-based NDVI above different land-use types. Theoretical Applications of Climatology, 98, 171-186. doi:10.1007/s00704-009-0103-3 
Turner, D. P., Ritts, W. D., Cohen, W. B., Gower, S. T., Zhao, M., Running, S. W., ... Munger, J. W. (2003). Scaling gross primary production (GPP) over boreal and deciduous forest landscapes in support of MODIS GPP product validation. Remote Sensing of Environment, 88(3), 256-270. doi:10.1016/j.rse.2003.06.005

van Wijk, M.T., Williams, M. (2005). Optical instruments for measuring leaf area index in low vegetation: application in arctic ecosystems. Ecological Applications, 15, $1462-1470$.

van Wijk, M.T., Williams, M. (2005). Tight coupling between leaf area index and foliage $\mathrm{N}$ content in arctic plant communities. Oecologia, 142, 421-427.

Verhoeven, J. T. A., Koerselman, W., \& Meuleman, A. F. M. (1996). Nitrogen- or phosphorus-limited growth in herbaceous, wet vegetation: relations with atmospheric inputs and management regimes. Trends in Ecology \& Evolution, 11(12), 494-497.

Vermotea, E., Saleoup, N. E. L., \& Kaufmanb, Y. J. (1991). Data pre-processing : stratospheric aerosol perturbing effect on the remote sensing of vegetation : Correction method for the composite NDVI after the Pinatubo eruption, Remote Sensing Reviews, 15, 7-22.

Vourlitis, G. L., Oechel, W. C., Hope, A., Stow, D., Boynton, B., Zulueta, R., \& Hastings, S. J. (2000). Physiological models for scaling plot measurements of CO2 flux across an Arctic tundra landscape. Ecological Applications, 10(1), 60-72.

Walker, D. A., Raynolds, M. K., Daniëls, F. J. A., Einarsson, E., Elvebakk, A., Gould, W. a, ... Yurtsev, B. A. (2005). The circumpolar Arctic vegetation map. Journal of Vegetation Science, 16, 267-282.

Wang, F., Huang, J., Tang, Y., \& Wang, X. (2007). New Vegetation Index and Its Application in Estimating Leaf Area Index of Rice. Rice Science, 14(3), 195-203.

Watson, D. J., (1947). Comparative physiological studies in the growth of field crops. I. Variation in net assimilation rate and leaf area between species and varieties, and within and between years. Annals of Botany, 11, 41-76.

Whiting, G. J. (1994). CO2 exchange in the Hudson Bay lowlands : Community characteristics and multispectral reflectance properties season year are well documented. Journal of Geophysical Research, 99(D1), 1519-1528.

Whiting, G., Bartlett, D. S., Fan, S., Bakwin, P., \& Wofsy, S. (1992). Biosphere/ atmosphere $\mathrm{CO} 2$ exchange in tundra ecosystems: community characteristics with multispectral surface reflectance. Journal of Geophysical Research, 97, 671-680 